\title{
AN INNOVATIVE TECHNIQUE FOR THIN FILM INTERFACE TOUGHNESS RESEARCH
}

\section{December 2004}

\author{
Prepared by
}

John J. Wang, lan G. Wright, Ken C. Liu, Michael Lance, Sreeparna Sengupta, Roy L. Xu 


\title{
DOCUMENT AVAILABILITY
}

Reports produced after January 1, 1996, are generally available free via the U.S. Department of Energy (DOE) Information Bridge.

Web site http://www.osti.gov/bridge

Reports produced before January 1, 1996, may be purchased by members of the public from the following source.

\author{
National Technical Information Service \\ 5285 Port Royal Road \\ Springfield, VA 22161 \\ Telephone 703-605-6000 (1-800-553-6847) \\ TDD 703-487-4639 \\ Fax 703-605-6900 \\ E-mail info@ntis.fedworld.gov \\ Web site http://www.ntis.gov/support/ordernowabout.htm
}

Reports are available to DOE employees, DOE contractors, Energy Technology Data Exchange (ETDE) representatives, and International Nuclear Information System (INIS) representatives from the following source.

Office of Scientific and Technical Information

P.O. Box 62

Oak Ridge, TN 37831

Telephone 865-576-8401

Fax 865-576-5728

E-mail reports@adonis.osti.gov

Web site http://www.osti.gov/contact.html

This report was prepared as an account of work sponsored by an agency of the United States Government. Neither the United States government nor any agency thereof, nor any of their employees, makes any warranty, express or implied, or assumes any legal liability or responsibility for the accuracy, completeness, or usefulness of any information, apparatus, product, or process disclosed, or represents that its use would not infringe privately owned rights. Reference herein to any specific commercial product, process, or service by trade name, trademark, manufacturer, or otherwise, does not necessarily constitute or imply its endorsement, recommendation, or favoring by the United States Government or any agency thereof. The views and opinions of authors expressed herein do not necessarily state or reflect those of the United States Government or any agency thereof. 


\title{
AN INNOVATIVE TECHNIQUE FOR THIN FILM INTERFACE TOUGHNESS RESEARCH
}

John J. Wang, Ian G. Wright, Ken C. Liu, Michael Lance, Sreeparna Sengupta, ${ }^{*}$ Roy L. Xu*

Date Published: December 2004

\author{
Prepared by \\ OAK RIDGE NATIONAL LABORATORY \\ P.O. Box 2008 \\ Oak Ridge, Tennessee 37831-6285 \\ managed by \\ UT-Battelle, LLC \\ for the \\ U.S. DEPARTMENT OF ENERGY \\ under contract DE-AC05-00OR22725
}

\footnotetext{
* Vanderbilt University
} 



\section{CONTENTS}

Page

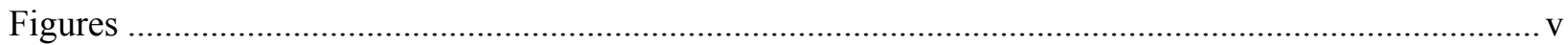

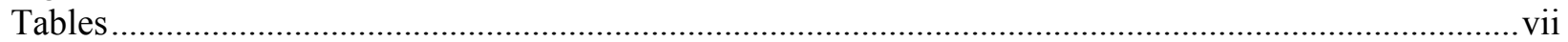

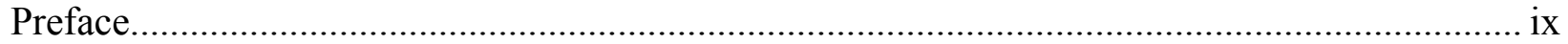

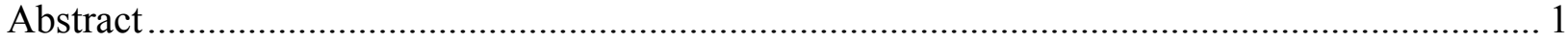

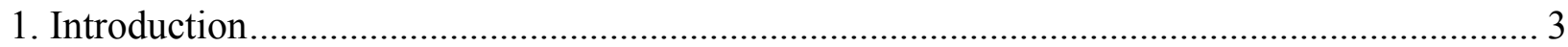

1.1. The Mechanics of Thin Film Materials ......................................................................... 3

1.2. Theoretical and Experimental Development of Interfacial Mechanics ............................ 4

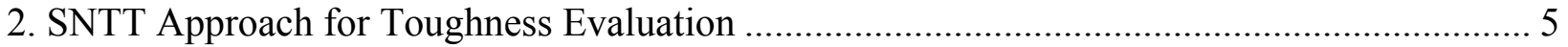

3. Rationale of the Proposed Research .................................................................................. 6

4. Proposed Experimental Approach for Thin Film Interface Fracture Toughness Testing.......... 7

4.1. The Proposed Thin Film SNTT Configuration ....................................................... 7

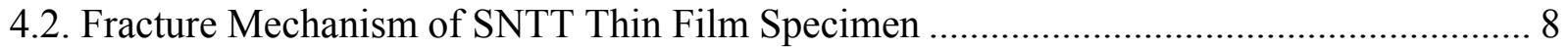

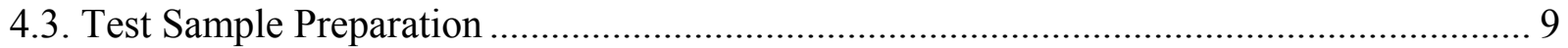

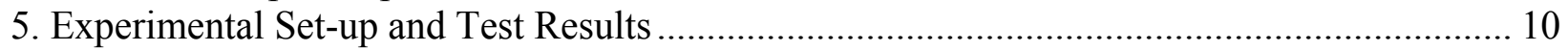

5.1. Baseline Fracture Toughness Experiment .......................................................... 11

5.2. Evaluation of Residual Stress of Thin Film Coating Material...................................... 12

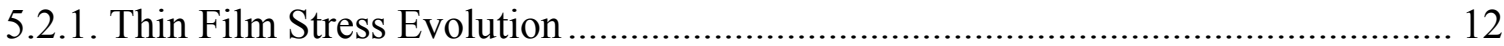

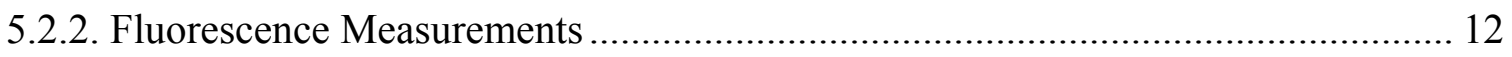

5.3. Postmortem Examination of Oxide SNTT Specimens .............................................. 14

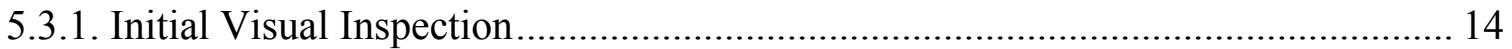

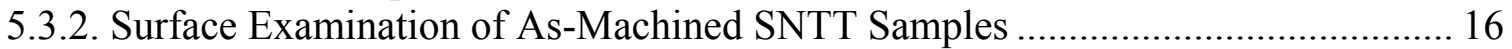

5.3.3. Surface Examination of Oxidized SNTT Samples before Torsion Test................ 17

5.3.4. Examination of Oxidized SNTT Samples after Torsion Testing........................... 18

5.3.5. Examination of Oxidized SNTT Specimens Fractured after Cyclic Torsion

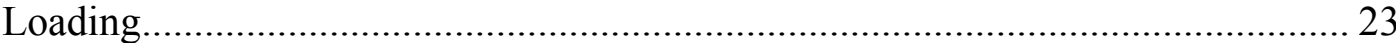

5.4. Test Results From SNTT Thin Film Fracture Test and Acoustic Emission Detection ..... 27

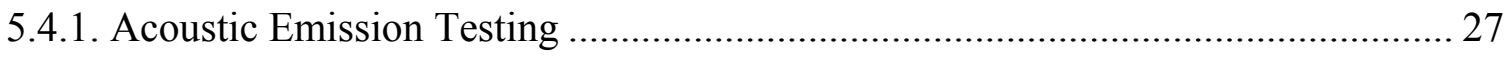

5.4.2. Test Results for Oxidized SNTT Samples (without Fatigue Pre-Cracks) .............. 29

5.4.3. Test Results for Oxidized SNTT Samples with a Fatigue Pre-Crack .................... 30

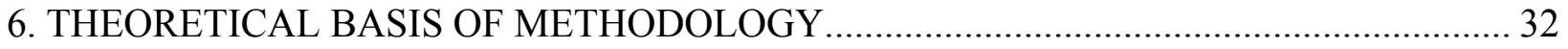

6.1. Development of Finite Element Models and Analyses ............................................... 32

6.2. Three-Dimensional Configuration of SNTT Finite Element Model .............................. 32

6. 3. Fracture Toughness and J-Integral Evaluation Along the Interface ............................. 35

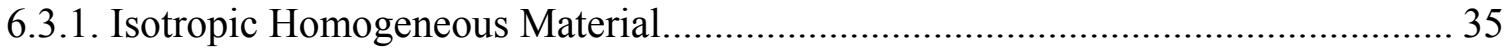

6.3.2. Interfacial Material Fracture Toughness .......................................................... 36

6.4. FEM Analysis Results and Fracture Toughness Evaluation......................................... 38

6.4.1. Fracture Toughness Evaluation for Oxide MA956 SNTT Specimens .................. 38

6.4.2. Finite Element Analysis Results of Oxide MA956 SNTT Thin Film Sample ....... 41

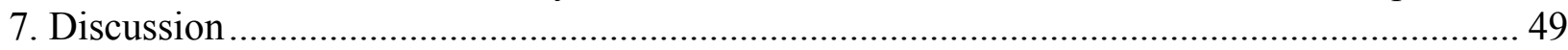

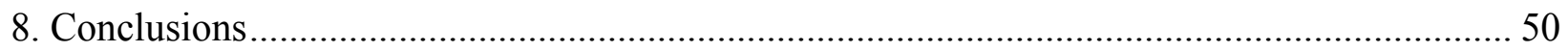

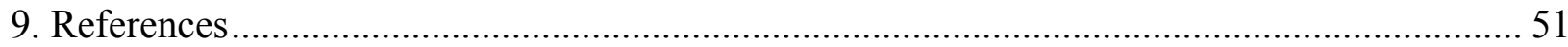

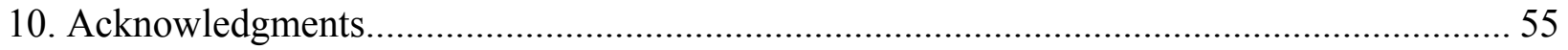





\section{FIGURES}

Figure

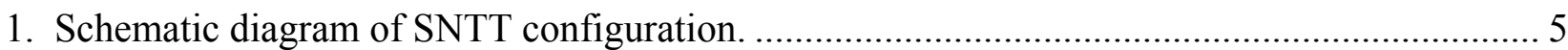

2. Schematic diagram of interface between bond coating and thermally grown oxide. .................. 7

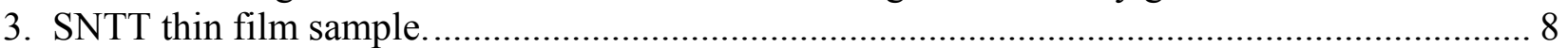

4. Schematic diagram of notch root geometry and the associated crack initiation sites................. 9

5. SNTT thin film specimen design configuration............................................................... 10

6. Experimental set-up, including acoustic emission sensors attached to the ends of SNTT

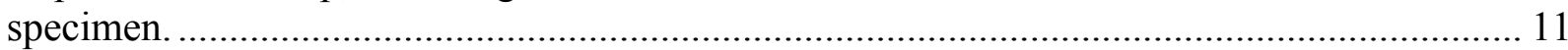

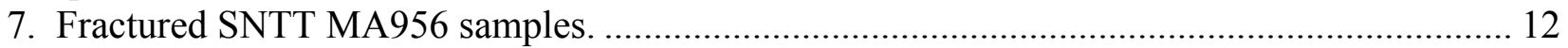

8. Residual stress profile across U-groove from specimen 7 before the torsion test and

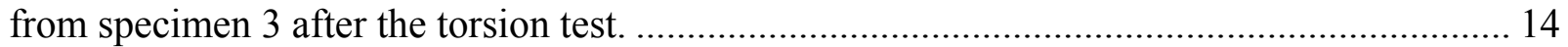

9. Schematic diagram of residual stress fields near the U-groove site.......................................... 15

10. Typical as-machined V-groove (specimen 1)................................................................... 16

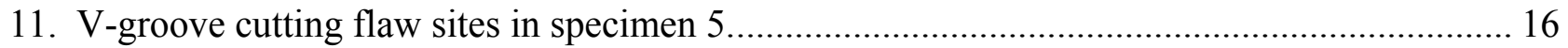

12. Cutting discontinuity (arrows ) on both as-machined V-groove walls (specimen 2)................ 16

13. Typical appearance of as-machined U-groove (specimen 9) …………..................................... 17

14. Views from south and north edges of U-groove on specimen 3 (not pre-cracked)................... 17

15. Specimen 7 (U-groove, not pre-cracked) after oxidation. ...................................................... 18

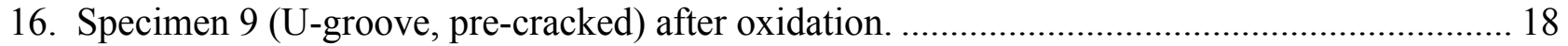

17. Scale spallation sites after torsion testing (specimen 3) ....................................................... 18

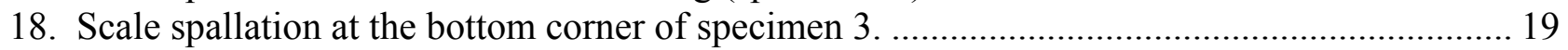

19. Scale delamination and spallation sites after torsion testing (specimen 7). ............................. 19

20. Scale crack and spallation sites along the bottom of the U-groove after torsion testing

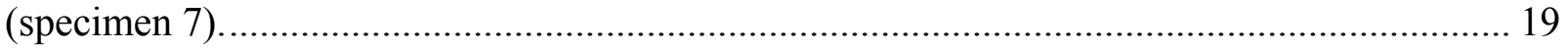

21. Scale spallation in groove after oxidation (specimen 9, pre-cracked).................................... 20

22. Spallation sites (a) top view, (b) bottom corner, (c) alumina crack sites at bottom corner, and (d) plan view of adherent scale (specimen 9) ...................................................... 20

23. Scale spallation and delamination sites after torsion testing (specimen 1) .............................. 21

24. Unusual features at spallation sites in the V-groove on pre-cracked specimen 1, after

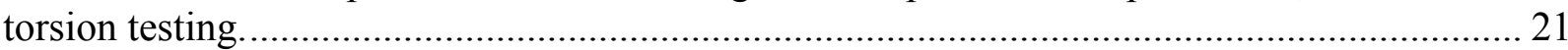

25. Fracture site (left) and spallation and delamination sites (right) after torsion testing

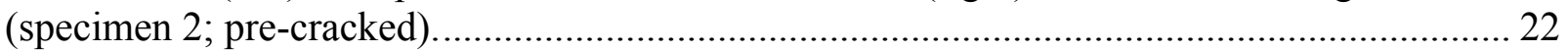

26. Scale spallation and crack sites on specimen 2 2................................................................. 22

27. Scale spallation site of pre-cracked specimen 5 after torsion testing. ...................................... 22

28. Irregular alumina formation near the edge of V-groove due to machining flaw at the

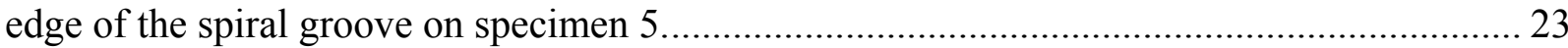

29. Scale spallation sites near the edge of groove on pre-cracked specimen 1............................. 24

30. Region B reveals a location where the alumina scale was adherent at temperature

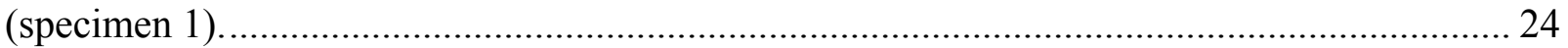

31. A pillar-like structure near the fatigue pre-crack site on specimen 1..................................... 24

32. Details of spallation sites at the bottom and bottom corner are shown in (a) and (c); corner/edge of the U-groove bottom as shown in (b); (specimen 7; not pre-cracked). 
33. The fracture reveals a distinct, unidentified layer between the alumina scale and the substrate as indicated by arrows in (a) the view from the underside of the bottom flat of the U-groove and (b) the view from the top of the bottom corner edge of the U-groove (specimen 7) ..................................................................................................... 26

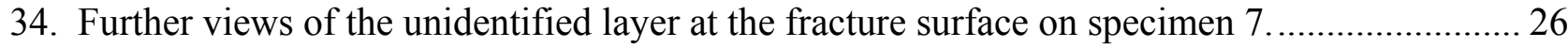

35. Schematic diagram of the formation of an oxide wedge. ................................................ 27

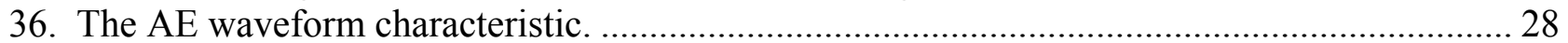

37. Torque load (top, in volts) and AE hits (bottom) time histories for specimen 3.................... 29

38. Torque load (top, in volts) and AE hits (bottom) time histories for specimen 7.................. 29

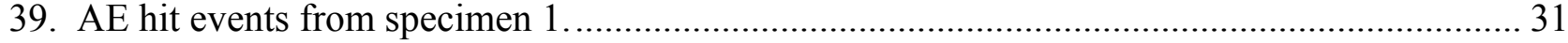

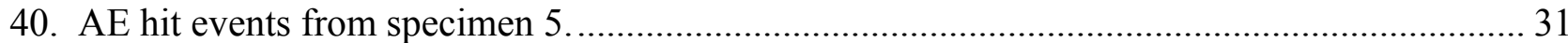

41. A 3-D sketch of proposed specimen configuration (a). The sketch indicates that the Xaxis of local coordinate 2 is the crack propagation orientation at the middle of the crack front. A 3-D sketch of fracture surface topology (b) based on the assumption that the crack propagation orientation is perpendicular and point to the central axis of the

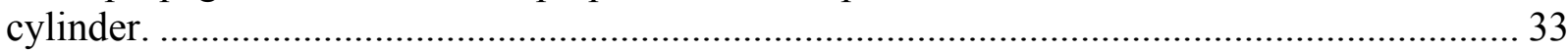

42. Elevation (a) and top view (b) of SNTT finite element model......................................... 33

43. The detailed mesh configuration near the bottom corner of the U-groove............................ 33

44. Finite element model for middle section of SNTT thin film sample.................................. 34

45. Details of SNTT thin film FEM near the U-groove site................................................. 35

46. Sub-model configuration around the crack front at the middle section of global model (a), with dimensions of 0.0004 in. diameter and 0.00125 in. length, the prescribed boundary displacements were evaluated from the global model configuration of Fig. 44. Mid-layer disk of the sub-model (b) with thickness of 0.000062 in. 35

47. Comparison of automated ball indentation curves, force vs. depth, which indicates that the oxide MA956 sample was softening compared with the baseline MA956 sample; oxide MA956 with partial coating sample shows slight hardening due to the thin film of alumina.

48. Deformation displacement contours at mid-layer of global model, which shows uniform deformation of test samples, except near the U-groove.

49. Hydrostatic pressure contours at mid-layer of global model; high tensile stress field shows near the bottom corner of the U-groove.

50. Hydrostatic pressure contours near crack tip at mid-layer of global model; the crack tip is indicated with an arrow at the highest negative hydrostatic pressure.............................. 42

51. Von Mises stress contours at mid-layer of global model, where the thin film presents a higher stress level than the substrate.

52. Von Mises stress contours near the bottom of the U-groove at mid-layer of global model, the crack tip is indicated with an arrow.

53. Von Mises strain contours near the bottom of the U-groove at mid-layer of global model.

54. Maximum principal stress contours at mid-layer of global model.

55. Maximum principal stress contours at bottom corner of mid-layer of global model; the highest maximum principal stress is at crack tip identified with an arrow.

56. Deformation displacement of sub-model configuration. ............................................... 45

57. Deformation displacement at the mid-layer of the sub-model............................................. 46

58. Hydrostatic pressure stress contour at mid-layer of sub-model......................................... 46 
59. Hydrostatic pressure near the crack tip at mid-layer of sub-model; the highest negative pressure is indicated with arrow at the crack tip.

60. Von Mises stress contours at the mid-layer of sub-model, which indicates the dissimilar stress contours around the crack tip, an important characteristic of a bi-material interface.

61. Von Mises stress contours near the crack tip at mid-layer of sub-model; the arrow indicates the site of highest Von Mises stress, at the crack tip.

62. Maximum principal stress near the crack tip at mid-layer of sub-model; the arrow indicates the site of the highest maximum principal stress, at the crack tip.

\section{TABLES}

Table

Page

1. Specifications of SNTT thin film samples. 10

2. Residual stress estimated from fluorescence measurements ................................................... 13

3. Acoustic emission and torsion test results for oxidized, non-pre-cracked, U-grooved specimens 3 and 7 .

4. Acoustic emission and torsion test results for oxidized, pre-cracked specimens $1,2,5$, and 9 ...

5. Material properties and criteria used in FEM analysis. 



\section{PREFACE}

ORNL/TM-2004/221/R1 supersedes the initially issued report ORNL/TM-2004/221. The revised report is being published to correct inaccuracies in the original text, not to add data or present additional conclusions. Changes have been made to Sects. 5.3.4.1 and 5.3.4.2 to correct the misidentification of specimen $\# 1$ and to move the related text and figures to the latter section. 


\begin{abstract}
A material configuration of central importance in microelectronics, optoelectronics, and thermal barrier coating technology is a thin or thick film of one material deposited onto a substrate of a different material. Fabrication of such a structure inevitably gives rise to stress in the film due to lattice mismatch, differing coefficients of thermal expansion, chemical reactions, or other physical effects. Therefore, in general, the weakest link in this composite system often resides at the interface between the film and substrate. In order to make multi-layered electronic devices and structural composites with long-term reliability, the fracture behavior of the material interfaces must be known. Unfortunately, none of the state-of-the-art testing methods for evaluating interface fracture toughness is fully conformed to fracture mechanics theory, as is evident from the severe scatter in the existing data and the procedure dependence in film/coating evaluation methods. This project is intended to address the problems associated with this deficiency and offers an innovative testing procedure for the determination of interface fracture toughness applicable to coating materials in general. This new approach and the associated bi-material fracture mechanics development proposed for evaluating interface fracture toughness are described herein. The effort includes development of specimen configuration and related instrumentation set-up, testing procedures, postmortem examination, and analytical evaluation. A spiral notch torsion fracture toughness test system was utilized. The objective of the testing procedure described is to enable the development of new coating materials by providing a reliable method for use in assessing their performance. This innovative technology for measuring interface toughness was demonstrated for oxide scales formed on high-temperature alloys of MA956. The estimated energy release rate (in terms of J-integral) at the interface of the alumina scale and MA956 substrate is $3.7 \mathrm{~N}-\mathrm{m} / \mathrm{m}^{2}$, and the estimated equivalent Mode I fracture toughness is $1.1 \mathrm{MPa} \sqrt{m}$. This innovative technique is expected to greatly assist the development of coating materials with improved protective capabilities and provide a reliable method for use in assessing material performance.
\end{abstract}





\section{INTRODUCTION}

During the last decades, the technology of electronics has advanced very rapidly, introducing manufacturing and packaging techniques that have led to extremely small components. Microelectromechanical systems ${ }^{[1,2]}$ evolved from the technology of silicon micro-fabrication and introduced the concept of micro-sized mechanical "moving" components, with the attendant mechanics of materials problems. Multi-layered and composite systems, which often contain metal/ceramic interfaces, are widely used in industry, both in microelectronic packaging and as structural materials. Examples are thin film materials with particular electrical, magnetic, and optical properties that are used extensively in the microfabrication of integrated circuits, sensors, and actuators.$^{[1,2]}$ In a completely different field, increasing the power and/or efficiency of propulsion systems requires them to operate at higher temperatures, and the point was reached several years ago where the materials considerations required to provide strength at high temperatures are incompatible with those required to provide environmental protection. As a result, such systems must rely on coatings or composite structures, in which the mechanical and chemical integrity of interfaces are critical to their successful application. ${ }^{[3,4]}$ Because of the need to maintain interfacial integrity at high temperatures under conditions of high heat flux, and the consequent effects on thermochemical stability and interdiffusion, it is difficult to obtain the combination of required properties from a single material; therefore coatings are used extensively. ${ }^{[5-9]}$ These coatings comprise a thermallyinsulating layer of ceramic together with a metallic layer intended to develop a specific, protective oxide film beneath the ceramic as well as to provide the means of securing the ceramic to the metallic substrate. [10-11]

Also relevant is the mechanical behavior of these different types of films, which can range in thickness from nanometers to microns. Residual stresses and material discontinuities arise naturally from the deposition or growth processes used to produce these films, and further stresses may be imposed from thermal cycling in service and mismatch in coefficients of thermal expansion (CTEs) [which can be severe in the case of thermal barrier coatings (TBCs)]. These undesirable stresses and other physical effects due to service can lead to fracture, delamination, and other modes of damage initiated at the interface(s). ${ }^{[12-19]}$ Thus, the need to understand the processes that govern the mechanical properties of the interfaces between these dissimilar materials becomes important, since the mechanical properties of these interfaces ultimately control the reliability of the device and the performance of the composite structural material.

\subsection{THE MECHANICS OF THIN FILM MATERIALS}

For the case of thin film materials and other small structures intended for electronic applications, interest is focused on the role of mechanical stress in defect nucleation and growth. Stress typically arises in such materials as a result of the constraint of epitaxy, a mismatch in coefficients of thermal expansion, or intrinsically as a result of growth processes. The simplest and most common configuration of this kind involving epitaxial structures is a thin layer grown onto a substrate under circumstances where the lattice parameter of the layer material differs from that of the substrate by a small amount. The strain in the layer induced by epitaxy may be a byproduct of material selection on some non-mechanical grounds, or it may be exploited to tailor the electronic properties of the film material. In either case, the stress associated with this strain provides a driving force for nucleation and growth of crystal defects, mainly dislocations and stacking faults.

In the electronics industry, the reduction of component size has been intensely pursued, and the thickness of large-scale integrated circuit (LSI) devices is reaching less than $1 \mu \mathrm{m}$. Since the sub-micron components consist of the multi-layered films made of ceramics, intermetallic compounds, and metals, 
delamination at the interface becomes one of the major failure modes in the processing and in the service of LSI devices. Therefore, it is important in terms of reliability to evaluate the interface toughness between the thin films, especially the delamination crack that usually initiates at the edges of thin films because of the stress concentration originating from the mismatch of deformation, namely the free edge effect. ${ }^{[20,21]}$

For TBCs, the predominant failure mode appears to involve a cyclic displacement instability occurring in the interfacial thermally-grown oxide (TGO). ${ }^{[1,22-27]}$ The instability occurs because the TGO is a thin layer subject to large levels of residual compression. The compression is caused by a combination of growth strain (converting the aluminum in the alloy to $\mathrm{Al}_{2} \mathrm{O}_{3}$ ) and a low CTE that results in a misfit with the metallic substrate upon cooling. The compressive stress reaches several GPa at ambient temperature. ${ }^{[28,29]}$ One of the mechanisms available to relieve the compressive stress is out-ofplane displacement of the thin oxide layer, but this can locally disrupt the outer ceramic thermal barrier layer and lead to failure of the TBC system. There is a complex interplay of phase change and morphological developments in the growing oxide film and modification of the properties of the oxidesubstrate interface resulting from segregation of specific elements from the metallic substrate or the nucleation of voids. All of these result in time-dependent changes in the properties of the interface. Ongoing research is developing an improved mechanistic understanding of how such changes occur; the ability to link this understanding with the effects on the mechanical integrity of the interface could provide routes for increased stability and hence longer service life.

\subsection{THEORETICAL AND EXPERIMENTAL DEVELOPMENT OF INTERFACIAL MECHANICS}

Bi-material systems with property mismatch are encountered in advanced material and nanotechnology development. A theoretical framework for analyzing the mechanics of fracture of dissimilar material interfaces was developed by Williams, and subsequently expanded by many others, including Rice and Sih, Erdogan, Bogy, and Huntchson and Suo. ${ }^{[30-36]}$ A resurgence of interest in quantifying fracture behavior of bi-material systems, in terms of fracture toughness and fracture mode mixity, is evident from the works reported in many recent papers. Yet both the fundamental mechanics and experimental techniques capable of systematically characterizing such fracture, are incompletely developed because of a lack of appropriate testing procedures that can properly characterize the interfacial mechanical properties.

Experimental techniques typically used in bi-material interface research are double-cantilever beam tests, four-point bending tests, indentation techniques, and laser spallation. ${ }^{[37-42]}$ The first two approaches can provide information regarding toughness evaluation, but the large uncertainty involved casts doubt regarding the validity of the test results. For example, in double-cantilever beam tests and four point bending tests, the interfacial crack generally does not propagate along the interface but often will kink out of the interface. In the indentation technique, the test result is dependent on the indentation load, penetration depth, and specimen size and geometry. Moreover, the penetration depth during the indentation test is difficult if not impossible to control because of the sudden release of the compressive residual stress when the indenter penetrates through the thin film or coating. Furthermore, the indention technique requires very large plastic deformation to induce crack initiation, which is likely to provide a non-conservative estimate of interface toughness. The laser spallation technique has been used for estimating interface strength subject to high strain-rate. ${ }^{[42]}$ However, because of the nature of laserinduced kinetic energy stored in the lattice structure, the consequence of instantaneous spallation, and complicated stress wave interaction at edges/boundaries, this technique also fails to provide quantitative interface toughness. 
The spiral notch torsion test (SNTT) methodology, a 2002 R\&D 100 Award winner, was developed by some of the authors of this report. ${ }^{[4-49]}$ The applicability of SNTT has been verified for homogeneous materials and for relatively large test samples (compared with the micrometer-level thickness of thin films). Consequently, the applicability of this concept to thin film test samples of bi-materials needs to be validated. In this feasibility study, SNTT technology was modified for use in measuring the interfacial toughness of thin, protective oxide scales formed on a high-temperature alloy, Inconel ${ }^{\circledR}$ MA956 (nominally: Fe-20 Cr-4.5 Al-0.5 $\mathrm{Y}_{2} \mathrm{O}_{3}$ ) after thermal treatment. In the feasibility study, significant technical challenges were encountered both in developing the experimental procedures in the testing apparatus for the proposed configurations and in analytical fracture toughness evaluation.

\section{SNTT APPROACH FOR TOUGHNESS EVALUATION}

The SNTT methodology operates by applying pure torsion to cylindrical specimens machined with a notch line that spirals around the specimen at a $45^{\circ}$ pitch angle. The pure torsion loading creates a uniform, equi-biaxial tension/compression stress field on each concentric cylinder, and the grooved line effectively becomes a Mode I (tensile) crack mouth opening, as illustrated in Fig. 1. It is not difficult to visualize this rod specimen as a variant of a compact-tension specimen having a width equivalent to the total length of the spiral notch. Compact-tension specimen testing has an inherent problem, which is lack of a means to uniformly distribute the applied load throughout the entire specimen thickness. This is because the stresses at and near the two free surfaces are anomalous, resulting in shear lip formation that often is discernible in fractured specimens. In contrast, the torque load acting on every cross-section along the rod specimen is the same and directly measurable, so that a plane-strain condition is achieved on every plane normal to the spiral groove.

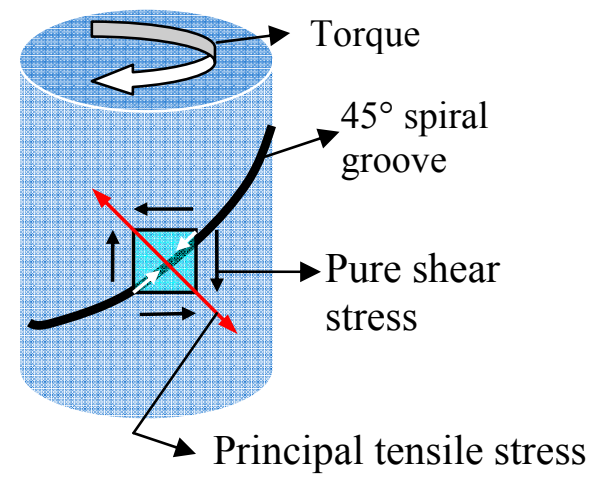

Fig. 1. Schematic diagram of SNTT configuration.

Specimen miniaturization is an important option of the SNTT methodology and serves the need of advanced materials development with limited material availability. Another feature of this technique is that the $\mathrm{K}_{\mathrm{IC}}$ values determined are virtually independent of specimen size. In typical fracture toughness tests, the direction of crack propagation is unpredictable and often deflects in zigzags or a thumbnail pattern, resulting in large data scatter. When a rod sample is twisted, the spiral notch provides a consistent location for cracking to start; and the pure torsion load ensures that the crack will advance perpendicularly toward the central axis of the test specimen. This consistent cracking behavior has been verified from postmortem examination of fracture surfaces. Therefore, the SNTT methodology is expected to significantly reduce uncertainty in fracture toughness evaluation. Furthermore, the ability of 
SNTT to confine the plastic deformation within a thin plane provides the opportunity to investigate the interfacial material properties. In addition, SNTT provides an expedient means to investigate mixed-mode failure mechanisms by simply varying the pitch of the starter notch. The benefits of applying SNTT to thin film research can be summarized as follows:

- The size effect in fracture toughness evaluation using SNTT is minimized. A long and uniform crack front will yield an accurate fracture toughness value, which is more likely near the statistical mean; thus, fewer test samples are needed to generate valid $\mathrm{K}_{\mathrm{IC}}$.

- For valid fracture toughness $\left(\mathrm{K}_{\mathrm{IC}}\right)$ testing, conventional ASTM standards not only require fairly large specimens, but also require a fatigue precrack procedure to develop a sharp crack front. This is a very difficult task for interfacial fracture testing, and the fatigue precrack itself results in a very large uncertainty in $\mathrm{K}_{\mathrm{IC}}$ evaluation. For the SNTT approach, no fatigue precrack is needed for brittle materials such as ceramics or oxide layers; and, for the ductile interface, the fatigue crack growth is not expected to change course along the interface. Thus, the SNTT approach has several advantages for evaluating the intrinsic toughness at interfaces. This phenomenon will be further examined in this research.

- Mode mixity plays an important role in interface failure mechanisms. Recent publications indicate that a combination of Mode I and Mode III is more detrimental than Mode I alone for many materials of interest. ${ }^{[50,51]}$ For example, as a result of residual stresses, thin, thermallygrown thermal protective oxide layers seek mechanisms to relieve compressive residual stress, which typically occurs by means of out-of-plane displacement. Thus, the combined effect of out-of-plane Mode III (tearing shear mode) and Mode I needs to be assessed. The SNTT method provides an excellent tool for investigating combined Mode I and Mode III failure mechanisms.

\section{RATIONALE OF THE PROPOSED RESEARCH}

An example of an interface for which the information generated by the proposed technique would be extremely valuable is that between the metallic bond coating component of a TBC and the alumina scale that is deliberately grown on that bond coating to provide environmental protection and to anchor the outer ceramic thermal barrier layer. Recall that the use of TBCs has been pioneered on the airfoil surfaces of advanced gas turbine engines; they are needed there (in conjunction with internal cooling of the airfoils) to increase power and/or efficiency of operation, which is achieved by operating at combustion gas temperatures above the melting point of the alloys used for the airfoils. The failure mode of TBCs typically involves crack propagation near or along the interfaces between the ceramic and TGO or between the TGO and the bond coating. When the characteristics of the ceramic layer are optimized, the weakest link in the TBC system will be at the TGO-bond coating interface. Our research was focused on the fracture behavior and toughness of such an interface, which is illustrated in Fig. 2. 


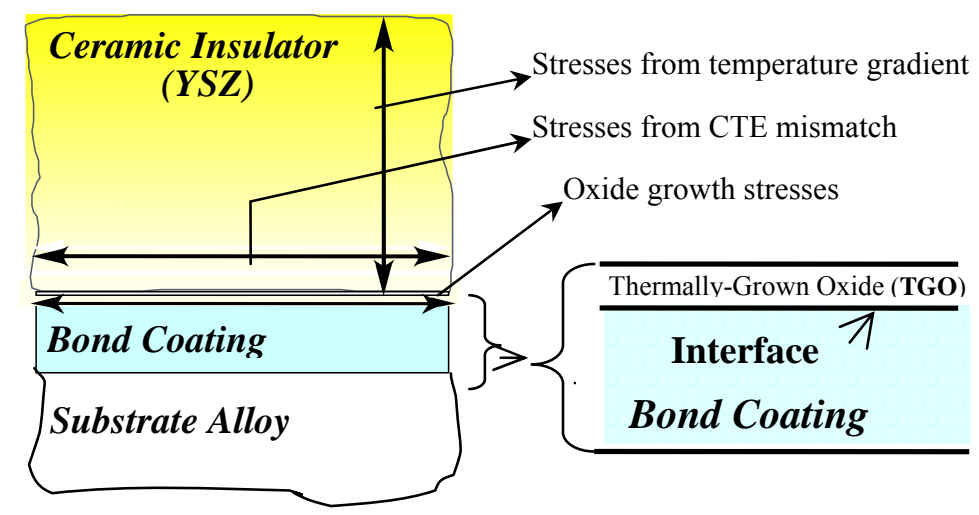

Fig. 2. Schematic diagram of interface between bond coating and thermally grown oxide.

Significant efforts have recently been made to model the mode of failure of TBCs in order to provide some life prediction capability, since unexpected failure of a TBC in service could have catastrophic results. Much of this effort has been focused on trying to understand the criteria for initiation of cracking, especially of cracking that leads to separation of the TGO scale from the bond coating. In addition to understanding the factors that govern the development of stress along the TGO-bond coating interface, especially from growth of the oxide and from CTE mismatch during thermal cycling, techniques have been developed to try measuring some of these parameters in situ. In particular, photo-stimulated luminescence spectroscopy has been used to measure the stress level and crystal phase of the alumina scale itself, and attempts are being made to derive correlations with the tendency for scale spallation (hence loss of the TBC), so that such techniques may be used for monitoring conditions in service.

The unequivocal measurement of the fracture parameters for the interface in question would provide the datum point against which all such in situ measurement techniques could be calibrated. Further, the ability to measure the fracture toughness of the interface would provide a quantitative measure of the effectiveness of TBC developments intended to increase service life and would lead not only to longer life but also to assured performance and lower costs.

\section{PROPOSED EXPERIMENTAL APPROACH FOR THIN FILM INTERFACE FRACTURE TOUGHNESS TESTING}

The focus of this thin film interface research was the interface of a thin, protective oxide scale (alumina) formed on a high-temperature alloy, MA956®, and its substrate. The development of the testing procedure for thin films required a major upgrade of the SNTT specimen preparation and the SNTT methodology, both in experimental procedures and in analytical evaluation. In this study, several configurations of proposed SNTT specimens were investigated. Two types of notch configurations, a Vshape and a square U-shape with different aspect ratios, were used. An acoustic emission device was utilized to detect the crack initiation.

\subsection{THE PROPOSED THIN FILM SNTT CONFIGURATION}

The conceptual design used for testing the thin film is illustrated in Fig. 3. A circular rod of alloy MA956, machined with a shallow spiral groove, was used as the baseline. This alloy was chosen for its ability to reliably form a uniformly thick, adherent surface film of $\alpha$-alumina, which is very similar to that 
formed on bond coating alloys used with TBCs. Thus, the complication of using coatings was avoided. A 10-15-mm-thick alumina scale was formed after oxidation in air at $1100^{\circ} \mathrm{C}$ for 100 hours. This specimen design utilized a $45^{\circ}$-pitch angle of the spiral groove under pure torsion to generate opening mode stress along the interface between the oxide and the alloy. The optional fatigue precrack procedure applied to the baseline MA956 sample was also investigated. A parameter study of notch geometry, such as V-or Ushape notches and the depth of the notch, was conducted to determine the most suitable configuration for thin film testing.

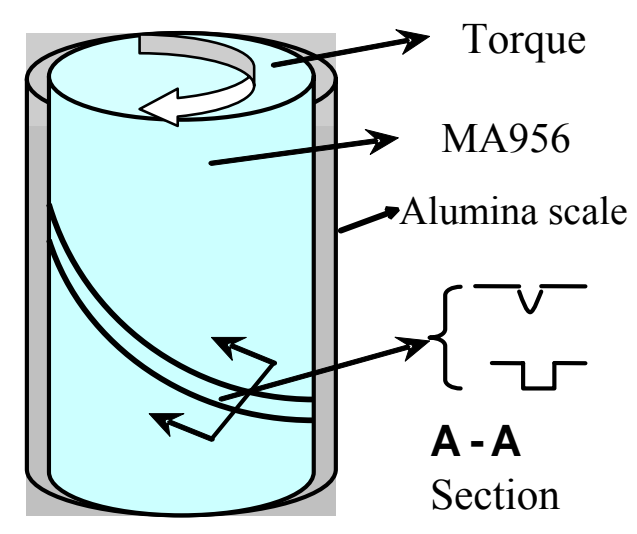

Fig. 3. SNTT thin film sample.

\subsection{FRACTURE MECHANISM OF SNTT THIN FILM SPECIMEN}

The details of notch root geometry and the indicated failure initiation sites of an oxide MA956 SNTT sample are illustrated in Fig. 4. The shaded area of alumina scale indicates the region of thin film that is capable of transmitting the resultant force of the principal stress induced by pure torsion loading. The orientation of the crack propagation for the proposed SNTT configuration is material-dependent. With (1) thin film alumina scale of high hardness compared with that of the substrate and the compressive residual stress of the thin film (acting normal to the principal stress), and (2) potential notch root blunting or substrate yielding because of high tensile stress fields near the corner of the notch root, a crack is more likely to initiate from the corner of the notch root and to propagate upward (in the orientation of Fig. 4) along the interface. After the threshold for crack growth along the interface (vertical in Fig. 4) has been exceeded, the compressive residual stress in the alumina will cause the unsupported portion of alumina scale to buckle (as a result of the lack of lateral support from the substrate). 


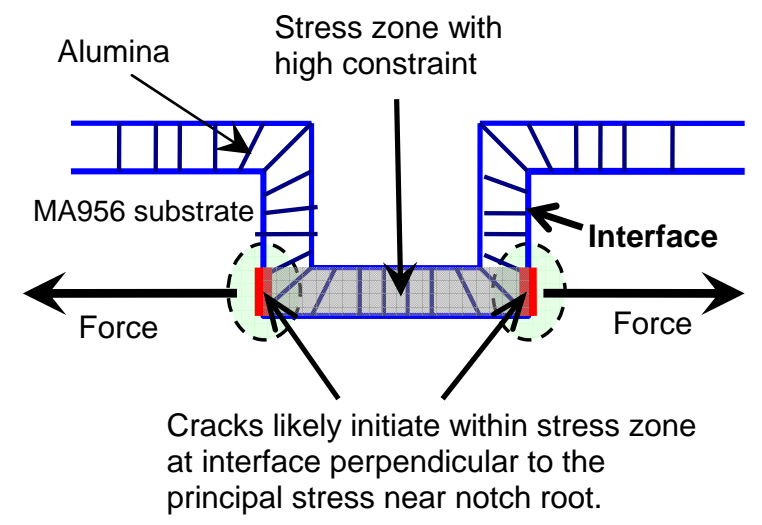

Fig. 4. Schematic diagram of notch root geometry and the associated crack initiation sites.

This hypothesized SNTT failure mode was confirmed from scanning electron microscope (SEM) examination of tested SNTT thin film samples. Thus, for a non-precracked, oxidized SNTT MA956 sample, cracking is expected to initiate at the corner interface (at the bottom of the groove) and to grow upward along the interface before it penetrates down into the substrate.

Because of the small dimensions of the thin film test sample, sensitive instrument control was needed; in particular, optical devices were needed for measurement of subtle deformation. Additionally, acoustic and infrared instruments were needed to capture the onset of the crack initiation underneath the coating.

\subsection{TEST SAMPLE PREPARATION}

SNTT specimens were fabricated to the design shown schematically in Fig. 5 from a 1.5-in.-diam rod of alloy MA956 (956 ANN2300F), and from a $1 / 2$ by 2 -in. cross-section plate of a higher-aluminum variant (MA956HT, heat WBD0667). Both were in the recrystallized $\left(1 \mathrm{~h}\right.$ at $\left.1300^{\circ} \mathrm{C}\right)$ condition. A total of 10 SNTT specimens were made, including five with V-notch grooves and five with U-notch grooves. Because of the limited material available and the constraint of the dimensions of the received raw materials, all the SNTT specimens were machined in L-T orientation. While the size of the test specimen is optional, depending on the form of the available material, these specimens had a uniform gage section of $1 \frac{1}{4}$ in., on which a complete lobe of a spiral groove with a pitch of $45^{\circ}$ was machined. The squared end sections were made to transmit torque, and the threaded ends were made for zero axial load control. Four SNTT specimens were used in the as-machined condition for calibrating fatigue precrack and evaluating fracture toughness of MA956. The other six SNTT samples were oxidized to grow an alumina surface film of thickness in the range of 7 to $12 \mu \mathrm{m}$ (alloy MA956HT oxidizes more slowly than the standard alloy and so grew a thinner film under the same oxidation conditions of $100 \mathrm{~h}$ in air at $1100^{\circ} \mathrm{C}$ ). The alumina film was expected to be uniform in thickness and to cover the entire rod surface, including the spiral grooves. The corresponding material ID, groove geometry, baseline fatigue precrack, and heat treatment of the oxidized SNTT thin film specimens are listed in Table 1. Specimens with V-and U-type grooves were used in the thin film study. 


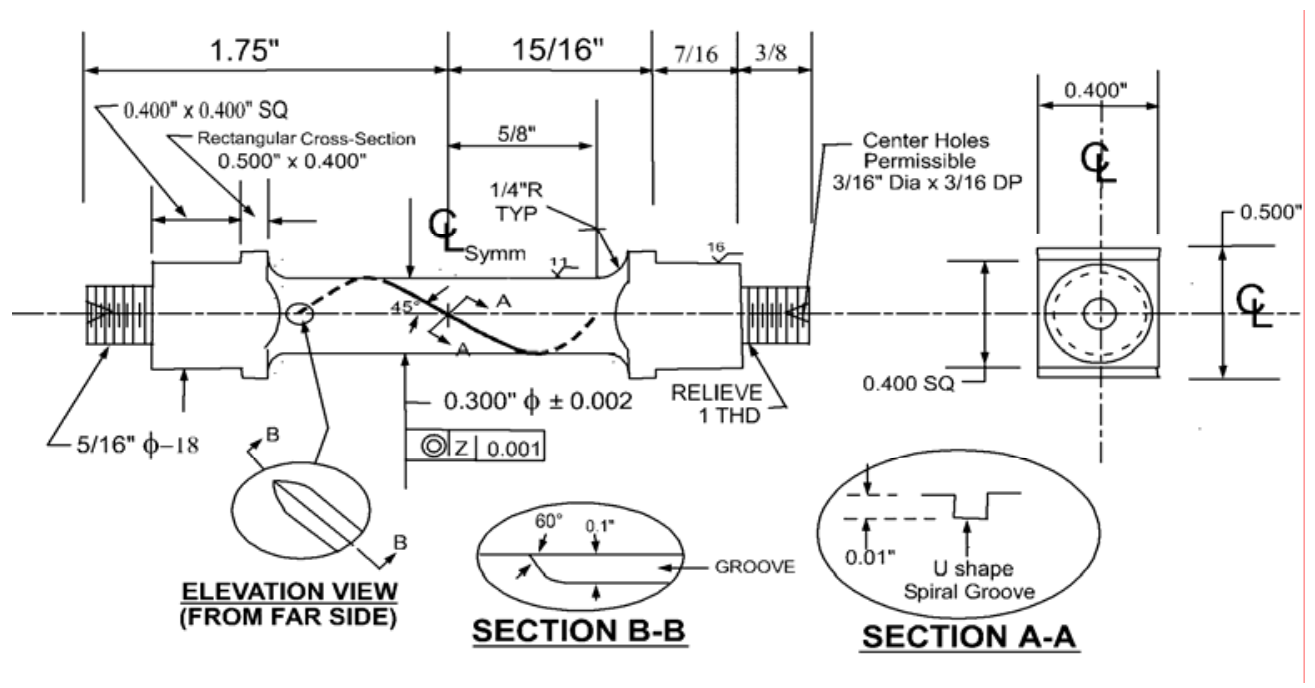

Fig. 5. SNTT thin film specimen design configuration.

Table 1. Specifications of SNTT thin film samples

\begin{tabular}{|c|c|c|c|c|}
\hline Specimen ID & Material ID & $\begin{array}{l}\text { Spiral notch } \\
\text { type }\end{array}$ & $\begin{array}{l}\text { Baseline } \\
\text { precrack }\end{array}$ & Temp. $\left({ }^{\circ} \mathrm{F}\right) /$ time $(\mathrm{hr})$ \\
\hline 1 & Heat $1^{a}$ & V shape- $1^{c}$ & Yes & $1100^{\circ} \mathrm{C} / 100 \mathrm{~h}$ \\
\hline 2 & Heat 1 & $\mathrm{~V}$ shape-2 ${ }^{d}$ & Yes & $1100^{\circ} \mathrm{C} / 100 \mathrm{~h}$ \\
\hline 3 & Heat 1 & U shape-1 ${ }^{e}$ & No & $1100^{\circ} \mathrm{C} / 100 \mathrm{~h}$ \\
\hline 5 & Heat $2^{b}$ & V shape-1 & Yes & $1100^{\circ} \mathrm{C} / 100 \mathrm{~h}$ \\
\hline 7 & Heat 2 & U shape-1 & No & $1100^{\circ} \mathrm{C} / 100 \mathrm{~h}$ \\
\hline 9 & Heat 2 & U shape-1 & Yes & $1100^{\circ} \mathrm{C} / 100 \mathrm{~h}$ \\
\hline \multicolumn{5}{|c|}{$\begin{array}{l}{ }^{a} \text { MA956-ANN 2300F; } \\
{ }^{b} \text { MA956HT- Heat No:WBD0667. } \\
{ }^{c} \text { Type V-1: } 0.015 " \text { deep, } 60^{\circ} \text { vee; } \\
{ }^{d} \text { Type V-2: } 0.032 " \text { deep, } 90^{\circ} \text { vee } \\
{ }^{e} \text { Type U-1: } 0.016 " \text { deep and } 0.0197 \text { " wide }\end{array}$} \\
\hline
\end{tabular}

\section{EXPERIMENTAL SET-UP AND TEST RESULTS}

Torsion tests were performed using a closed loop-controlled, electro-hydraulic, biaxial testing system, shown in Fig. 6. Test specimens were subjected to pure torsion controlled by LVDT and RVDT, in association with a high-sensitivity, biaxial load cell to maintain a zero axial load. In order to capture the onset of crack initiation, an acoustic emission device was used. Precracking for baseline MA956 specimens was accomplished by cyclic torsion, using the Haver sine wave form. The maximum torque used in precracking varies with materials and must be determined experimentally; normally about 60$80 \%$ of the torque that generates the maximum shear stress around the specimen diameter will suffice. We did not use compliance to monitor the fatigue crack growth; instead, an approximate compliance function was used to estimate crack growth under loading and unloading sequences in torsion. To date, the closedform solution for torsion compliance has not been developed. An exploratory procedure estimating load- 
displacement (or stress-strain) slope change at different phases of fatigue loading was adopted to estimate fatigue crack growth. The fatigue crack growth was measured by postmortem examination. In general, precracking was not needed for a brittle SNTT specimen, such as a ceramic. Also, for investigating interface cracking of an oxidized MA956 SNTT specimen, the precrack was considered to be redundant because the material discontinuity was a natural stress riser. However, in order to provide a comparison between the precracked baseline sample and the oxidized sample, two sets of SNTT baseline samples were prepared, one with a precrack and one without a precrack.

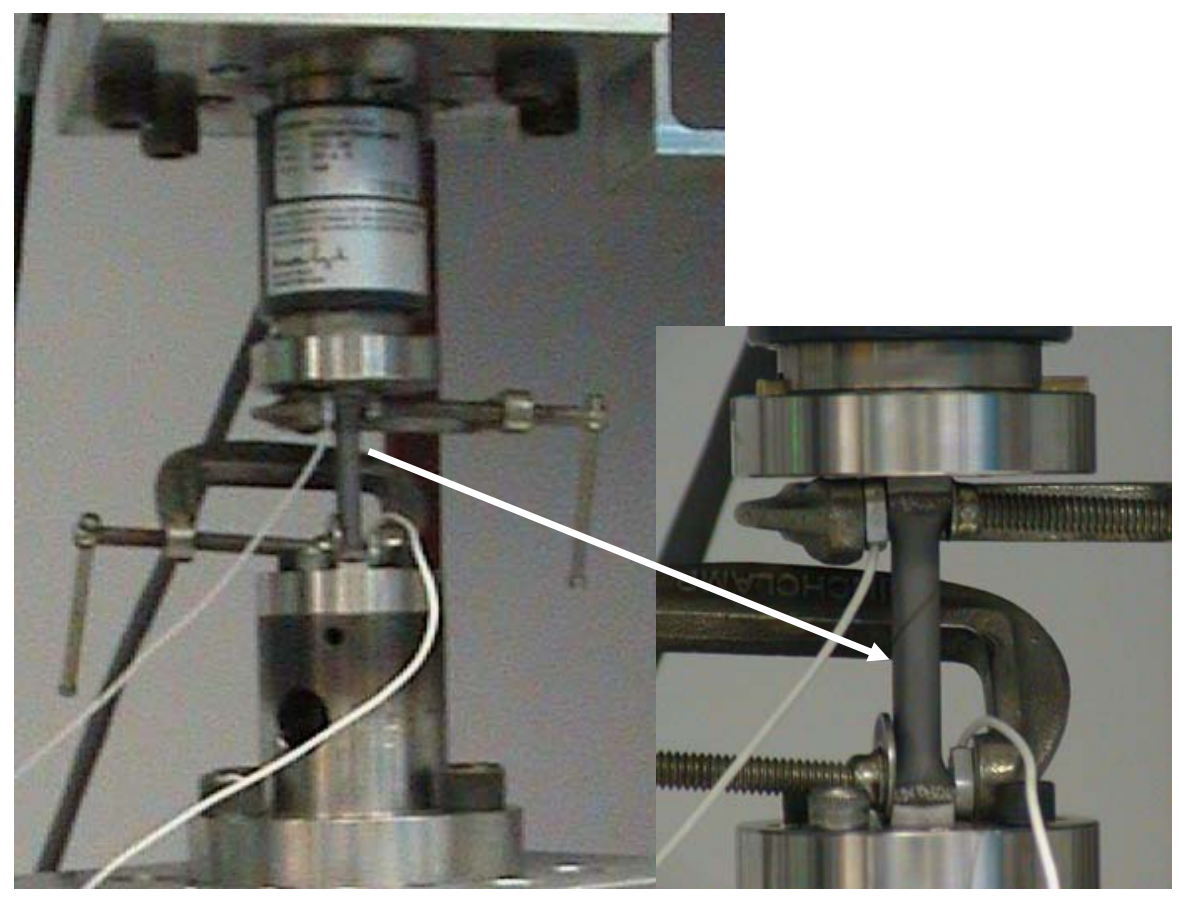

Fig. 6. Experimental set-up, including acoustic emission sensors attached to the ends of SNTT specimen.

The fracture torque load at the crack initiation is needed as input for the interfacial fracture toughness evaluation, using a new SNTT analytical procedure developed for this project. Determining the torque at crack initiation required the use of several techniques concurrently, because of the micro-scale of oxide thickness. In recent years, infrared (IR) imaging has been applied successfully for detecting and monitoring fatigue crack growth. ${ }^{[52,53]}$ However, because of the highly insulating nature of the alumina film, the surface temperature profile of the SNTT oxide sample revealed from IR imaging was not useful for detecting or determining evolution of an interfacial crack underneath the alumina film. The acoustic emission technique provided very consistent and distinct signals during the fracture test.

\subsection{BASELINE FRACTURE TOUGHNESS EXPERIMENT}

Because of limited availability of alloy MA956, only four SNTT samples were used for exploring fatigue precrack and fracture behavior for the as-received (non-oxidized) alloy. Of the three SNTT MA956 specimens used for evaluating the fatigue precrack procedures, all fractured during the exploration of the fatigue precrack testing procedure. This fatigue precrack procedure was then used to precrack some of the SNTT baseline samples. One sample used to measure the fracture toughness of 
MA956 was fractured at $32 \mathrm{~N}$-m with a 0.06 -in. deep crack. Instead of carrying out detailed finite element analysis for fracture toughness evaluation, the fracture toughness data were estimated and projected from the earlier SNTT fracture toughness data for A302B steel, with a/W ratio (crack length to diameter ratio) at about 0.4. The estimated toughness of the as-received MA956 material was about $68 \mathrm{MPa} \sqrt{\mathrm{m}}$.

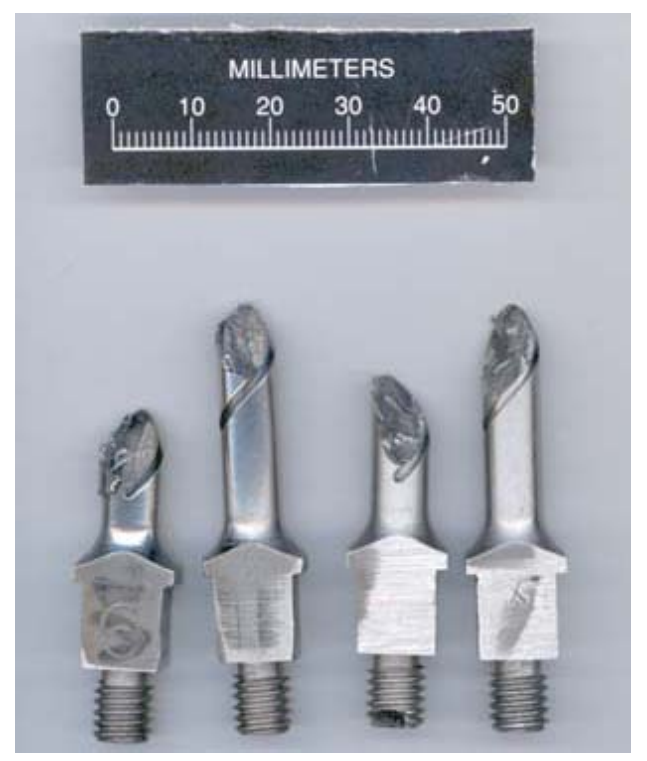

Fig. 7. Fractured SNTT MA956 samples.

\subsection{EVALUATION OF RESIDUAL STRESS OF THIN FILM COATING MATERIAL}

\subsubsection{Thin Film Stress Evolution}

Since the oxide film grown by oxidation of the surface of alloy MA956 has a greater volume than that of the metal consumed, stresses invariably develop between the oxide and the underlying alloy. Further, the CTE of MA956 is significantly higher than that of alumina, ${ }^{[54]}$ providing a further source of stress during heating and cooling. There is a prevailing consensus that failure of an oxide film occurs when the stored elastic strain energy in the scale (the product of the scale thickness and the square of the stress) reaches a critical value. Therefore, the stress state in an oxidized scale is an important parameter in predicting the loss of integrity of the scale and hence in assessing the long-term protection afforded the underlying alloy. In general, the CTE thermal stress is much greater than the scale growth stress. Stott and Atkinson ${ }^{[55]}$ reviewed the general approaches used to describe the generation of stresses during oxidation. They also demonstrated the importance of stress relaxation during scale growth at high temperature in the model of stress generation during the oxidation of silicon.

\subsubsection{Fluorescence Measurements}

The technique of $\mathrm{Cr}^{3}+$ fluorescence piezospectroscopy was used in this study to measure the stress in the $\alpha$-alumina film formed by thermal oxidation. ${ }^{[56-58]}$ Three types of information concerning the scales can be obtained from the fluorescence measurements: the strain from the piezospectroscopic shift of the R-lines; the strain gradient through the oxide thickness from the broadening of the R-lines; and the crystallographic texture of the oxide film from the intensity ratio of the two R-lines. Measurements of the $\mathrm{Cr}^{3}+\mathrm{R}$-line fluorescence were made by exciting the oxide using an argon-ion laser operating at $514 \mathrm{~nm}$. The laser was focused onto areas of interest with an optical microprobe. The excited fluorescence was 
collected along the same optical path. The fluorescence spectrum was dispersed using a triple-grating spectrometer equipped with a liquid-nitrogen-cooled charge-coupled device (CCD) detector. The fluorescence line frequencies and widths were obtained by fitting spectra to double pseudo-Voigtian functions, one for each of the R-lines. All measurements were made at room temperature.

Table 2 shows the average hydrostatic stress collected from the thermally-grown $\alpha-\mathrm{Al}_{2} \mathrm{O}_{3}$ scale from both the bulk (far away from the groove) and within the groove. The bulk stress varies slightly between samples as a result of different heating conditions. Average measurements collected within the groove show less stress and more stress variation than the bulk measurements, a difference most likely caused by the alumina scale spallation and interfacial cracking in this area. Stress measured in the bottom corner of specimen 9 was much lower than all the other measurements because the scale was completely delaminated (but still intact) in this region. Figure 8 shows a residual stress profile across the U-groove site of specimen 7 before the torsion test, and from specimen 3 after the torsion test. The scan profile region spans from near the middle of the bottom groove, through the corner, up along the side wall, to the top edge of the corner (orientation as in Fig. 4). Even though specimens 3 and 7 were made from MA956 and $956 \mathrm{HT}$, respectively, the residual stress profiles were very similar, which may indicate that most of the films are still intact after the torsion test. The estimated residual stress from the bulk and side of the Ugroove of specimen 3 was used as input for the boundary condition of the SNTT finite element model analysis.

Table 2. Residual stress estimated from fluorescence measurements

\begin{tabular}{|c|c|c|c|}
\hline $\begin{array}{c}\text { Specimen ID- } \\
\text { groove shape }\end{array}$ & Location & $\begin{array}{c}\text { Hydrostatic stress } \\
(\mathrm{GPa})\end{array}$ & St. dev. \\
\hline 1-U & bulk & -3.58 & 0.03 \\
\hline $2-\mathrm{V}$ & bulk & -3.49 & 0.03 \\
\hline \multirow{3}{*}{$3-\mathrm{U}$} & bulk & -3.66 & 0.01 \\
\cline { 2 - 4 } & groove/bottom & -2.59 & 0.14 \\
\cline { 2 - 4 } & groove/corner & -2.50 & 0.33 \\
\cline { 2 - 4 } & groove/wall & -2.71 & 0.17 \\
\hline \multirow{2}{*}{$5-\mathrm{V}$} & bulk & -3.85 & 0.01 \\
\hline 7-U & bulk & -4.02 & 0.02 \\
\hline \multirow{2}{*}{$9-\mathrm{U}$} & bulk & -3.92 & 0.02 \\
\cline { 2 - 4 } & groove/bottom & -2.68 & 0.08 \\
\cline { 2 - 4 } & groove/corner & -0.27 & 0.01 \\
\hline
\end{tabular}




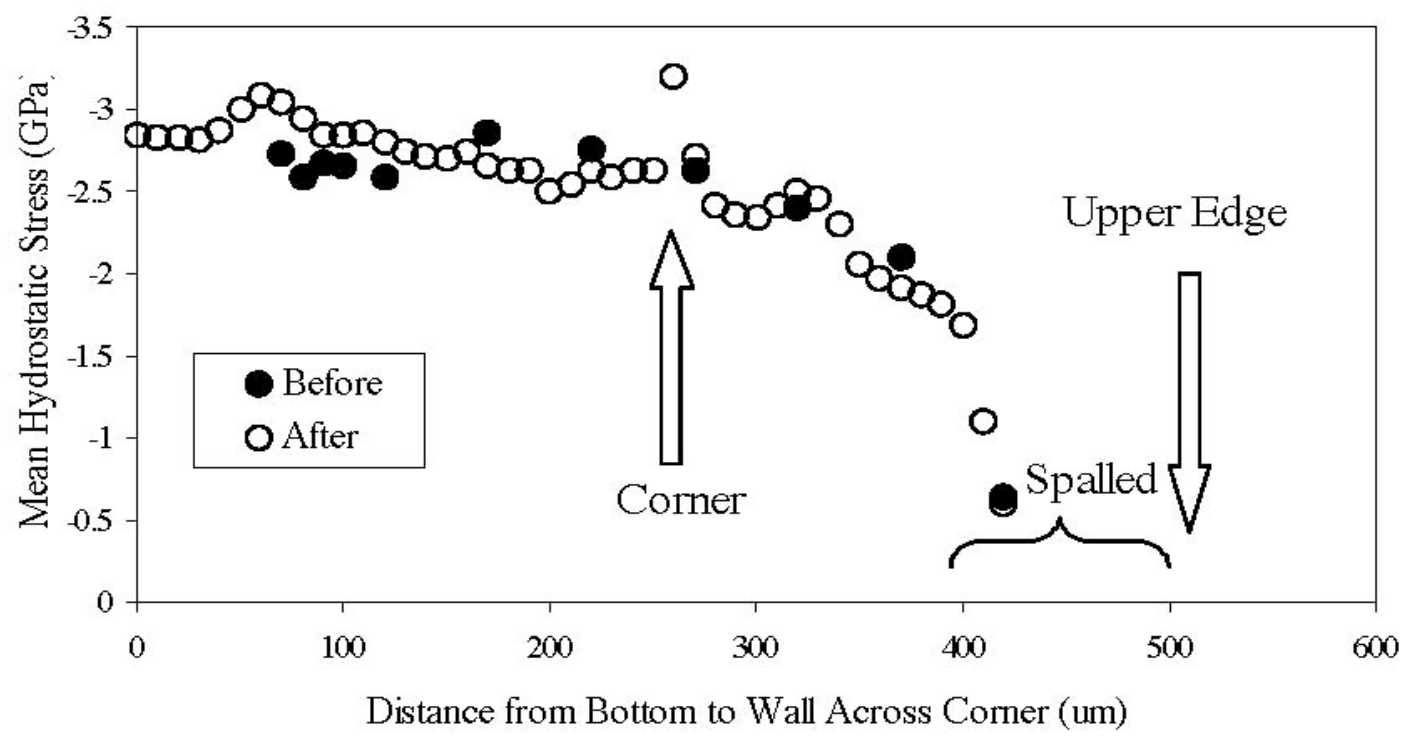

Fig. 8. Residual stress profile across U-groove from specimen 7 before the torsion test and from specimen 3 after the torsion test.

\subsection{POSTMORTEM EXAMINATION OF OXIDE SNTT SPECIMENS}

\subsubsection{Initial Visual Inspection}

Initial visual examination was made following the oxidation treatment of the SNTT samples. It appeared that the alumina scale at the top corners (see Fig. 9) of the V-or U-groove sites was all spalled, while the alumina scale remained intact on the rest of the SNTT samples. The residual stress distribution near the U-groove site is shown schematically in Fig. 9. For a thin TGO normal stress is not usually a concern except at the sites near delamination, such as at free edges. As indicated earlier, biaxial compressive residual stress fields exist within such films as a result of growth stress and of stress induced by CTE mismatch, which is a function of temperature and cooling rate, film thickness, etc. The out-ofplane normal stress typically does not exist, or is very small, for a flat plate with a relatively thick substrate. The stress fields of a thin film can be characterized as equal bi-axial stress fields and estimated from hydrostatic pressure obtained from a nondestructive evaluation, such as the $\mathrm{Cr}^{3}+$ fluorescence piezospectroscopy technique. As for the case considered here, a circular rod with notch may present a different problem compared with a flat surface. However, the above mentioned normal stress condition can still hold for a curved surface with a curvature that is much larger than the thin film thickness. In our specimen design with a 0.15 -in. diameter, the corresponding curvature is much larger than the film thickness at $10 \mu \mathrm{m}$ range. Thus, the issue regarding residual normal stress still holds for most of the cylinder surface, except at the U-groove. Owing to lack of information regarding spallation in real time, the possible causes of the alumina spallation at the top corner of the U-groove are discussed below, with reference to Fig. 9.

Wright et al. showed that the regions of local curvature can result in significant tensile stress along the exterior surface of the oxide and large stress gradients in the scale as it bends, as well as contracts, upon cooling. ${ }^{[59]}$ Further numerical analysis of surface cracks at regions of curvature in oxide scales was done by Williamson et al.; ${ }^{60}$ with a continuous rod curvature $\left(2 \times 2 \mathrm{~mm}^{2}\right)$ samples were used in the study. In their work on geometry effect, ratios of corner radii to scale thickness $\left(r_{s} / t\right)$ of $0.5,2$, and 4 are 
considered. The results show initial crack motion perpendicular to the free surface of the scale, followed by a $90^{\circ}$ turn, resulting in a path nearly parallel to the free surface, and finally breaking through the scale within the curved section. ${ }^{[60]}$ However, these models were developed within a continuous curvature domain, which may not directly apply to a substrate with a right angle corner that has a discontinuous curvature characteristic and a near-zero $r_{s} / t$ ratio. Nevertheless, the Williamson models show that the stress intensity factor increases with decreasing $r_{s} / t$ ratio. Therefore, the tensile crack of a thin film will likely initiate at the corner. Thus, after the initial crack at the corner, the problem will be simplified to conventional free edge thin film case. It is well known that the free edge of a thin film can act as a site for delamination. However, that does not fully explain why the alumina scale at the vicinity of the top corner of the U-groove is completely spalled.

As shown in Fig. 9, Corner A is adjacent to two perpendicular thin film layers. The top corner of the substrate would not possess the characteristics of a free edge if the corner film remained intact. From the point of a physical singularity and the surface slope discontinuity at a corner, it would be difficult to form a thin film with a well organized and orientated columnar structure and subsequently to maintain the integrity of the thin film and its bonding with substrate during cooling. Furthermore, considering the residual stress distribution during cooling, as illustrated in the lower portion of Fig. 9, the tensile residual stresses of the substrate will have a tendency to pull the corner of the substrate away from its original position in a diagonal direction; while the compressive residual stress in the film will have a tendency to push the alumina film away from the top corner of the substrate, also in a diagonal direction. It is also expected that the Corner A block will have less residual stress as a result of lack of direct contact with the substrate and will act as connecting block between the two perpendicular alumina scales. It is not difficult to visualize that, with increasing residual stress during cooling, the combined effect of tensile and compressive residual stresses at the corner will eventually detach the alumina film initially at the top corner of the U-groove. After the interface crack growth reaches a threshold crack length, the compressive residual stress will then buckle the delaminated alumina scales and result in spallation of the alumina scale at the vicinity of the top corner of the U-groove.

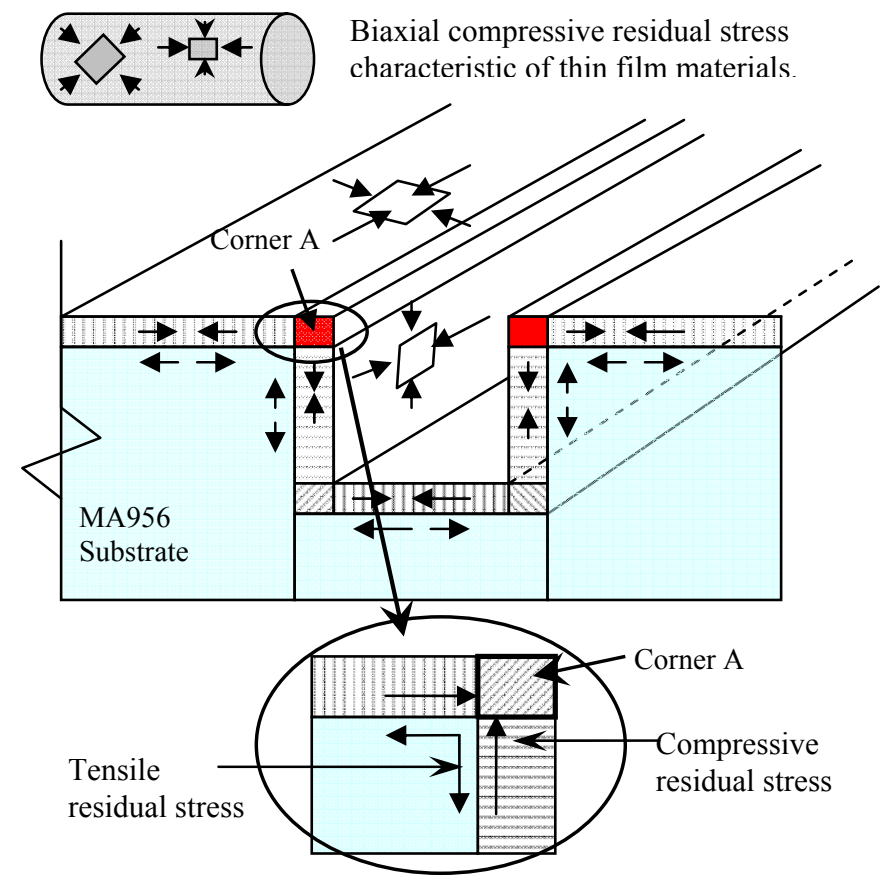

Fig. 9. Schematic diagram of residual stress fields near the U-groove site. 


\subsubsection{Surface Examination of As-Machined SNTT Samples}

After the initial visual examination of the SNTT samples, the areas around the spiral grooves were also examined in detail by optical microscopy. This revealed the surface finish of the test samples to be fairly rough, especially at the spiral groove sites for specimens 2 and 5 . The surface roughness may have been due to machining performance or to the machining properties of alloy of MA956. Microscopic surface images for typical V-groove SNTT samples are shown in Fig. 10 (for specimen 1). Significant surface flaw sites were revealed around the V-groove in specimen 5, including chipped edges and a wavy groove bottom (Fig. 11). Figure 12 shows two shallow grooves on both V-groove walls for specimen 2; these were thought to be due to cutting errors during machining.

Surface images of typical U-groove sample (specimen 9) are shown in Fig. 13. U-grooves seem to have less machining damage than $\mathrm{V}$-grooves.

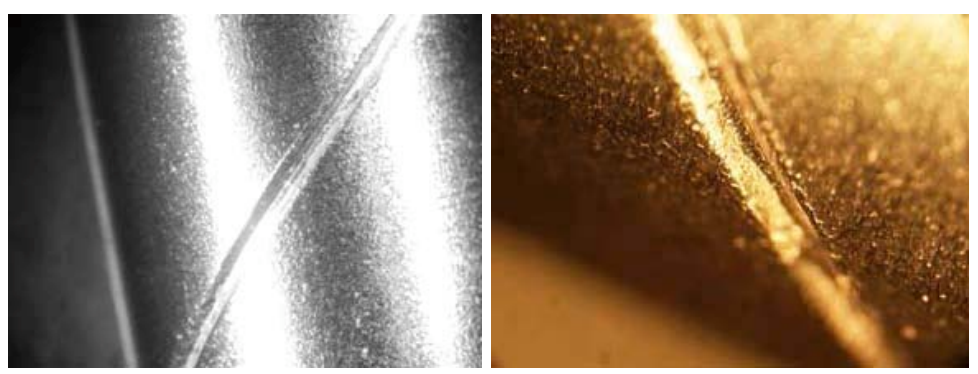

Fig. 10. Typical as-machined V-groove (specimen 1).

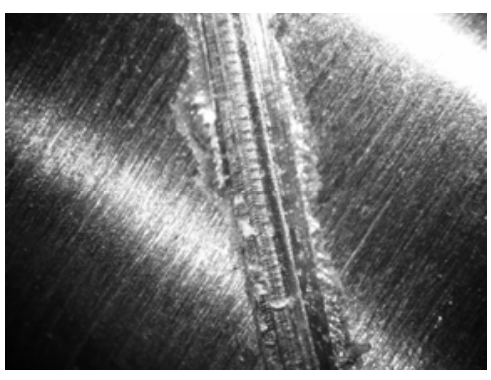

Fig. 11. V-groove cutting flaw sites in specimen 5.
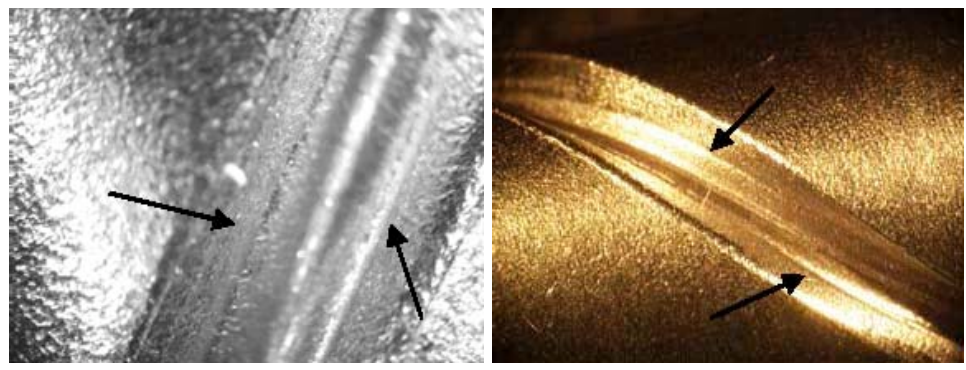

Fig. 12. Cutting discontinuity (arrows ) on both asmachined V-groove walls (specimen 2). 


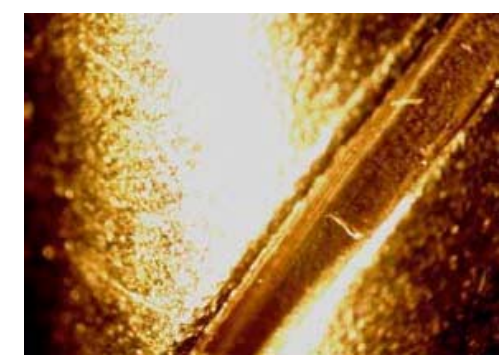

Fig. 13. Typical appearance of as-machined U-groove (specimen

9).

\subsubsection{Surface Examination of Oxidized SNTT Samples before Torsion Test}

Plan views of the surfaces of oxidized U-groove SNTT specimens 3, 7, and 9 shown in Figs. 14-16 show that the alumina scales had spalled from both the top corners of the U-groove. The scale on specimen 9 was thinner than that on specimen 3; shiny residues also were visible at the bottom of the groove. The difference of thin-film thickness between specimens 9 and 3 was due to the different baseline materials, MA956 and 956HT, used to manufacture these two samples. Plan views of the surfaces of oxidized V-groove SNTT specimens also show that the alumina scales had spalled from both the top corners of the V-groove.
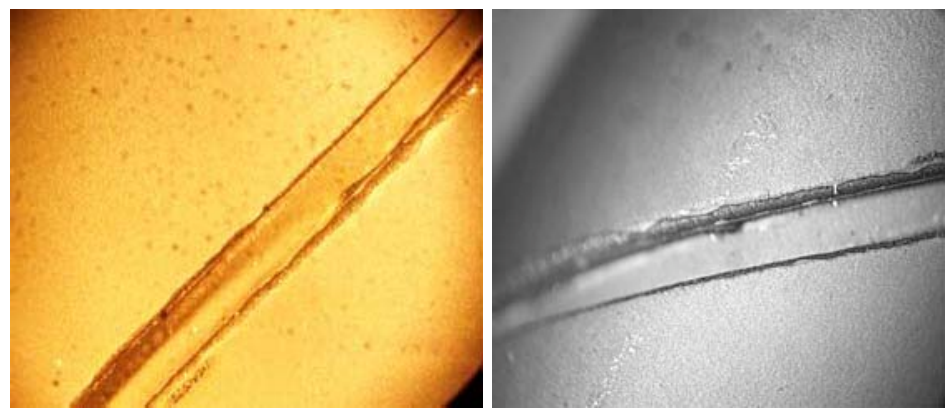

Fig. 14. Views from south and north edges of $U$ groove on specimen 3 (not pre-cracked). 


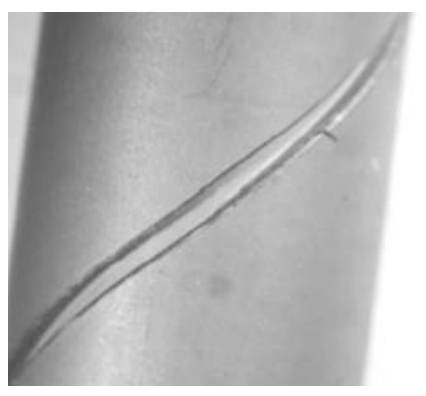

Fig. 15. Specimen 7 (U-groove, not pre-cracked) after oxidation.

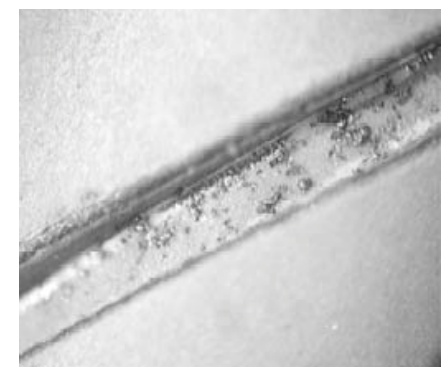

Fig. 16. Specimen 9 (Ugroove, pre-cracked) after oxidation.

\subsubsection{Examination of Oxidized SNTT Samples after Torsion Testing}

\subsubsection{Specimens with U-Section Grooves}

\section{Not Pre-Cracked}

Figures 17-20 illustrate the fracture and spallation sites of the alumina scale as indicated with arrow marks for specimens 3 and 7 after torsion testing. Most of the alumina scale at the bottom of the spiral groove appeared to be intact. A crack along the edge of the bottom corner of the spiral groove on specimen 3 is shown in Figs. 17 and 18(a). A more detailed view of the alumina scale spallation at the bottom corner of the groove is shown in Fig. 18(b). A similar scale cracking and spallation site at the bottom of the groove on specimen 7 is shown in Figs. 19-20. There was no damage apparent at the bottom of the U-grooves in the as-machined samples prior to oxidation.

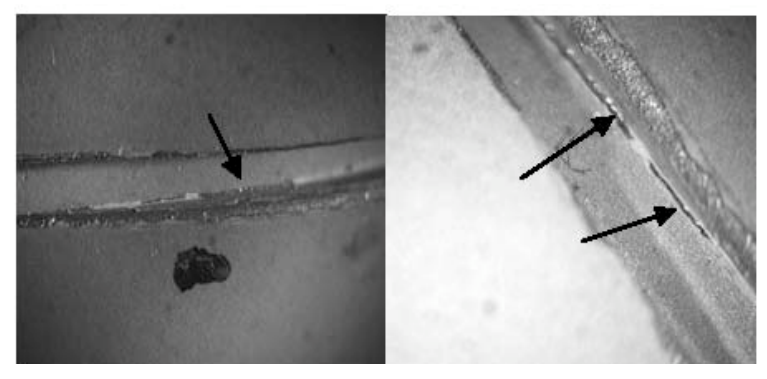

Fig. 17. Scale spallation sites after torsion testing (specimen 3). 


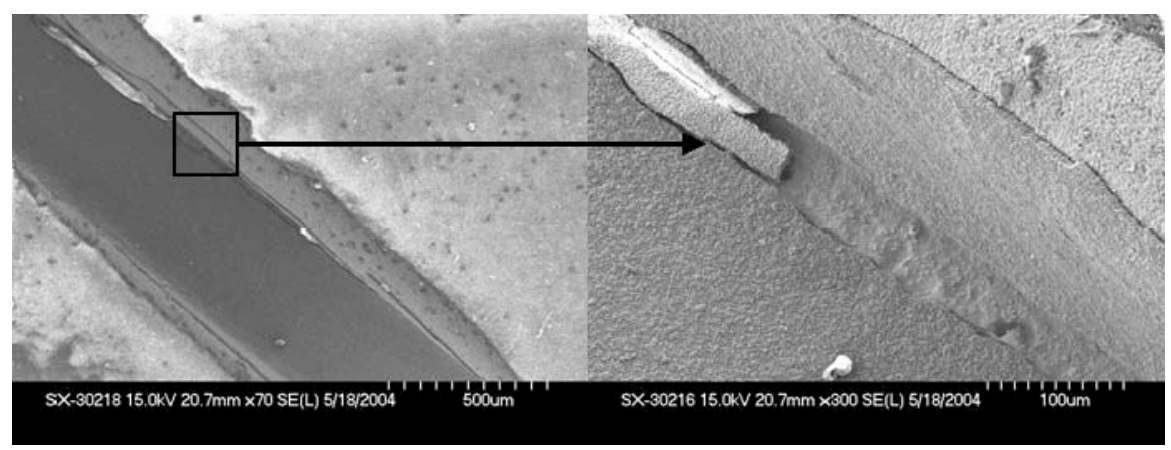

(a) (b)

Fig. 18. Scale spallation at the bottom corner of specimen 3.

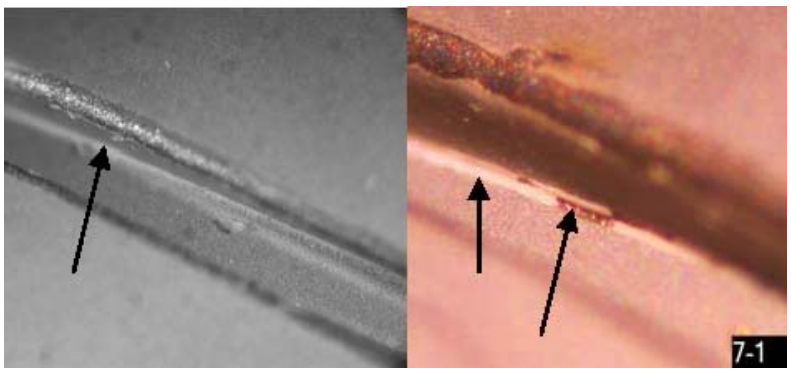

Fig. 19. Scale delamination and spallation sites after torsion testing (specimen 7).

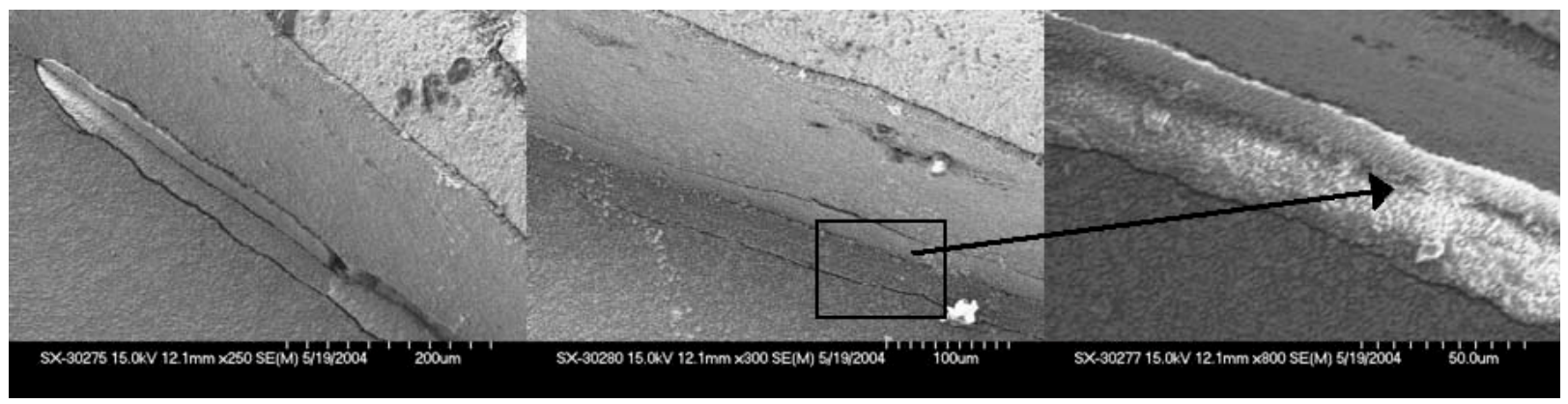

Fig. 20. Scale crack and spallation sites along the bottom of the U-groove after torsion testing (specimen 7).

\section{Pre-Cracked}

Comparison of the oxide on the U-grooves of specimens 9 and 7 (not pre-cracked), shown in Figs. 21 and 19, indicates fewer spallation sites on the non-pre-cracked specimen. This delamination on the precracked specimens may have resulted from the development of an oxide wedge at the tip of the pre-crack sites during oxidation. Figure 22(a) shows typical U-groove spallation and crack sites on specimen 9, which are similar to those of non-precracked samples but more extensive. Details of the alumina scale spallation site at the bottom corner of the U-groove are shown in Fig. 22(b), and 22(c) shows typical 
crack sites near the bottom corner of the groove. Figure 22(d) shows the external features of the alumina scale.

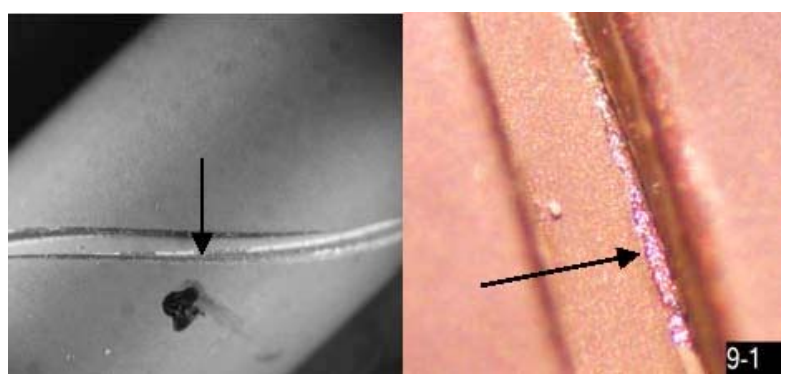

Fig. 21. Scale spallation in groove after oxidation (specimen 9, pre-cracked).

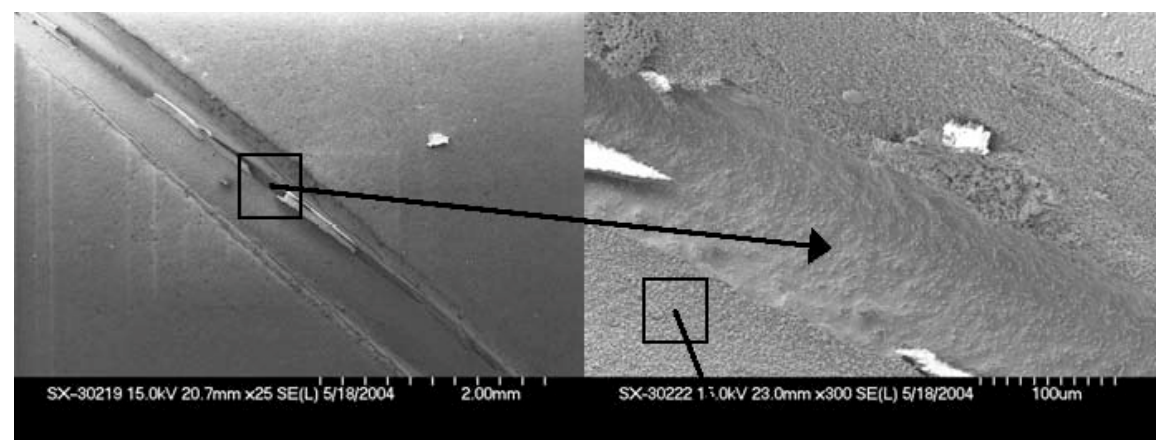

(a)

(b)

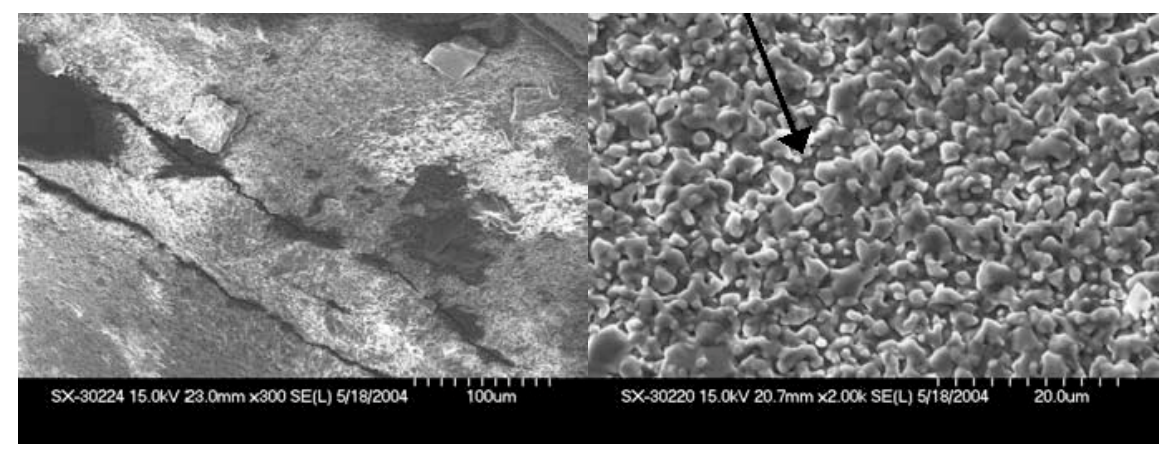

(c)

(d)

Fig. 22. Spallation sites (a) top view, (b) bottom corner, (c) alumina crack sites at bottom corner, and (d) plan view of adherent scale (specimen 9).

\subsubsection{Specimens with V-Section Grooves}

On the pre-cracked samples ( 1 and 2), a large portion of the alumina scale near the center region of the spiral groove appeared to be delaminated from the substrate. The scale failure sites on specimen 1 are shown in Figs. 23 and 24; the scale appears to be spalled or delaminated in the middle section of the groove. The alumina spallation sites near the center did not exhibit an "oxide footprint" pattern (Fig. 24b, d), compared with the spallation sites at the top corner of the V-groove, suggesting that the oxide may not be in contact with the alloy at the conclusion of the oxidation treatment. The widespread damage was 
most likely attributable to the pre-cracking of the samples. Figure 24(b) shows a large cavity beneath the alumina scale, possibly associated with an original machining defect in the groove.

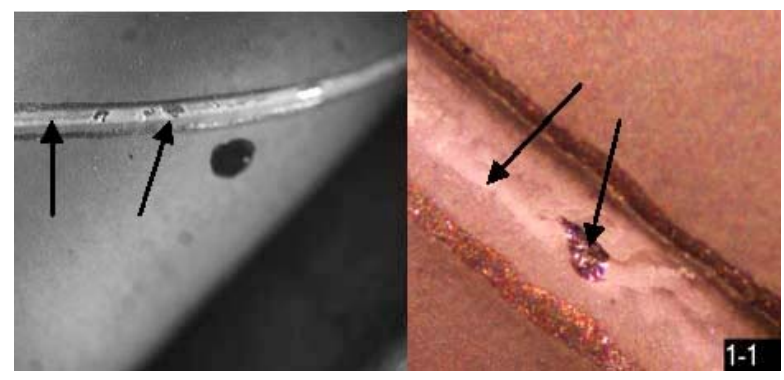

Fig. 23. Scale spallation and delamination sites after torsion testing (specimen 1).

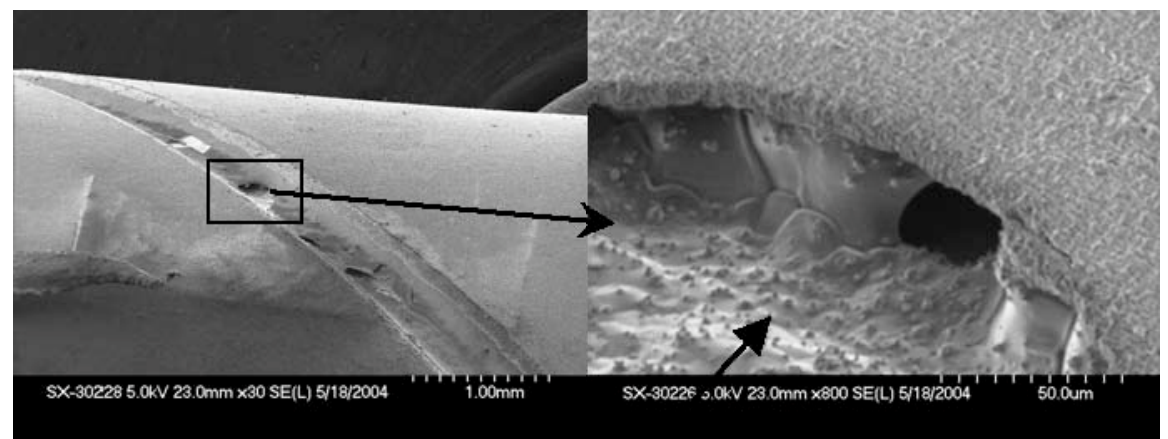

(a)

(b)

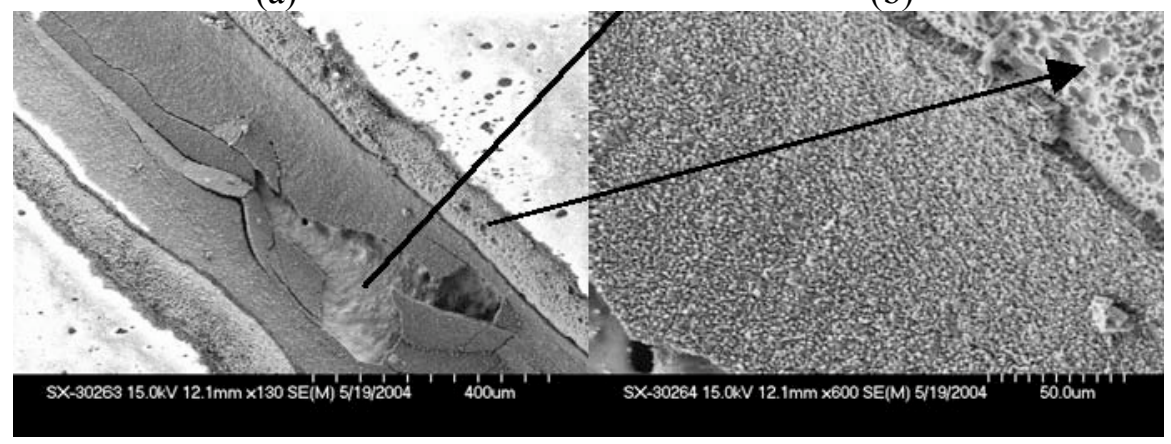

(c)

(d)

Fig. 24. Unusual features at spallation sites in the V-groove on precracked specimen 1 , after torsion testing.

Two parallel spallation lines were observed on pre-cracked specimen 2 (Fig. 25), which are consistent with the flaw sites identified on the baseline sample. Also in Fig. 25, a crack line can be seen near the root of the $\mathrm{V}$-groove, and some scale delamination sites are also visible near the bottom of the spiral groove (Figs. 25b and 26). Figures 27 and 28 illustrate a scale spallation pattern on pre-cracked specimen 5 that corresponds to the rough, as-machined surface shown in Fig. 13 and demonstrates the detrimental effects of poor initial surface quality on the structure and adhesion of the oxide scale. 


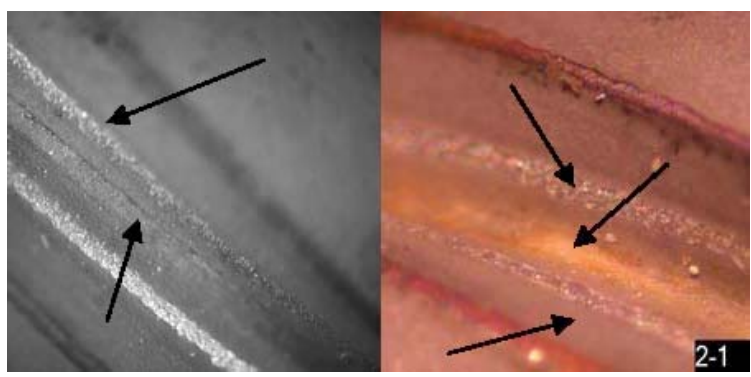

(a)

(b)

Fig. 25. Fracture site (left) and spallation and delamination sites (right) after torsion testing (specimen 2; pre-cracked).

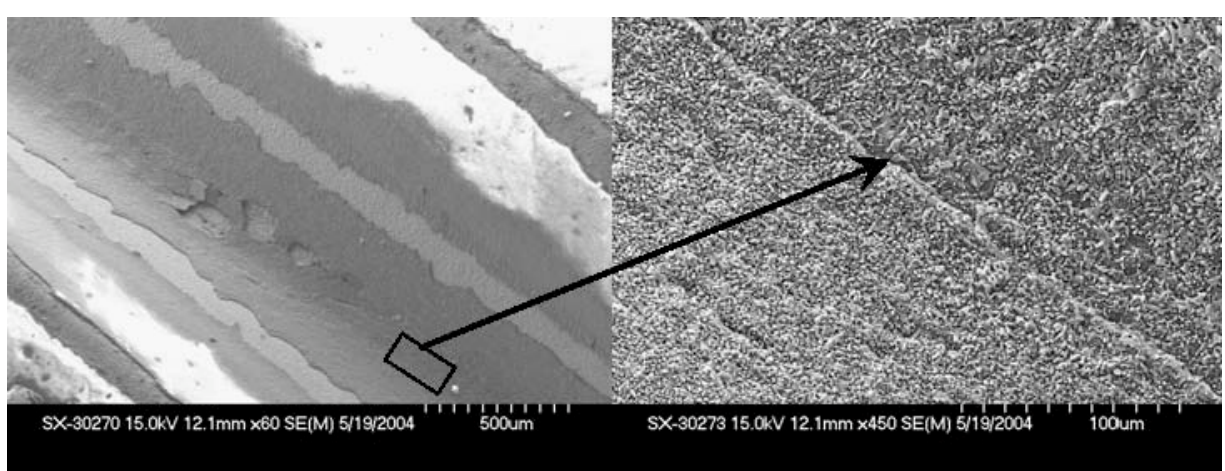

Fig. 26. Scale spallation and crack sites on specimen 2.

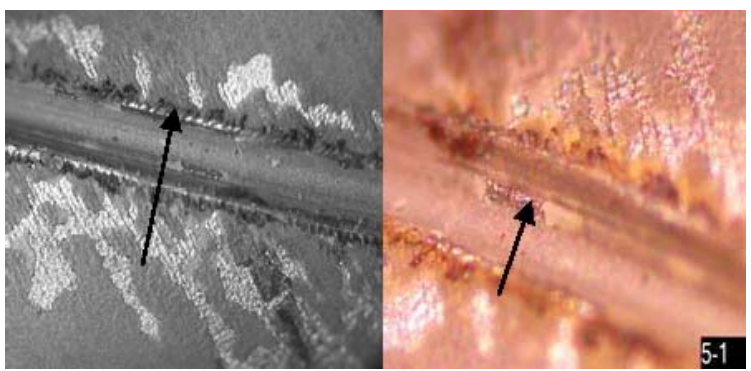

Fig. 27. Scale spallation site of pre-cracked specimen 5 after torsion testing. 


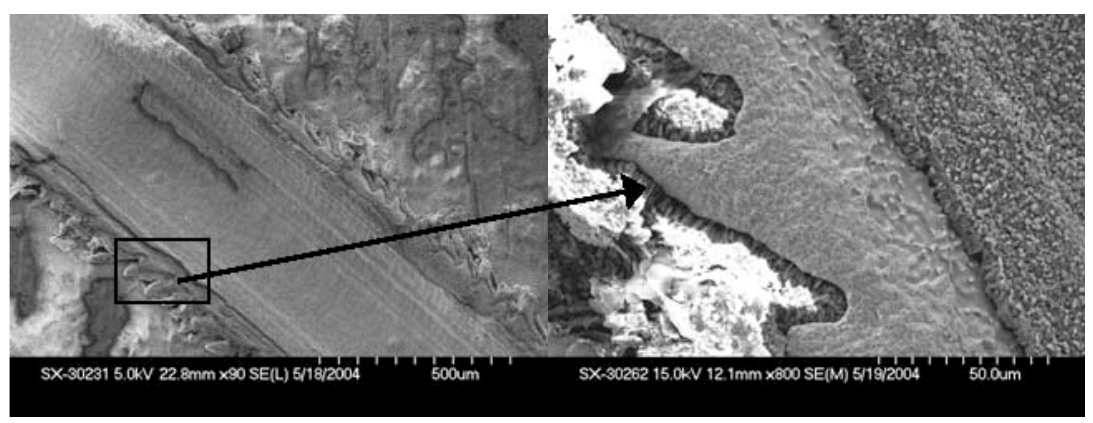

Fig. 28. Irregular alumina formation near the edge of V-groove due to machining flaw at the edge of the spiral groove on specimen 5.

\subsubsection{Examination of Oxidized SNTT Specimens Fractured after Cyclic Torsion Loading}

In order to further examine the surface features beneath the oxide film, a control cycle fatigue procedure was used to fracture SNTT specimens 1 (pre-cracked V-grooved) and 7 (not pre-cracked Ugrooved) to allow access for SEM imaging of the side wall, the bottom of the spiral groove, and the bottom corner along the spiral groove.

\subsubsection{Pre-Cracked Specimen}

Figure 29 shows alumina spallation sites near the top edge of the spiral V-groove from the fractured specimen 1. The scale over region A in Fig. 29 apparently was not in contact with the alloy (lack of "oxide footprints," so spallation occurred during cooling following oxidation. The remaining spallation sites in Fig. 29 apparently formed during the fatigue fracture test, since the alloy surface exhibits extensive oxide footprints, signifying an adherent oxide. Figures 30-31 show details of spallation sites at the bottom of the spiral groove. The oxide appears to have bridged areas containing deep voids; the lack of oxide footprints on the flat surface between the voids and the smooth contours of the voids themselves indicate that these constituted a very large cavity beneath the original scale. The fact that the oxide was in contact only with the tops of the "pillars" shown in Fig. 30 (Region B) and 31 and yet grew with the expected columnar grain structure to a uniform thickness is surprising, and it suggests that transport of aluminum vapor species across the cavity was faster than oxygen diffusion through the oxide. This spallation site is near the location of the fatigue pre-crack that was formed at the bottom of the U-groove prior to oxidation. 


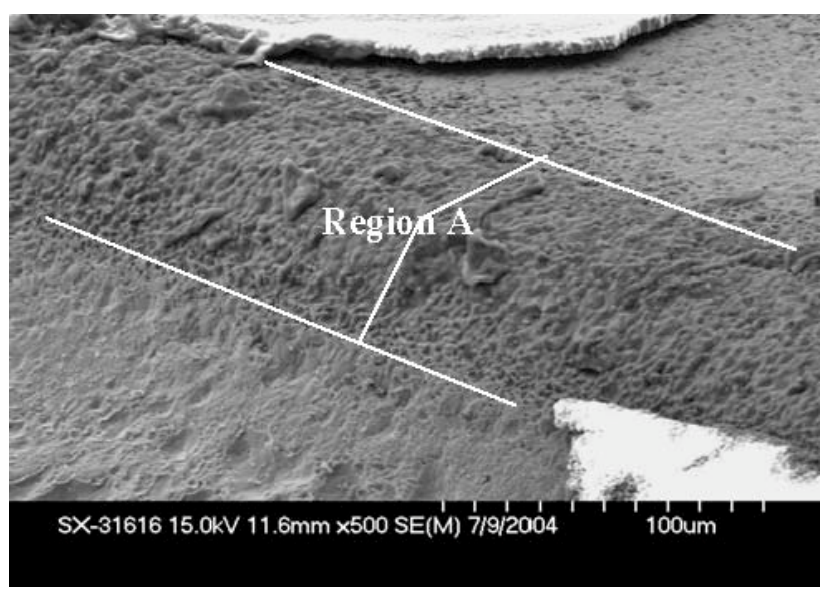

Fig. 29. Scale spallation sites near the edge of groove on pre-cracked specimen 1.

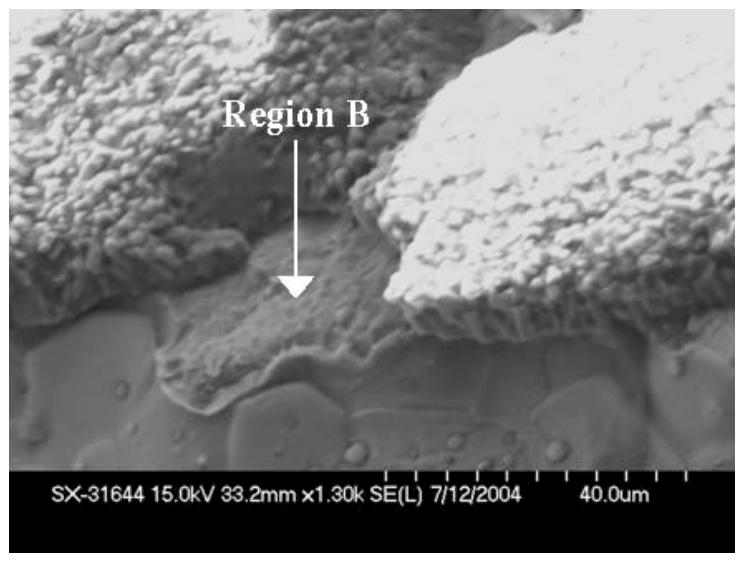

Fig. 30. Region $B$ reveals a location where the alumina scale was adherent at temperature (specimen 1).

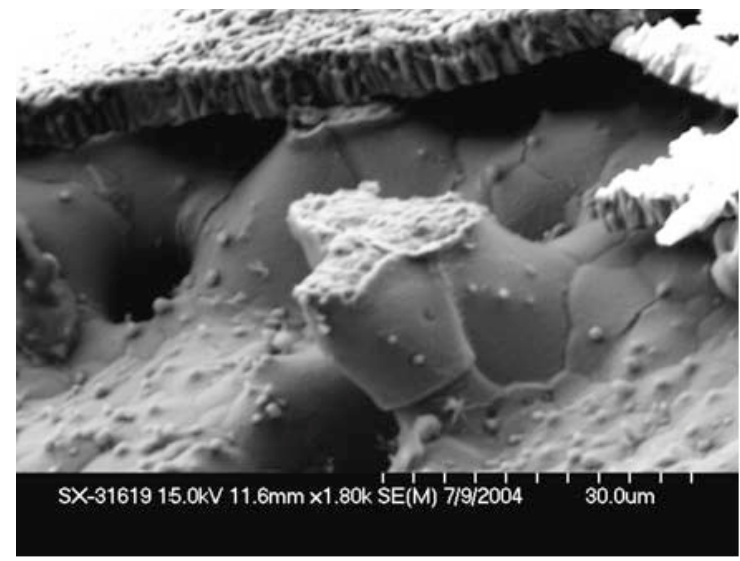

Fig. 31. A pillar-like structure near the fatigue pre-crack site on specimen 1.

\subsubsection{Non-Pre-Cracked Specimen}

Figure 32 illustrates scale spallation sites on the right side wall and the bottom portion of the Ugroove on specimen 7. Spallation typically was focused at the intersection of the side wall and bottom of the U-groove (Fig. 32b). The scale on the rest of the side-wall and bottom of the groove remained intact, indicating that good bonding between the alumina scale and the substrate still remains even after numerous torsion fatigue cycles.

Figure 33 shows two views of the fracture faces of the adherent scale on the bottom flat portion of the U-groove near the site of the overall fatigue failure. The cross section of the oxide appears typical of the normal scale grown on this alloy. However, a distinct layer of different appearance from the oxide and alloy is located between the alumina scale and the substrate, as indicated by the arrows. Further examples of the layer from the corner between the wall and the bottom of the groove are shown in Fig. 34, illustrating where the bottom section of the groove was broken away when the specimen fractured. This underlying structure was found in the fractured SNTT specimen 7 purely by chance by SEM with a proper viewing angle. Since the oxide has grown on this layer in the expected way, the layer is clearly 
MA956. The proximity of the layer and the structures that resemble the pillars noted earlier (Fig. 31) suggests some connection: the smooth sides of the pillars and the fracture face of the layer and the absence of oxide footprints around the base of the pillars further suggest the presence of a larger cavity between the unidentified layer and the alloy during the oxidation process. The layer may possibly be associated with gross machining that remained attached to the surface. However, the observed uniform thickness of this distinct layer throughout the fractured U-groove section (both at the bottom and on the side-wall of the U-groove) may indicate this distinct layer is indeed a material characteristic of the oxide MA956 sample instead of an anomaly. Thus further investigation is needed to clarify the fundamental forming mechanism of this phenomenon.

The topography shown in Fig. 34 reveals a complicated structure near the bottom of the side-wall of the U-groove, such as pillar-like and void structures. These phenomena may well be due to the violent fatigue fracture event of the fractured SNTT sample 7. Nevertheless, the observed structure clearly indicates that the potential defects exist at or near the bottom corner of the U-groove. This defect formation phenomenon is likely due to high-intensity stress fields existing at the bottom corner of the Ugroove. This high-stress field is the result of the interaction between the geometry constraint of a Ugroove, oxide growth stresses, and the high residual stresses associated with the formation of the alumina scale. For a brittle material, the fatigue pre-crack procedure is not required while utilizing the SNTT approach to evaluate valid fracture toughness where a shallow notch or flaw will be sufficient. Furthermore, to induce a pre-crack at the bi-material interface is an extremely difficult task, if not impossible. Potential flaw sites that exist near the bottom corner of the U-groove shown in Fig. 35 provide a crack starter or crack initiation site for a valid SNTT fracture toughness evaluation.

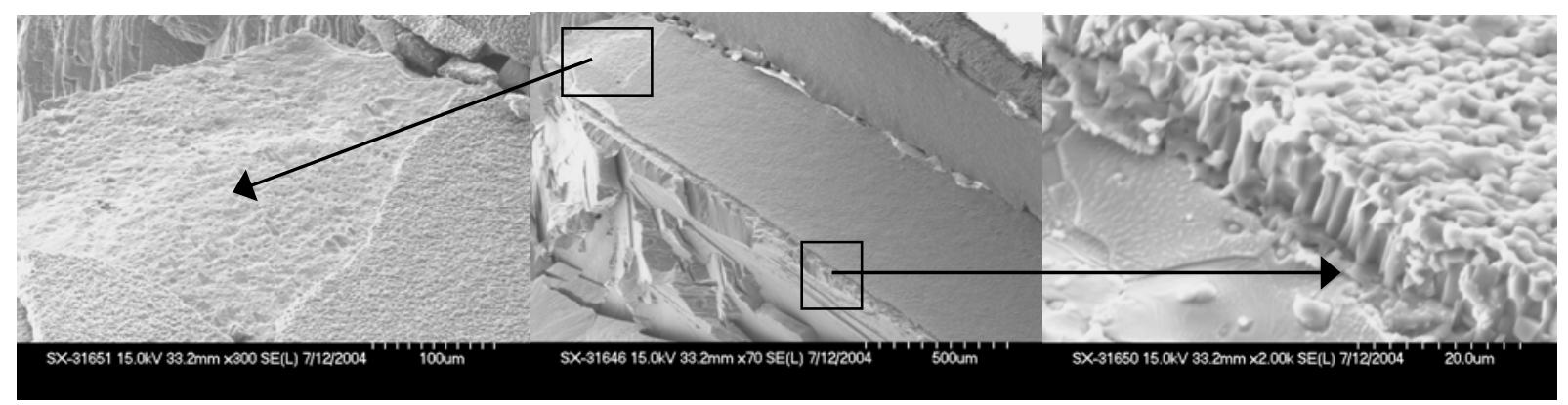

(a)

(b)

(c)

Fig. 32. Details of spallation sites at the bottom and bottom corner are shown in (a) and (c); corner/edge of the U-groove bottom as shown in (b); (specimen 7; not pre-cracked). 


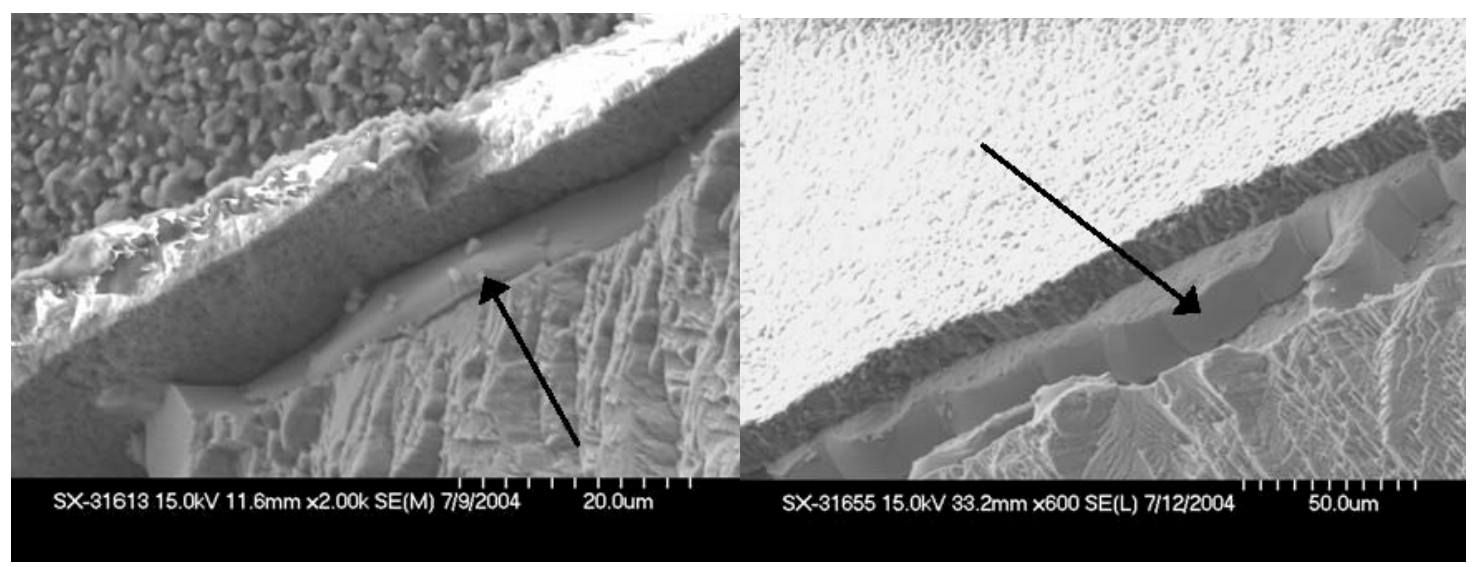

Fig. 33. The fracture reveals a distinct, unidentified layer between the alumina scale and the substrate as indicated by arrows in (a) the view from the underside of the bottom flat of the $U$ groove and (b) the view from the top of the bottom corner edge of the U-groove (specimen 7).

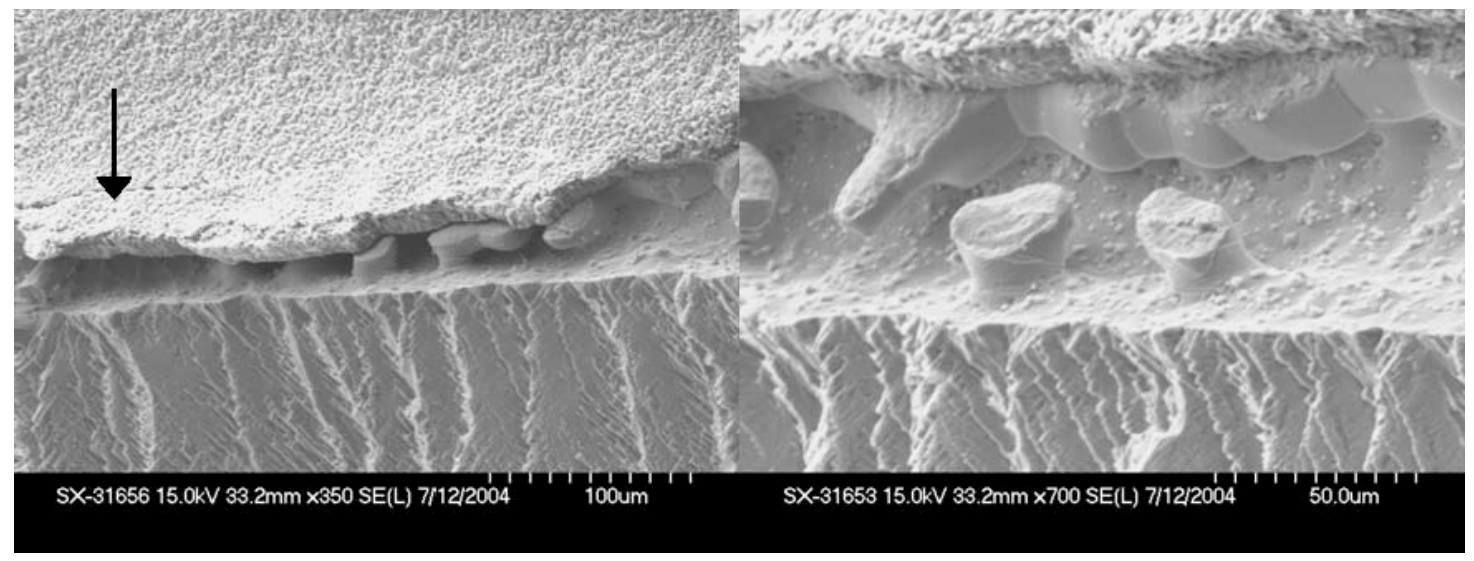

Fig. 34. Further views of the unidentified layer at the fracture surface on specimen 7.

\subsubsection{Oxide Wedging in V-Grooved Specimens}

A schematic diagram of the formation of such a wedge is illustrated in Fig. 35, which represents a pre-crack initially closed but reopened during oxidation. Consequently, the alumina scale grew into the crack to form an oxide wedge. Upon cooling or loading, this oxide wedge will provide a driving force to extend the crack further into the alloy substrate. This crack growth phenomenon beneath the alumina scale is thought to be the main cause of the observed scale delamination and spallation at the center section of pre-cracked V-grooved SNTT samples. 


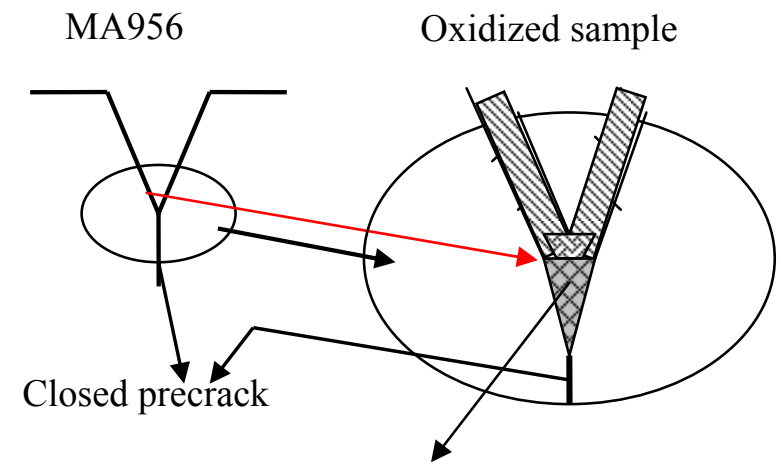

Wedge shape alumina scale developed due to precrack reopening during oxidation.

Fig. 35. Schematic diagram of the formation of an oxide wedge.

\subsection{TEST RESULTS FROM SNTT THIN FILM FRACTURE TEST AND ACOUSTIC EMISSION DETECTION}

\subsubsection{Acoustic Emission Testing}

A material under stress accumulates energy, and sudden deformation produces elastic waves and generates acoustic emission (AE) signals. The stress and the associated strain can be tensile, compressive, or shear, so that under stress a material expands, contracts, and/or shears. Up to the yield point, strain is elastic; but it is permanent or plastic after yielding. Acoustic emission is associated with permanent strain. Therefore, AE can be defined as transient elastic waves generated by the rapid release of energy within a material. With AE equipment one can "listen" to the sounds of crack growth and many other modes of active damage in the stressed materials. The ideal AE source generates spherical waves, but in real structures the propagation is affected by surfaces. An AE system, LOCAN 320, was used in this research for detecting crack initiation in oxidized SNTT samples under torsional loading. LOCAN 320 is a computerized system that performs AE signal measurements and stores, displays, and analyzes the resulting data in real time ${ }^{[61]}$ The acoustic signals from the loaded structure are converted into electrical signals by the sensors, amplified to useable voltage levels by the preamplifiers, and measured in twochannel computerized modules known as independent channel controllers (ICCs). Each AE source event in a structure may be detected by one, two, or more channels; detection on any one channel constitutes a "hit," so that each event may produce one or several hits. Each AE signal (hit) is described in terms of its features, as shown schematically in Fig. 36, which include:

1. Hit-a burst acoustic emission signal

2. Time-the time of detection signal, in $\mu \mathrm{s}$

3. Rise time-the time from the first threshold crossing to the peak, in $\mu \mathrm{s}$

4. Duration-the time from the first to the last threshold crossing, in $\mu \mathrm{s}$

5. AE counts-the number of times the acoustic emission signal crosses the threshold

6. AE count to peak

7. Energy-area under the signal envelope

8. Average frequency

9. Threshold level, in $\mathrm{dB}$

10. Peak AE amplitude -the peak voltage of the AE signal (usually logarithmic), in $\mathrm{dB}$ 


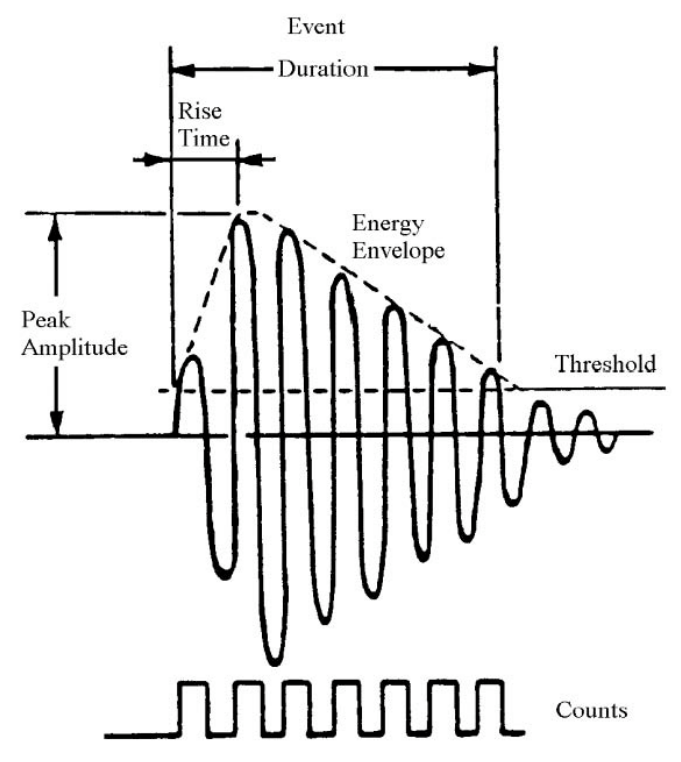

Fig. 36. The AE waveform characteristic.

The time, rise time, energy, amplitude, and AE counts are useful in identifying the crack initiation and its characteristics during a torsion test. For example, the AE amplitude is useful for comparing the relative distance of source sites from the sensors, since amplitude attenuation is proportional to distance. Each AE signal contains background noise. There are two categories of noise, electrical and mechanical. Electrical noise includes white noise; ground loop noise; and mechanical noise, which includes test machine and friction noise, etc. In order to obtain accurate AE test results, these noise sources must be controlled. Use of a suitable "threshold" can filter out background noise and is the prime variable that controls channel sensitivity. Gain has an important effect on energy measurements; gain also has to be set high for high-sensitivity testing.

In the current study, the threshold was set as $45 \mathrm{~dB}$ and the gain was set as $20 \mathrm{~dB}$ during the $\mathrm{AE}$ data collection. Furthermore, in order to increase the sensitivity of fracture load evaluation for study of thin films, a smaller biaxial load cell (load capacity $200 \mathrm{in}$.-lb) was installed (in addition to the original biaxial load-cell with a capacity of $10,000 \mathrm{in}$.-lb). The calibrated ratio of torque to voltage was $2.051 \mathrm{~N}-\mathrm{m}$ per volt for the smaller load cell. A Haver sine function torque loading with displacement control was applied to the oxidized SNTT specimens. The torque voltage readout of the small load cell was set as parametric input for the LOCAN 320 system during the test. Based on the real time history of torque loading and AE signal characteristics, one can estimate the fracture load of the crack initiation event for an SNTT thin film specimen during the pure torsion test. The other information, such as rise time, duration, energy, and amplitude of AE signal, were used to identify the material zone and the crack growth characteristics of inhomogeneous materials. 


\subsubsection{Test Results for Oxidized SNTT Samples (without Fatigue Pre-Cracks)}

Distinct AE hits were detected during pure torsion loading cycles, as illustrated in Figs. 37-38 for non-pre-cracked, U-grooved specimens 3 and 7. The related Haver sine loading cycles are shown in the top portions of Figs. 37-38. The torque limit was set to be around $60-80 \%$ of the estimated torque that generated the maximum shear stress on the alumina scale on a 0.3-in.-diameter SNTT specimen. The long spiral groove and uniform stress field distributed along the axis of the SNTT specimen provide equal opportunities for generating interfacial crack sites along the groove and at the consecutive or repetitive loading cycles. Therefore, the SNTT thin film samples were tested repeatedly under the Haver sine loading cycles.

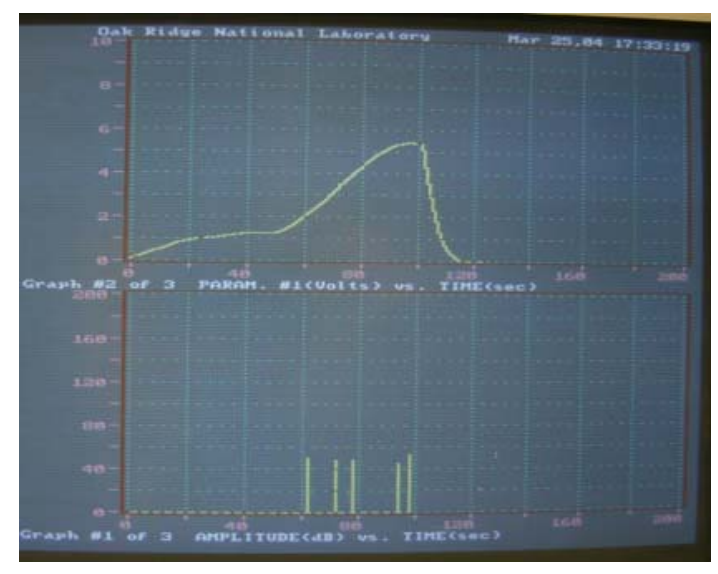

Fig. 37. Torque load (top, in volts) and AE hits (bottom) time histories for specimen 3.

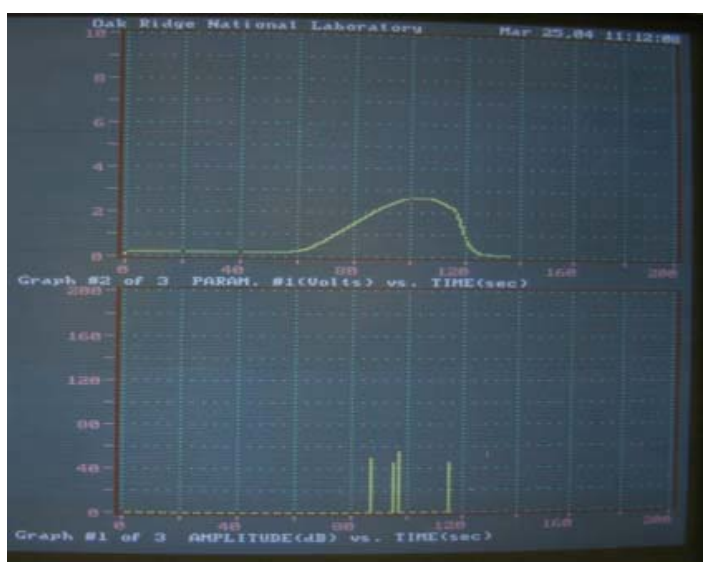

Fig. 38. Torque load (top, in volts) and AE hits (bottom) time histories for specimen 7.

During the first three tests, few spallation sites of alumina scale were identified. However, after a series of tests, numerous spallation sites along the bottom corner of the spiral groove were revealed; as a consequence, AE hit signals became more complicated compared with those from the earlier tests. Thus, the first three torsion tests and the associated $\mathrm{AE}$ results were considered to be valid and were used to estimate the fracture torque that caused the delamination of the alumina scale. The first hit of each loading cycle was considered to originate at the interface between the thin film and the substrate, assuming that the oxide-metal interface was the weakest link. The remaining hits may initiate from other interfaces, such as from the cracks associated with buckling of the scale, or from the substrate. The first three test results for specimens 3 and 7, related to the first AE hits, are listed in Table 3.

Table 3. Acoustic emission and torsion test results for oxidized, non-pre-cracked, U-grooved specimens 3 and 7.

\begin{tabular}{|l|l|l|l|l|l|l|l|l|}
\hline $\begin{array}{c}\text { Specimen } \\
\text { ID }\end{array}$ & Test no. & $\begin{array}{c}\text { Param1 } \\
\text { volt }\end{array}$ & $\begin{array}{c}\text { Torque } \\
\mathbf{N}-\mathbf{m}\end{array}$ & $\begin{array}{c}\text { Rise } \\
\mu \mathrm{s}\end{array}$ & Count & Energy & $\begin{array}{c}\text { Duration } \\
\mu \mathrm{s}\end{array}$ & $\begin{array}{c}\text { Amplitude } \\
\mathrm{dB}\end{array}$ \\
\hline 3 & 1 & 2.30 & $\mathbf{4 . 7 1}$ & 109 & 10 & 12 & 353 & 50 \\
\hline 3 & 2 & 2.33 & $\mathbf{4 . 7 7}$ & 2 & 1 & 5 & 2 & 44 \\
\hline 3 & 3 & 2.51 & $\mathbf{5 . 1 4}$ & 92 & 33 & 24 & 535 & 55 \\
\hline 7 & 1 & 2.06 & $\mathbf{4 . 2 2}$ & 19 & 7 & 11 & 152 & 49 \\
\hline 7 & 2 & 2.02 & $\mathbf{4 . 1 4}$ & 9 & 14 & 13 & 216 & 53 \\
\hline 7 & 3 & 2.73 & $\mathbf{5 . 5 9}$ & 1 & 1 & 5 & 2 & 45 \\
\hline
\end{tabular}


From the "torque" value listed in Table 3, it can be seen that the scatter in the estimated interface fracture torque (identified from the first AE hits) was fairly small. The AE test results indicate that the proposed testing procedure is repeatable and reliable until the threshold (or maximum damage density) of the alumina scale spallation (or delamination) is reached. The test data from a high-damage-density sample may provide a non-conservative or unreliable estimate of the interface toughness, as a result of complex AE hit responses originating from numerous crack sites. Furthermore, detailed and thorough analyses may be needed to distinguish the sources of these AE hits.

The energy count of AE hits can provide a very useful index for identifying the likelihood of the AE source. This is due to the fact that more energy can be stored in the substrate than in the thin film; therefore, a much larger energy count would be anticipated for AE hit sources from the substrate than from other AE hit sources. Indeed, many such AE signals were observed from the torsion loading cycles, especially for the pre-cracked SNTT samples. Furthermore, it is anticipated that less energy (or load) is required to initiate an interface crack than is required to fracture the alumina scale of high residual stress. Moreover, the AE hits initiated from an interfacial crack source underneath the thin film will have a lower energy count (or intensity) than those initiated from a source at the fracture sites in the thin film.

Therefore, the energy count of each AE hit will also provide a valuable insight regarding the source and fracture zone of crack initiation.

\subsubsection{Test Results for Oxidized SNTT Samples with a Fatigue Pre-Crack}

Time histories of AE hit signals from pre-cracked SNTT samples during the torsion tests are shown in Figs. 39-40. These show significantly higher counts of AE hits and higher energy intensity that those from oxidized, non-pre-cracked SNTT specimens. In many cases, the estimated torque from the first AE hit data from the four pre-cracked samples (specimens 1, 2, 5 and 9) was much lower than that obtained from the non-pre-cracked samples. This is likely to result from the rough surfaces, with numerous crack sites developing during the fatigue pre-cracking cycles. During oxidation of the SNTT samples, numerous potential flaw and anomalies can be developed at such sites, and these may fail under very low loading. The bottom portions of Figs. 39-40 are the time histories of the energy counts for the AE hit events, which show that many hits had extremely high energy counts. As discussed earlier, the alloy substrate is the likely source of high energy counts, so these probably initiated at the fatigue pre-crack sites.

Table 4 lists some of the AE test results for the pre-cracked, oxidized SNTT samples. Comparison of the data in Tables 3 and 4 indicates that non-pre-cracked SNTT samples are more suitable for studying thin film interface toughness than pre-cracked samples. On issues related to the sensitivity of these results to the groove geometry, no conclusion can be reached owing to lack of a non-pre-cracked, V-groove thin film sample. A detailed study is needed for non-precrack SNTT V-groove samples to clarify the sensitivity and impact of the groove configuration to the SNTT interface toughness evaluation. 


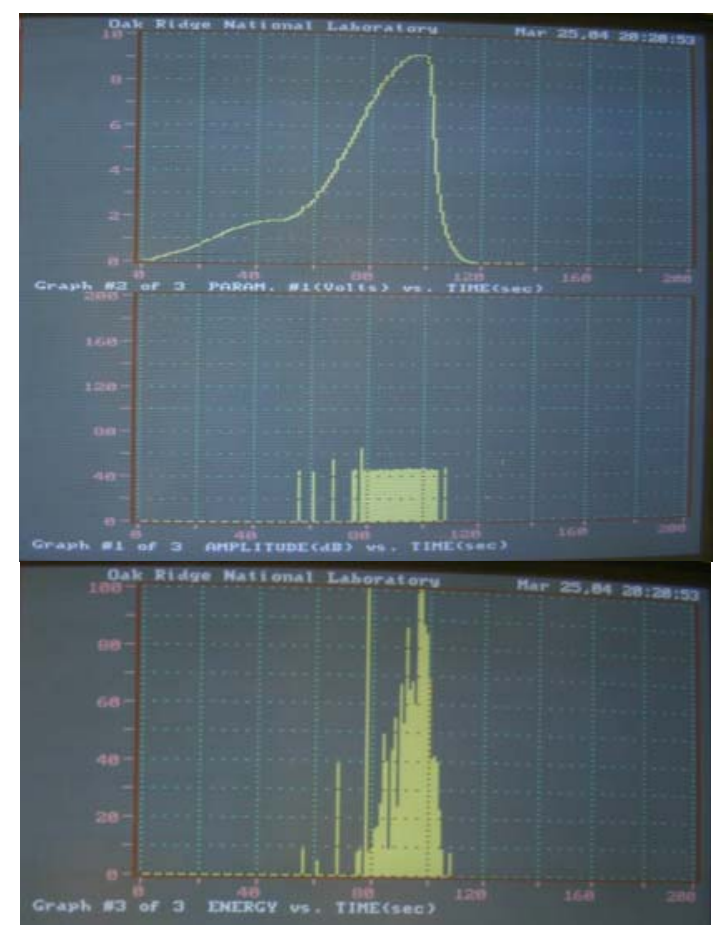

Fig. 39. AE hit events from specimen 1.

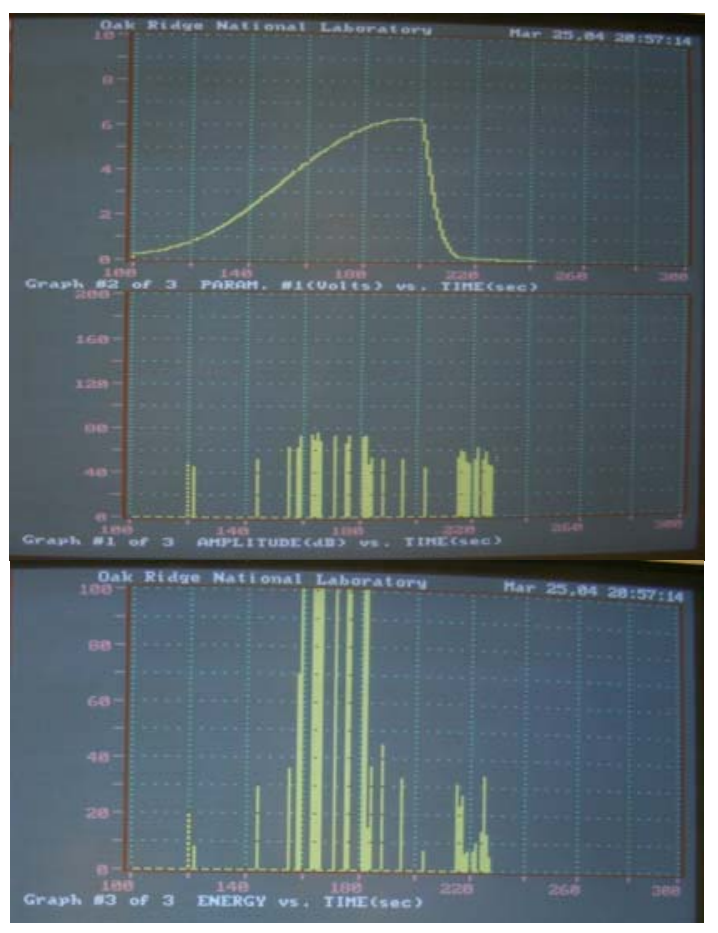

Fig. 40. AE hit events from specimen 5.

Table 4. Acoustic emission and torsion test results for oxidized, pre-cracked specimens $1,2,5$, and 9.

\begin{tabular}{|l|l|l|l|l|l|l|l|l|}
\hline $\begin{array}{c}\text { Specimen } \\
\text { ID }\end{array}$ & Test no. & $\begin{array}{c}\text { Param1 } \\
\text { volt }\end{array}$ & $\begin{array}{c}\text { Torque } \\
\mathbf{N}-\mathbf{m}\end{array}$ & $\begin{array}{c}\text { Rise } \\
\mu \mathrm{s}\end{array}$ & $\begin{array}{c}\text { Coun } \\
\mathrm{t}\end{array}$ & $\begin{array}{c}\text { Energ } \\
\mathrm{y}\end{array}$ & $\begin{array}{c}\text { Duration } \\
\mu \mathrm{s}\end{array}$ & $\begin{array}{c}\text { Amplitude } \\
\mathrm{dB}\end{array}$ \\
\hline 1 & 1 & 2.36 & $\mathbf{4 . 8 3}$ & 72 & 1 & 9 & 72 & 45 \\
\hline 1 & 2 & 1.51 & $\mathbf{3 . 0 9}$ & 2 & 1 & 7 & 1 & 45 \\
\hline 2 & 1 & 0.33 & $\mathbf{0 . 6 7}$ & 12 & 5 & 7 & 39 & 53 \\
\hline 2 & 2 & 0.35 & $\mathbf{0 . 7 1}$ & 13 & 5 & 6 & 35 & 49 \\
\hline 5 & 1 & 0.83 & $\mathbf{1 . 7 0}$ & 22 & 1 & 8 & 22 & 47 \\
\hline 5 & 2 & 2.82 & $\mathbf{5 . 7 8}$ & 44 & 85 & 43 & 1127 & 59 \\
\hline 9 & 1 & 2.63 & $\mathbf{5 . 3 9}$ & 1 & 1 & 8 & 1 & 46 \\
\hline 9 & 2 & 0.85 & $\mathbf{1 . 7 4}$ & 10 & 28 & 17 & 328 & 53 \\
\hline
\end{tabular}




\section{THEORETICAL BASIS OF METHODOLOGY}

\subsection{DEVELOPMENT OF FINITE ELEMENT MODELS AND ANALYSES}

Analytical solutions are available to describe the biaxial stress-strain conditions through the thickness of infinite plates of joined dissimilar linear-elastic or simple elastic-plastic materials. ${ }^{[62,63]}$ As for more complex nonlinear material behavior or complex geometrical configuration, the finite element methods are considered in many practical applications. ${ }^{[20,59,60,64,65]} \mathrm{A}$ three-dimensional (3-D) finite element model (FEM) of the SNTT specimen has been developed in this project. This model has a thin film of alumina on the outside and a substrate composed of Incoloy MA956. Our main goal in the FEM is to develop a model that can closely resemble the SNTT configuration with the crack propagation orientation perpendicular to the central axis of the cylinder. The PATRAN mesh generator was used to create 3-D finite element meshes, and the ABAQUS code was used for finite element analysis. Since the stress distribution of an SNTT specimen under pure torsion loading is uniform throughout the specimen, a slice of the gage length at the middle section was modeled and analyzed with appropriate boundary conditions for fracture toughness evaluations. Prismatic, quadratic, isoparametric, singular elements adjacent to the crack tip are modified to facilitate computational flexibility in linear elastic and non-linear elastic-plastic fracture mechanics analyses. In the former, the nodes at the crack tip are constrained to have the same displacement in order to embody the $r^{-1 / 2}$ singularity.

\subsection{THREE-DIMENSIONAL CONFIGURATION OF SNTT FINITE ELEMENT MODEL}

A global and two local Cartesian coordinate systems depicted in Fig. 41a are used to define the orientations of the specimen and a small imaginary cylinder centered at the spiral crack front. The first local coordinate system is located at the lower end of the crack front, and the second one is located at the mid-length of the crack front. The XY plane of the two local coordinates is normal to the crack front. Since the specimen is uniformly twisted along the entire length, it is postulated that the crack propagates in the XZ plane toward the center axis of the specimen (see Fig. 41b). Postmortem examination of fracture surfaces also supports the assumption from the earlier study. ${ }^{34}$ The mid-section of the SNTT specimen was used in FEM development, as shown in Fig. 42, which includes a cylinder with a radius of $3.81 \mathrm{~mm}\left(0.15 \mathrm{in}\right.$.) and a height of $2.54 \mathrm{~mm}\left(0.1 \mathrm{in}\right.$.) with a $45^{\circ}$ spiral U-groove at a depth of $0.423 \mathrm{~mm}$ (0.0166 in.). The oxide film thickness is set at 15 microns, as estimated from SEM examination of specimen 3, and the initial interfacial crack length is set at 5 microns. In order to simulate the potential flaw site at the bottom corner of the U-groove observed from SEM of the fatigue fracture SNTT sample, a void element was also incorporated into the model just below the flaw. This configuration will also ensure the initial crack growth will propagate upward along the interface. The detailed mesh configuration near the bottom of the U-groove of an SNTT FEM is shown in Fig. 43. 


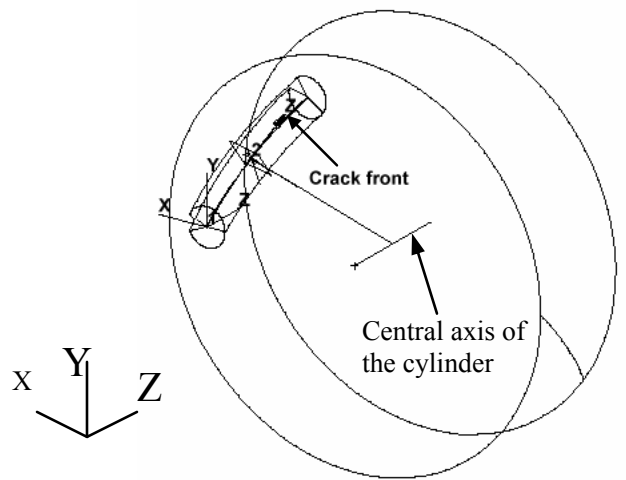

(a)

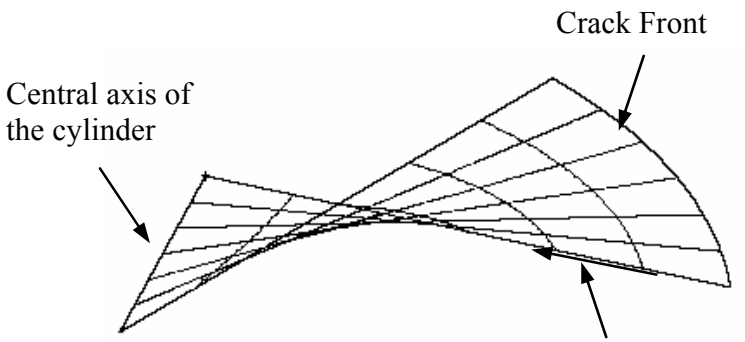

Crack propagation orientation

(b)

Fig. 41. A 3-D sketch of proposed specimen configuration (a). The sketch indicates that the $X$-axis of local coordinate 2 is the crack propagation orientation at the middle of the crack front. A 3-D sketch of fracture surface topology (b) based on the assumption that the crack propagation orientation is perpendicular and point to the central axis of the cylinder.

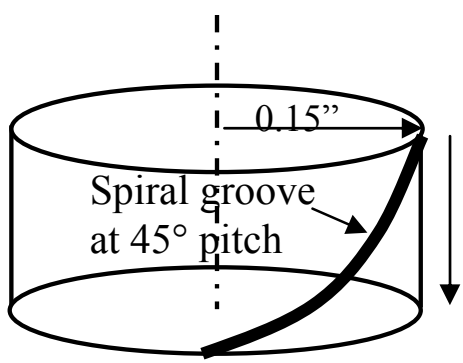

(a)

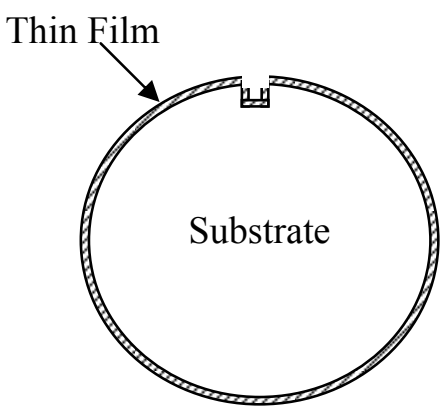

(b)

Fig. 42. Elevation (a) and top view (b) of SNTT finite element model.

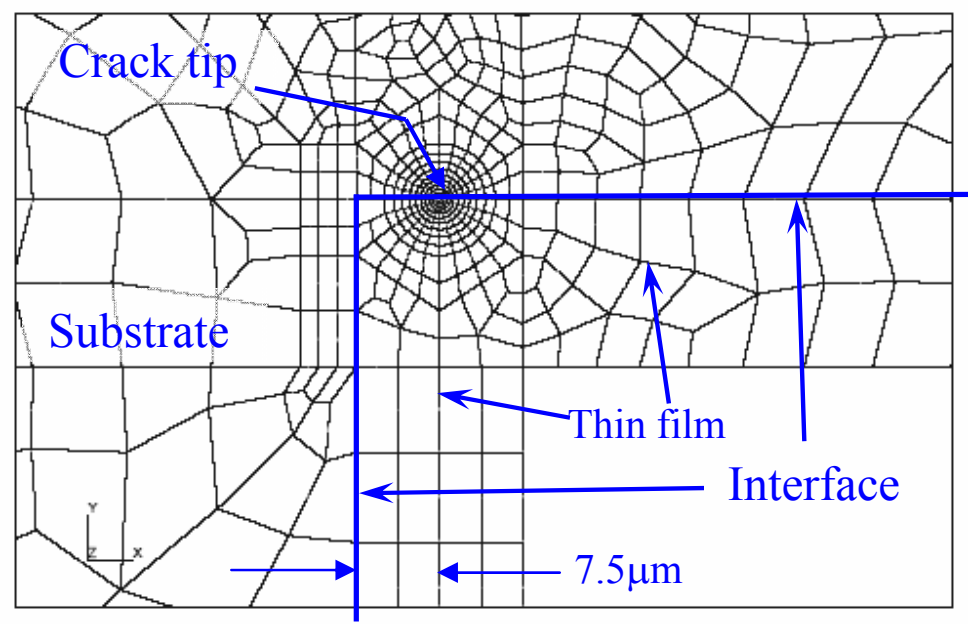

Fig. 43. The detailed mesh configuration near the bottom corner of the U-groove. 
A major difficulty in constructing an FEM for SNTT thin film samples is incorporating the relatively large meshes of the substrate and the very small meshes of the thin film that surround the substrate into one 3-D FEM. The wide ranges of FEM meshes require several layers of transition zones to mitigate the gradient of the adjacent-mesh sizes. The thin film located at the top corners of the U-groove was not included in the model because of the spallation of the thin film at these sites observed from as- received oxide SNTT samples. Two types of meshes were generated around the crack tips: (1) sharp crack tip geometry and (2) a dull crack front that was modeled with a $0.22 \mu \mathrm{m}$ hole at the tip. These two scenarios provide the bounds of the interface fracture toughness evaluation of the proposed SNTT thin film configuration. Furthermore, in order to increase the mesh density around the crack front, a sub-model approach was incorporated into the finite element analysis. The details of the 3-D FEMs for the middle section of an SNTT thin film specimen and the focused view of the U-groove site are shown in Figs. 4446 , respectively.

Boundary conditions and load cases of FEM were determined from experimental results, which yielded a fracture torque of $4.63 \mathrm{~N}-\mathrm{m}$. This fracture torque was applied to the top layer of the FEM in the form of displacement while the bottom layer of the model was kept fixed in the X-and Y-axis directions. Displacements were allowed in the "Z-axis" direction, i.e. along the axis of the cylinder. An initial end rotation of 0.002334 radians was assigned to the top of the FEM; this was estimated from the fracture torque applied to a smooth bar with the same dimensions as the SNTT FEM. Observed from ruby fluorescence, the alumina film residual stress in terms of hydrostatic pressure is $2.5 \mathrm{GPa}$ along the Ugroove site and 3.7 GPa elsewhere on the film. The initial end rotation and the residual stress fields were used as input for the load cases.

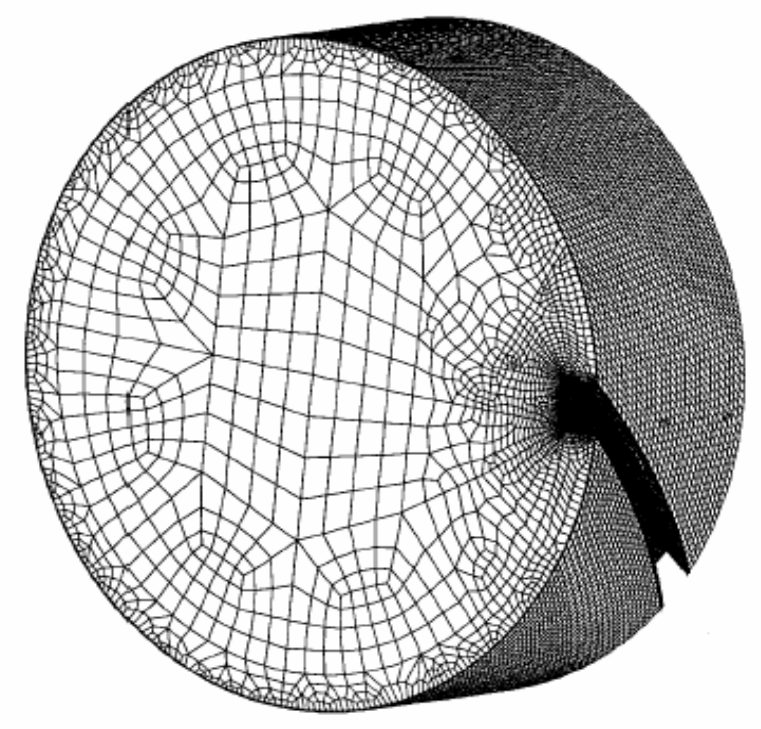

Fig. 44. Finite element model for middle section of SNTT thin film sample. 


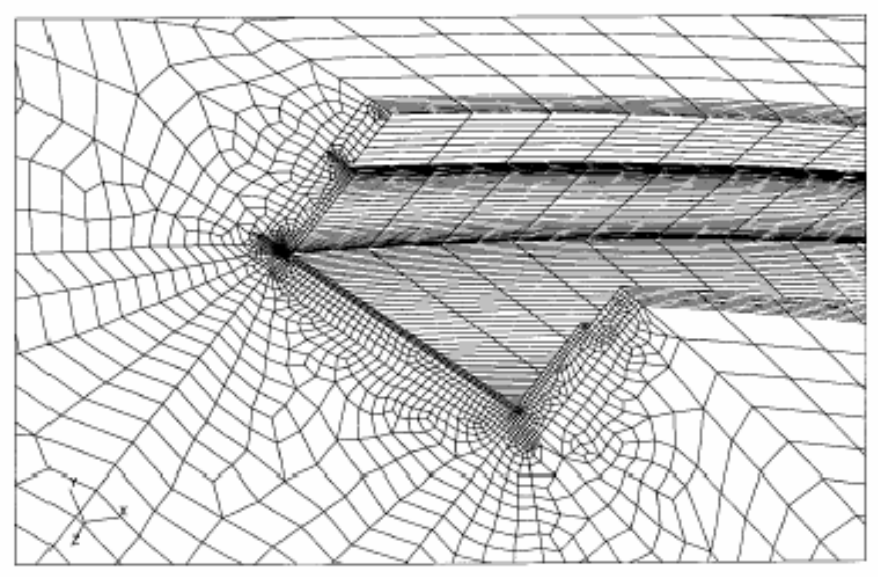

Fig. 45. Details of SNTT thin film FEM near the U-groove site.

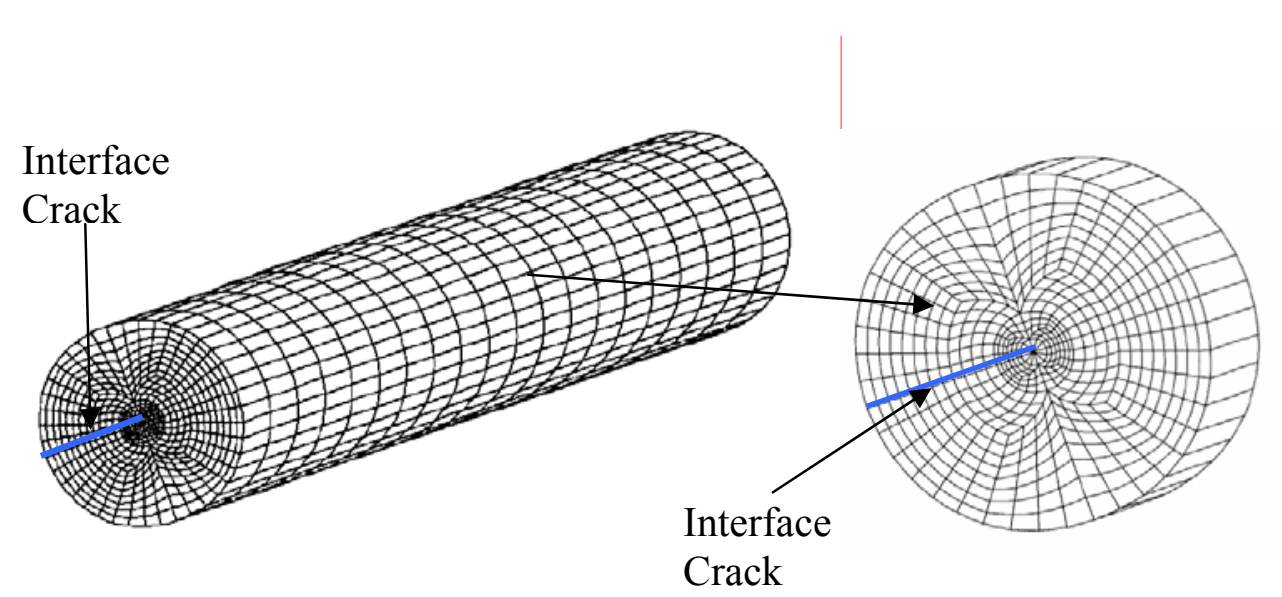

(a)

(b)

Fig. 46. Sub-model configuration around the crack front at the middle section of global model (a), with dimensions of $0.0004 \mathrm{in}$. diameter and $0.00125 \mathrm{in}$. length, the prescribed boundary displacements were evaluated from the global model configuration of Fig. 44. Mid-layer disk of the sub-model (b) with thickness of 0.000062 in.

\section{3. FRACTURE TOUGHNESS AND J-INTEGRAL EVALUATION ALONG THE INTERFACE}

\subsubsection{Isotropic Homogeneous Material}

The stress intensity factors $K_{I}, K_{I I}$, and $K_{I I I}$ characterize the influence of load or deformation on the magnitude of the crack-tip stress and strain fields and measure the propensity for crack propagation or the crack driving forces. Irwin ${ }^{[66]}$ shows that the stress intensity factor $K$ and the strain energy release rate $G$ are related. For plane strain mode $\mathrm{I}$, the energy release rate $G_{I}$ can be written as

$$
G_{I}=\frac{K_{I}^{2}\left(1-v^{2}\right)}{E}
$$


where $E$ is the Young's modulus and $v$ is the Poisson's ratio, and for mode II and mode III as,

$$
G_{I I}=\frac{K_{I I}{ }^{2}\left(1-v^{2}\right)}{E} \text {, and } G_{I I I}=\frac{K_{I I I}^{2}(1+v)}{E} \text {. }
$$

For a mixed mode of fracture, the total energy release rate is written as

$$
G=G_{I}+G_{I I}+G_{I I I} \text {. }
$$

For a linear elastic material, $G$ can also be related to the $J$-integral as

$$
J=G
$$

For a 2-D mixed-mode problem, Ishikawa, Kitagawa and Okamara ${ }^{[67]}$ show that it is possible to decouple the J-integral into mode I and II components. This is done by separating the stress, strain, traction, and displacement fields analytically into mode I and II components within a symmetric mesh region in the neighborhood of the crack tip. The mode III component is normal and therefore independent of modes I and II. Based on the above observations, and if the local coordinates coincide with the principal stresses, J-integral can be written as

$$
J=J_{I}+J_{I I}+J_{I I I} \text {. }
$$

For a linear elastic fracture mechanics problem in plane strain, $J_{i}$ can be written as

$$
J_{I}=\frac{\left(1-v^{2}\right) K_{I}^{2}}{E}, J_{I I}=\frac{\left(1-v^{2}\right) K_{I I}^{2}}{E}, J_{I I I}=\frac{(1+v) K_{I I I}^{2}}{E} \text {. }
$$

Since the $J$-integral is an energy approach, an elaborated expression of the crack tip singular fields is not necessary. This is due to the small contribution that the crack-tip field makes relative to the total $J$ (i.e. strain energy) of the body.

\subsubsection{Interfacial Material Fracture Toughness}

For an interfacial crack between two dissimilar isotropic materials with Young's moduli $E_{1}$ and $E_{2}$, Poisson's ratios $v_{1}$ and $v_{2}$, and shear moduli $\mu_{1}=E_{1} / 2\left(1+v_{1}\right)$ and $\mu_{2}=E_{2} / 2\left(1+v_{2}\right), J$ can be written as

$$
J=\frac{1-\beta^{2}}{E^{*}}\left(K_{I}^{2}+K_{I I}^{2}\right)+\frac{1}{2 \mu^{*}} K_{I I I}^{2},
$$

where

$$
\frac{1}{E^{*}}=\frac{1}{2}\left(\frac{1}{E_{1}}+\frac{1}{E_{2}}\right), \frac{1}{\mu^{*}}=\frac{1}{2}\left(\frac{1}{\mu_{1}}+\frac{1}{\mu_{2}}\right), \text { and } \beta=\frac{\mu_{1}\left(\kappa_{2}-1\right)-\mu_{2}\left(\kappa_{1}-1\right)}{\mu_{1}\left(\kappa_{2}+1\right)+\mu_{2}\left(\kappa_{1}+1\right)}
$$

and $\kappa=3-4 v$ for plane strain, axisymmetry, and three dimensions; and $\kappa=(3-v) /(1+v)$ for plane stress.

Unlike their analogues in a homogeneous material, $K_{I}$ and $K_{I I}$ are no longer the pure mode I and II stress intensity factors for an interfacial crack. They are simply the real and imaginary parts of a complex stress intensity factor, whose physical meaning can be understood from the interface traction expressions: 


$$
\left(\sigma_{22}+i \sigma_{12}\right)_{\theta=0}=\frac{\left(K_{I}+i K_{I I}\right) r^{i \varepsilon}}{\sqrt{2 \pi r}}, \quad\left(\sigma_{23}\right)_{\theta=0}=\frac{K_{I I I}}{\sqrt{2 \pi r}},
$$

where $r$ and $\theta$ are polar coordinates centered at the crack tip. The bi-material constant $\varepsilon$ is defined as

$$
\varepsilon=\frac{1}{2 \pi} \ln \left(\frac{1-\beta}{1+\beta}\right)
$$

The $J$-integral was calculated using the *CONTOUR INTEGRAL of ABAQUS, which is based on the domain integral method. Since the local coordinates of the SNTT FEM coincide with the principal stress orientation, under pure torsion loading, it is expected that the contribution of $K_{I I I}$ to the value of $J$ in the crack propagation orientation is much less than that of $K_{I}$ and $K_{I I}$. Furthermore, based on our experience, along the crack front of a homogeneous SNTT mullite sample with a shallow crack under a pure torsion loading, $99 \%$ of the $J$ value is contributed by $J_{\mathrm{I}}$. [ref. 46]. Thus, along the crack propagation orientation, contribution of $K_{I I I}$ to the $J$ is negligible for an SNTT configuration; and eq. (7) can be written as

$$
J=\frac{1-\beta^{2}}{E^{*}}\left(K_{I}^{2}+K_{I I}^{2}\right)=\frac{1-\beta^{2}}{E^{*}}\left|K^{*}\right|^{2},
$$

where $K^{*}=K_{I}+i K_{I I}$, and the magnitude of $K^{*},\left|K^{*}\right|$, can be written as

$$
\left|K^{*}\right|=\sqrt{\frac{E^{*} J}{\left(1-\beta^{2}\right)}} .
$$

It is clear from eq. (9) that tension and shear effects are inseparable near the interface crack tips. A measure of the relative portion of shear to normal traction (or mode I to mode II) requires the specification of a length quantity $L^{*}$. For oscillatory fields, the phase angle of the mode mixity is uniquely specified by ${ }^{[34]}$

$$
\tan \psi=\left(\frac{\sigma_{y x}}{\sigma_{y y}}\right)_{r=L^{*}} .
$$

The length $L^{*}$ is arbitary but must be unchanging for a material pair: i.e., $L^{*}$ must be independent of the overall specimen size. For an MA956 thin film interface material, the bi-material constant $\varepsilon$ is estimated as 0.00254 , which is relatively small. Thus, for simplification, the term of $K^{*} r^{i \varepsilon}$ in eq. (9) can be written as $K^{*}$, and the associated phase angle of mode mixity can be expressed as

$$
\tan \psi=\left(\frac{\sigma_{y x}}{\sigma_{y y}}\right)_{r \rightarrow 0}, \quad \text { or } \tan \psi=\frac{K_{I I}}{K_{I}} .
$$

An SNTT configuration along the crack propagation orientation has a relatively small $\sigma_{\mathrm{yx}} / \sigma_{\mathrm{yy}}$ ratio when $r \rightarrow 0$, for example at the quarter node of the singular element along the crack front, the $\sigma_{\mathrm{yx}} / \sigma_{\mathrm{yy}}$ ratio is estimated as 0.005 , and 0.1 at the end node of the singular element. For a practical purpose and to obtain an equivalent mode I interface fracture toughness, the associate phase angle $\psi$ can be set as zero from 
eq. (13). Therefore, at the phase angle approach $\psi=0$, the associated $\mathrm{K}_{\mathrm{II}} / \mathrm{K}_{\mathrm{I}}$ is also approach to zero, the estimated upper bound of the equivalent Mode I interface fracture toughness can then be written as

$$
K_{I C} *=\sqrt{\frac{E^{*} J_{C}}{\left(1-\beta^{2}\right)}},
$$

where the term $J_{C}$ is the estimated $J$-integral value at the fracture.

\subsection{FEM ANALYSIS RESULTS AND FRACTURE TOUGHNESS EVALUATION}

\subsubsection{Fracture Toughness Evaluation for Oxide MA956 SNTT Specimens}

Material properties of MA956, alumina scale, and FEM modeling used in the analysis are tabulated in Table 5. All material properties are assumed to be homogeneous and isotropic. In order to verify the material properties of the baseline and heat-treated MA956 for nonlinear analysis, the automated ball indentation (ABI) technique was used to estimate the tensile yield strength and ultimate tensile strength. Plasticity effects were precluded for the alumina scale; the MA956 was assumed to be governed by a Von Mises-yield condition and isotropic hardening, based on the true stress-plastic strain curve obtained from the ABI tests. The indentation load-vs.-depth curves of ABI, shown in Fig. 47, reveal material softening for heat-treated MA956 samples, specimen 1 and 3, as compared with the baseline MA956 sample. A thin layer of residual alumina scale remained on the ABI test site from specimen 1. This thin layer of alumina manifests itself with a slight hardening compared with specimen 3's ABI test data, which had the alumina scale completely removed from the ABI test site.

Throughout most gage lengths, uniform stress and strain fields exist in the test sample under pure torsion loading. However, only a portion of the gage length of test samples was used in FEM model. Thus, with simulated boundary conditions, the stress and strain distributions under pure torsion are not entirely uniform throughout the model sample; but the middle portion is reasonably uniform. Since a zero axial load is maintained during torsion, the specimen is permitted to deform freely along the axis. For all practical purposes, this condition can be simulated for the middle layer elements of the FEM, and was used as the FEM boundary condition. 
Table 5. Material properties and criteria used in FEM analysis.

\begin{tabular}{|c|c|}
\hline \multirow{3}{*}{ Material } & $\begin{array}{l}\text { Alumina (room temperature): } \\
\mathrm{E}=370 \mathrm{GPa}, v=0.20, \mathrm{~K}_{\mathrm{IC}}=4.0 \mathrm{MPa} \sqrt{m} \quad[\text { Ref. 71,72]; } \\
\mathrm{K}_{\mathrm{IC}}=2.0 \mathrm{MPa} \sqrt{m} \quad\left[\text { ref. 73]; } \mathrm{K}_{\mathrm{IC}}=2.3 \mathrm{MPa} \sqrt{m} \quad[\text { Ref. 74] }\right.\end{array}$ \\
\hline & $\begin{array}{l}\text { Alumina }\left(1100^{\circ} \mathrm{C} \text { temperature): }\right. \\
\mathrm{E}_{1100^{\circ} \mathrm{C}}:=324 \mathrm{GPa}, \mathrm{K}_{\mathrm{IC}}=0.78 \mathrm{MPa} \sqrt{m}\left(\mathrm{MA} 956 \text { exposed in } 1100^{\circ} \mathrm{C} / 5200 \mathrm{~h}\right)[\mathrm{ref} .75]\end{array}$ \\
\hline & $\begin{array}{l}\text { MA956 (Room Temperature): } \\
\mathrm{E}=269 \mathrm{GPa}, v=0.31, K_{I C}=68 \mathrm{MPa} \sqrt{m} \text { in L-T orientation.. } \\
\text { Tensile yield stress: } 708 \mathrm{MPa},{ }^{a} \text { ultimate tensile strength: } 940 \mathrm{MPa}{ }^{a}{ }^{b} \\
\text { Tensile yield stress: } 600 \mathrm{MPa},{ }^{b} \text { ultimate tensile strength: } 810 \mathrm{MPa} .{ }^{b} \\
\text { Tensile yield stress: } 870 \mathrm{MPa} \text {, ultimate tensile strength: } 890 \mathrm{MPa} . \text { [ref. } 76]\end{array}$ \\
\hline \multirow[b]{2}{*}{ FEM $^{\mathrm{c}}$} & $\begin{array}{l}\text { Global model: } 72,520 \text { 3-D solid brick elements and the associated } 316,200 \text { nodes. } \\
\text { The smallest element dimension is } 0.22 \mu \mathrm{m} \text {. Crack length is } 7.5 \mu \mathrm{m}(0.0003 \mathrm{in} \text {.) }\end{array}$ \\
\hline & $\begin{array}{l}\text { Sub-model: } 10,720 \text { 3-D solid brick elements (with singular element around the crack } \\
\text { front) and the associated } 46,844 \text { nodes were used to refine the FEM mesh near the } \\
\text { crack front at mid-layer of global model. }\end{array}$ \\
\hline $\begin{array}{l}\text { Loading } \\
\text { Condition }\end{array}$ & $\begin{array}{l}\text { Torque end rotation: } 3.593 \mathrm{E}-04 \mathrm{rad} \\
\text { Residual stresses: } 2.50 \mathrm{GPa} \text { at U-groove; the rest of alumina scale: } 3.7 \mathrm{GPa} \text {. }\end{array}$ \\
\hline $\begin{array}{l}\text { Boundary } \\
\text { Condition }\end{array}$ & $\begin{array}{l}\text { One end of the short bar constrained with zero displacements in } \mathrm{X} \text { and } \mathrm{Y} \text { axes of the } \\
\text { global coordinates, and the other end free. }\end{array}$ \\
\hline
\end{tabular}

Because of the large number of elements used for an SNTT thin film model, a minimum of $3 \mathrm{~GB}$ of RAM memory and 14GB of scratch disk space is required to carry out stress-strain analysis with ABAQUS code. Thus, in order to solve this problem within a reasonable timeframe, it will require a highpower and high-performance computing facility to carry out the analysis. Therefore, the finite element analysis was carried out on a supercomputer facility at ORNL; it took about 8,778 sec CPU time and a hard clock time of $4 \frac{1}{2}$ hours to complete the linear elastic fracture mechanics analysis of the global model. 


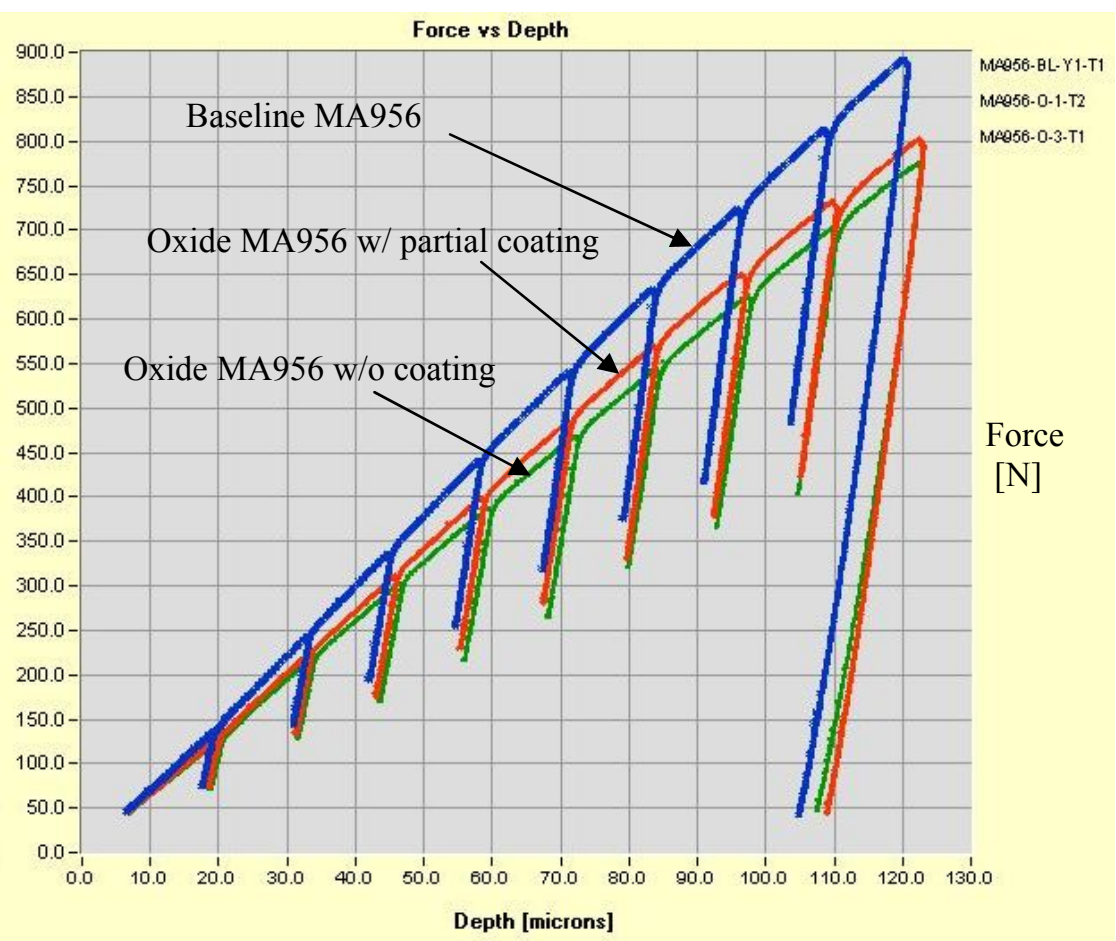

Fig. 47. Comparison of automated ball indentation curves, force vs. depth, which indicates that the oxide MA956 sample was softening compared with the baseline MA956 sample; oxide MA956 with partial coating sample shows slight hardening due to the thin film of alumina.

The torque applied to the specimen from the prescribed end displacement was calculated according to the following equation:

$$
\text { Torque }_{\mathrm{END}}=\sum_{\text {node } i}^{n}\left(R_{y}^{*} x-R_{x}^{*} y\right)_{\text {node } i},
$$

where $R_{x}$ and $R_{y}$ are the reaction forces at the fixed end of the FEM in the $\mathrm{X}$-axis and $\mathrm{Y}$-axis directions, respectively, derived from the linear elastic fracture mechanics (LEFM) for the fracture loading condition; $x$ and $y$ are the $\mathrm{x}$ - and $\mathrm{y}$-components of the distance between the node $i$ and the center of the circular bar, respectively.

The $3.593 \times 10^{-4}$ radian end rotation at the fracture load of $4.63 \mathrm{~N}-\mathrm{m}$ (41 in.-lb) was determined by iterative processes using eq. (15). Based on linear elastic fracture mechanics, at the fracture load, the $J$ value in the crack propagation orientation at the mid-layer of the FEM is estimated as $52 \mathrm{~N}-\mathrm{m} / \mathrm{m}^{2}(0.30$ lb-in./in. $\left.{ }^{2}\right)$ and $3.7 \mathrm{~N}-\mathrm{m} / \mathrm{m}^{2}\left(0.021 \mathrm{lb}\right.$-in./in $\left.{ }^{2}\right)$ for a dull crack front with a hole at the crack tip and sharp crack front, respectively. The $E^{*}$ and $\beta$ of eq. (8) are estimated as $311 \mathrm{GPa}\left(4.52 \times 10^{4} \mathrm{ksi}\right)$ and -0.008 , respectively. Substituting $E^{*}$ and $\beta$ value into eq. (10), we obtained the estimated equivalent Mode I interface fracture toughness as $4.0 \mathrm{MPa} \sqrt{m}(3.7 \mathrm{ksi} \sqrt{\text { in. }})$ and $1.1 \mathrm{MPa} \sqrt{m}(0.97 \mathrm{ksi} \sqrt{\text { in. }})$ for a dull crack front model (with a hole of 0.22 micrometer located at the tip) and a sharp crack front model, respectively. The estimated equivalent Mode I interface fracture toughness of a sharp crack front is 1.1 $\mathrm{MPa} \sqrt{m}$, which is lower than that of the alumina scale referred to in refs. 71-74. A non-linear elasticplastic fracture mechanics analysis was also carried out on the sub-model, where it was assumed that the 
alumina scale will remain in elastic owing to the embedded high compressive residual stress. This assumption was validated from the finite element analysis. The phenomenon of stress oscillation around the crack front from the linear elastic fracture mechanics analysis was significantly reduced as observed from the non-linear elastic-plastic fracture mechanics analysis. The estimated $J$-value of the interface crack initiation is $3.9 \mathrm{~N}-\mathrm{m} / \mathrm{m}^{2}\left(0.022 \mathrm{lb}-\mathrm{in} / \mathrm{in}^{2}\right)$.

\subsubsection{Finite Element Analysis Results of Oxide MA956 SNTT Thin Film Sample}

The finite element analysis results for the mid-layer of the global model are shown in Figs. 48-55. A the hydrostatic pressure contour shows that the stress contours near the crack tip have relative high negative hydrostatic pressure, i.e. in tensile stress state, as shown in Fig. 50. The maximum principal stress contour indicates that the highest maximum principal stress is at the crack tip.

The finite element analysis results for the middle section of the sub-model are shown in Figs. 56-62, which provide more details of the stress contours near the crack tip. It interested to note the hydrostatic stress fields shown in Figs. 58-59, which show that away from the crack tip, most of the thin film is under high compressive stress and the substrate is mostly in tensile stress fields. However, near the crack tip, as shown in Fig. 59, the alumina scale experiences tensile stress (in terms of negative hydrostatic pressure) and the substrate is under compressive stress (in terms of positive hydrostatic pressure). This stress oscillation along the interface is an important characteristic of stress fields near the crack tip along the interface from a linear elastic analysis. The details of Von Mises stress contours from Fig. 60 also reveal the dissimilar stress contours around the interface for alumina scale and substrate, which is an important characteristic of a bi-material interface.

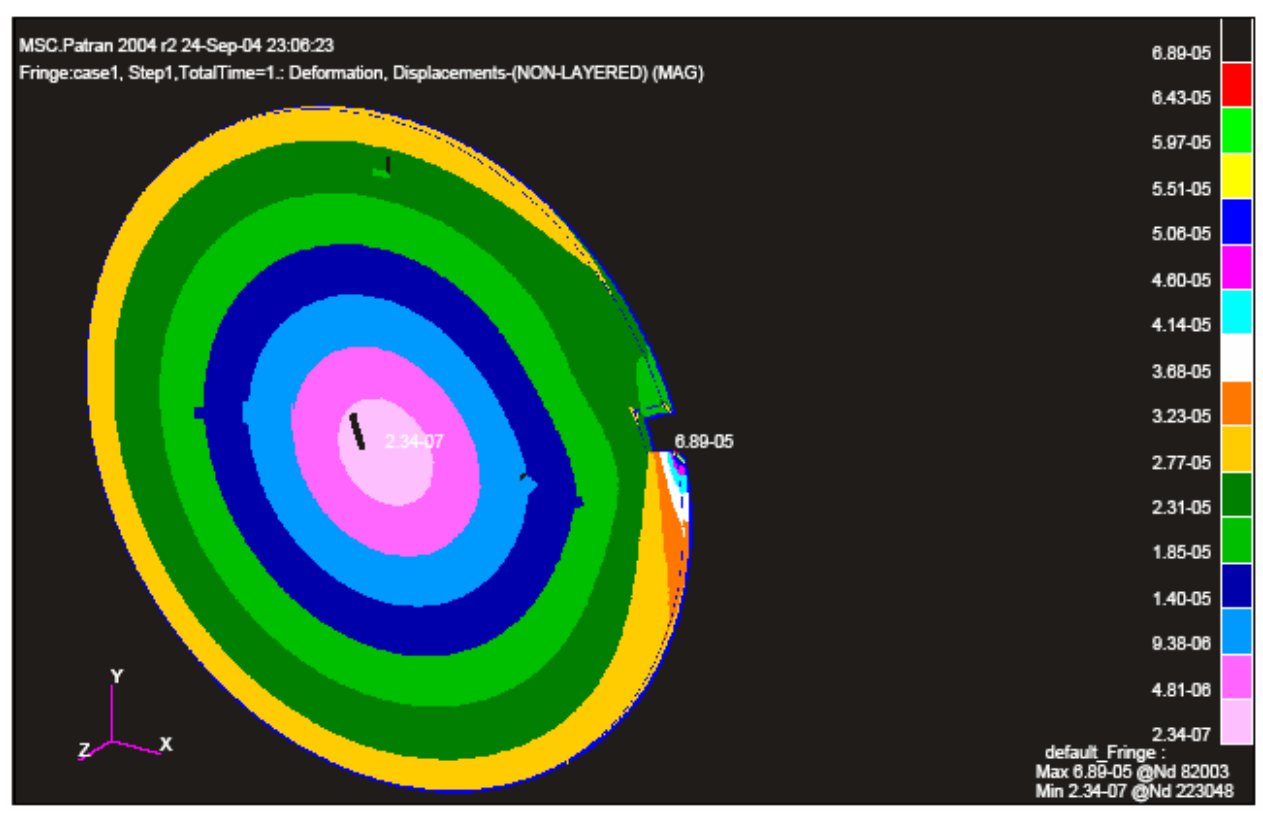

Fig. 48. Deformation displacement contours at mid-layer of global model, which shows uniform deformation of test samples, except near the U-groove. 


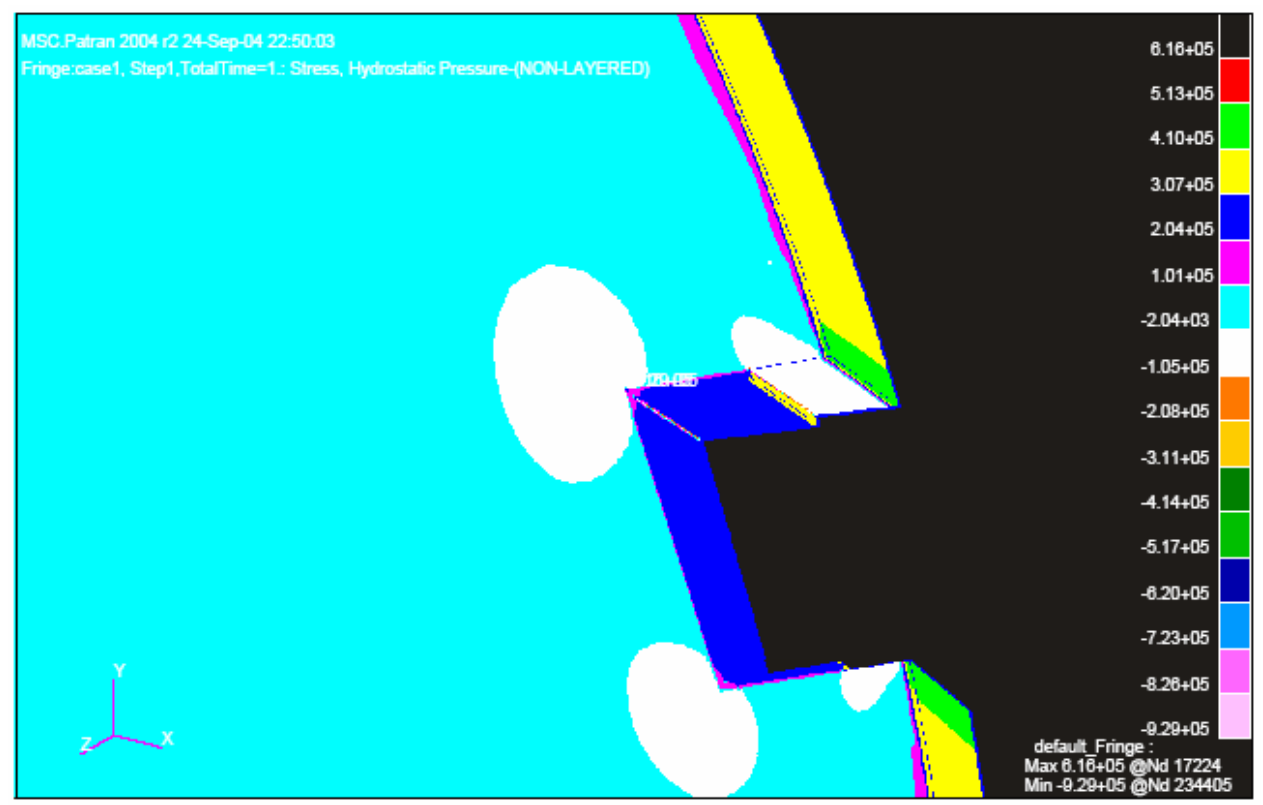

Fig. 49. Hydrostatic pressure contours at mid-layer of global model; high tensile stress field shows near the bottom corner of the U-groove.

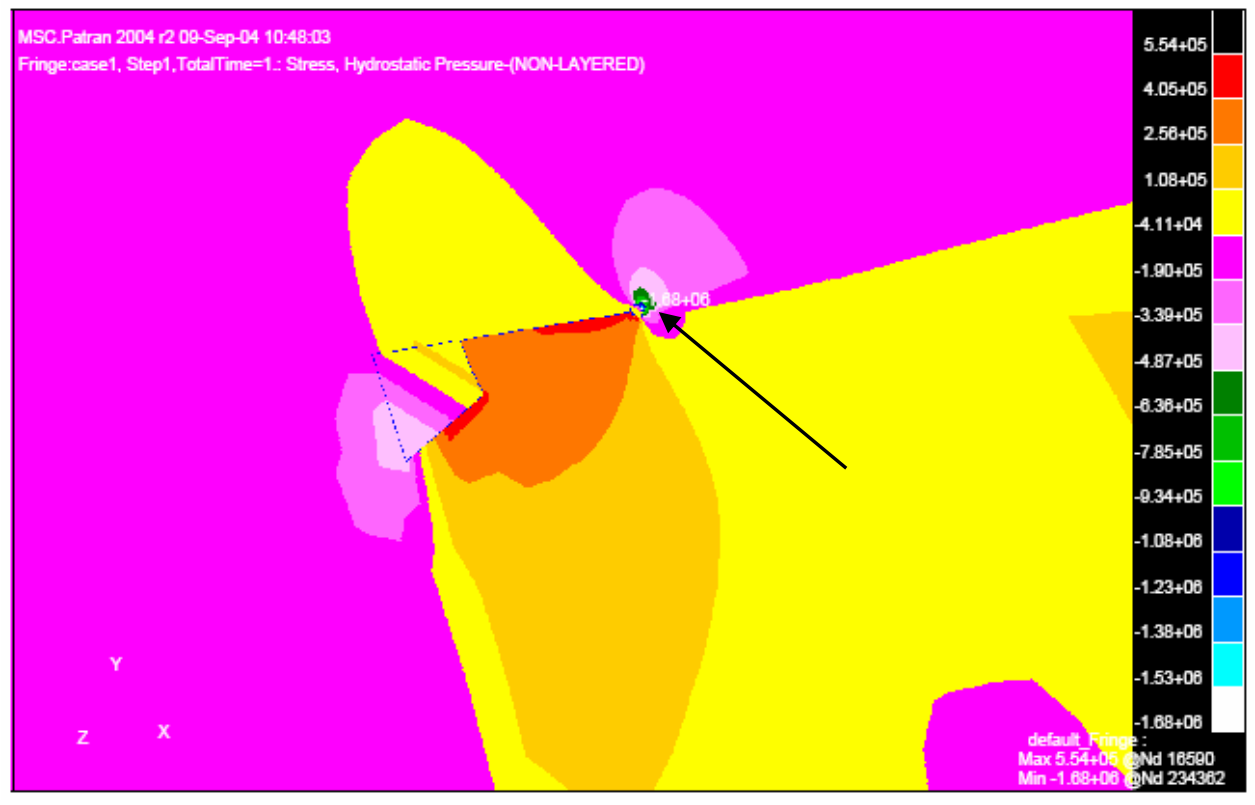

Fig. 50. Hydrostatic pressure contours near crack tip at mid-layer of global model; the crack tip is indicated with an arrow at the highest negative hydrostatic pressure. 


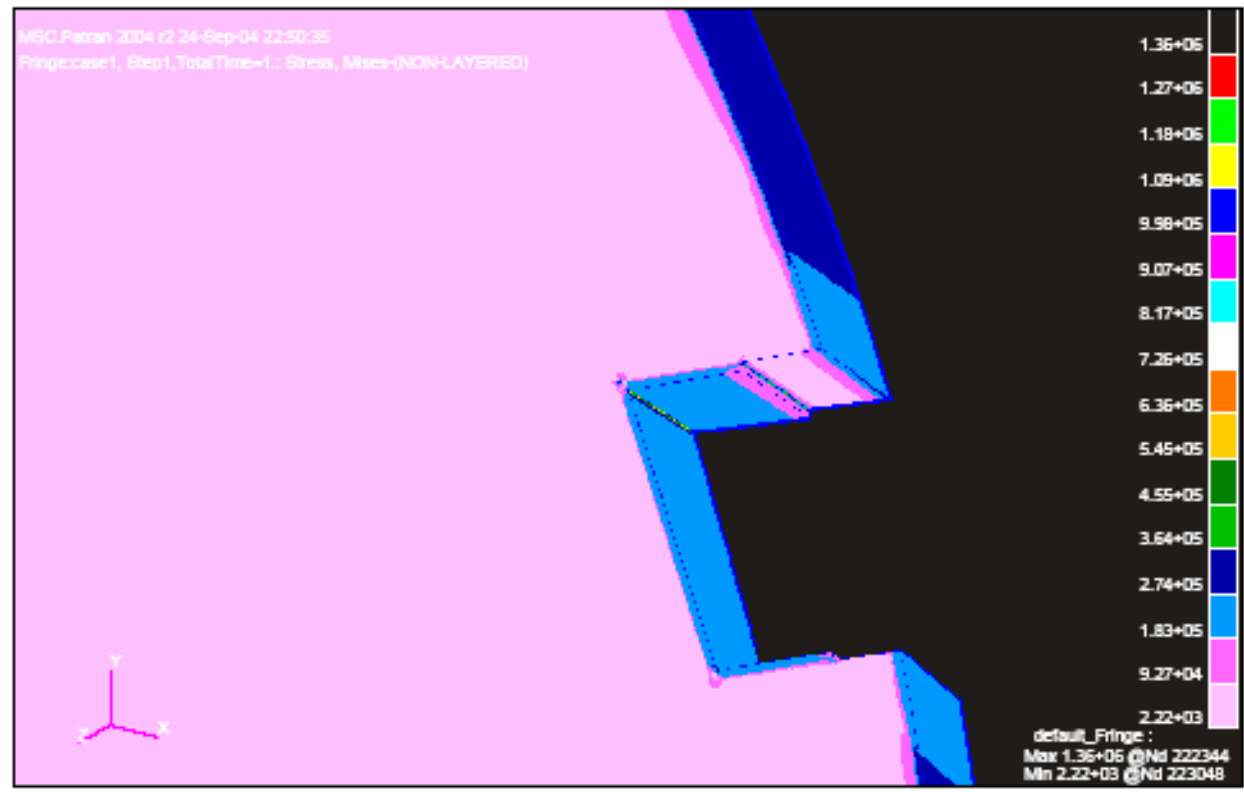

Fig. 51. Von Mises stress contours at mid-layer of global model, where the thin film presents a higher stress level than the substrate.

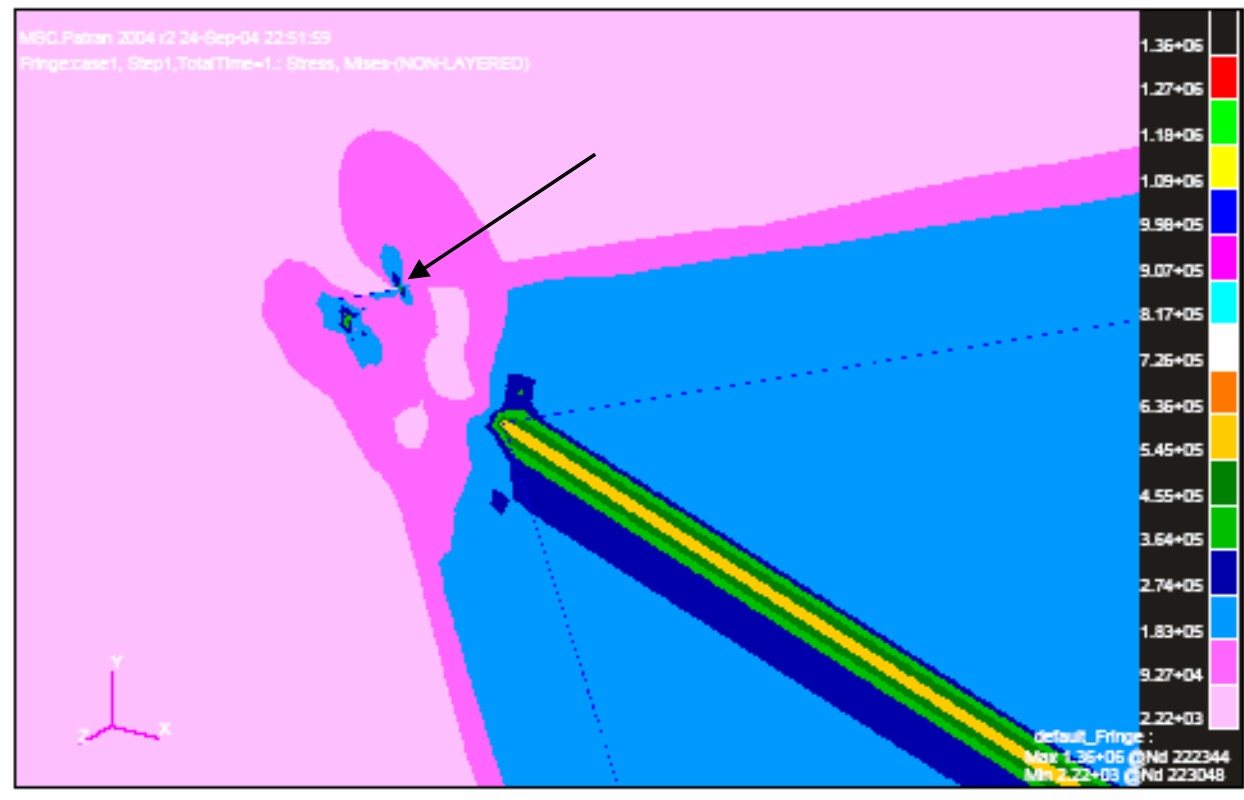

Fig. 52. Von Mises stress contours near the bottom of the U-groove at mid-layer of global model, the crack tip is indicated with an arrow. 


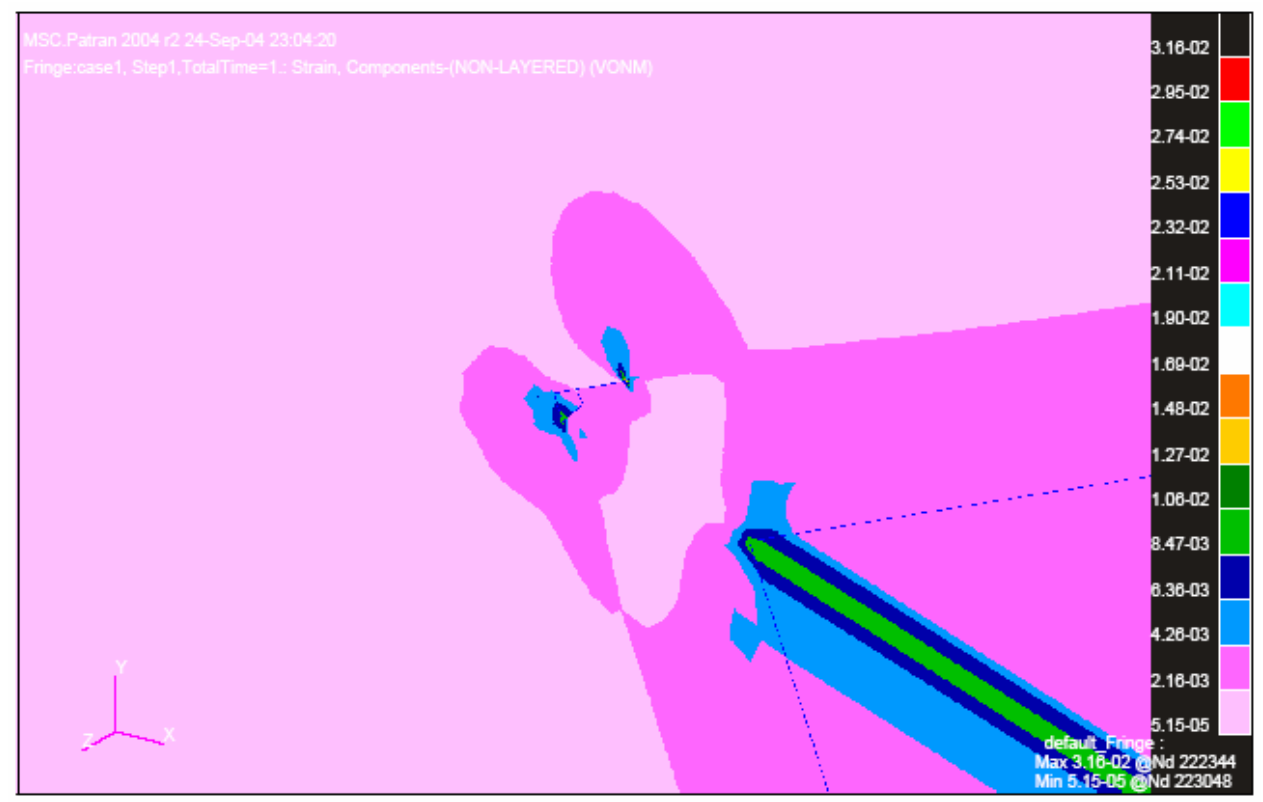

Fig. 53. Von Mises strain contours near the bottom of the U-groove at mid-layer of global model.

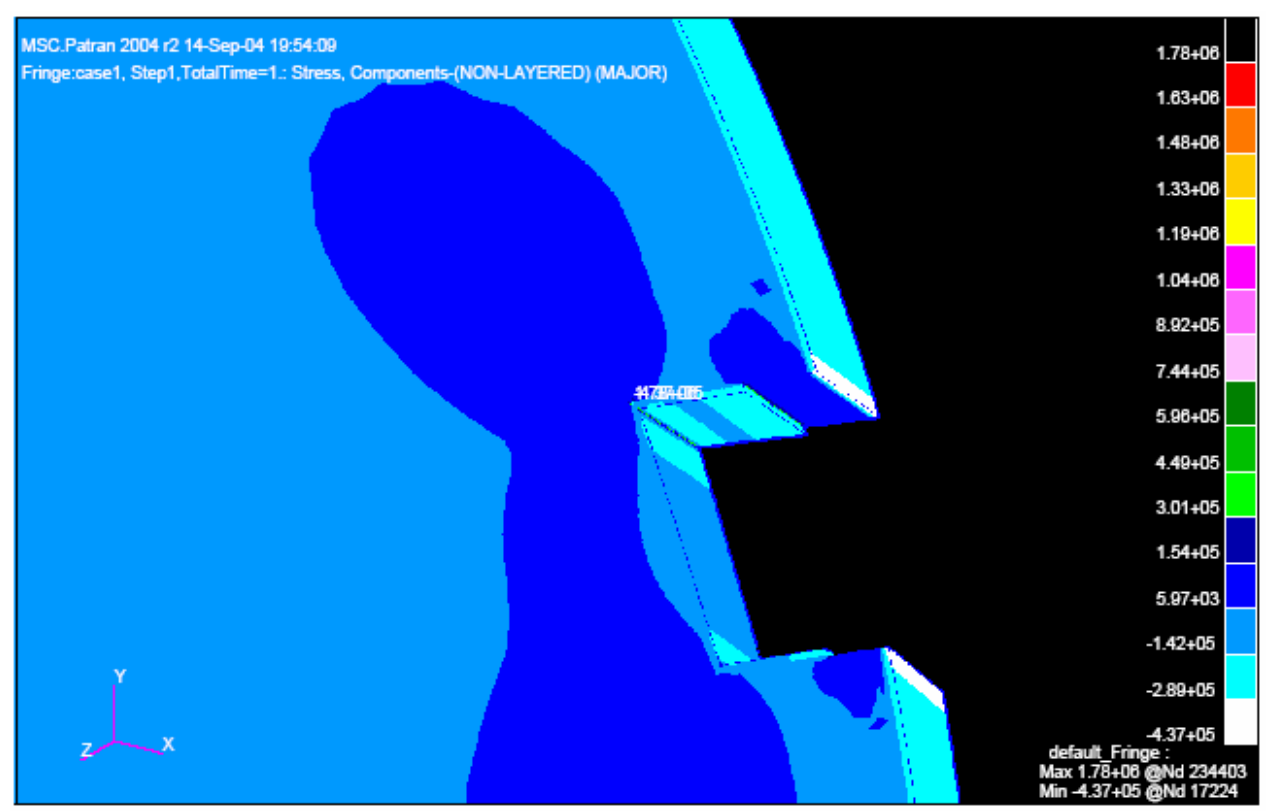

Fig. 54. Maximum principal stress contours at mid-layer of global model. 


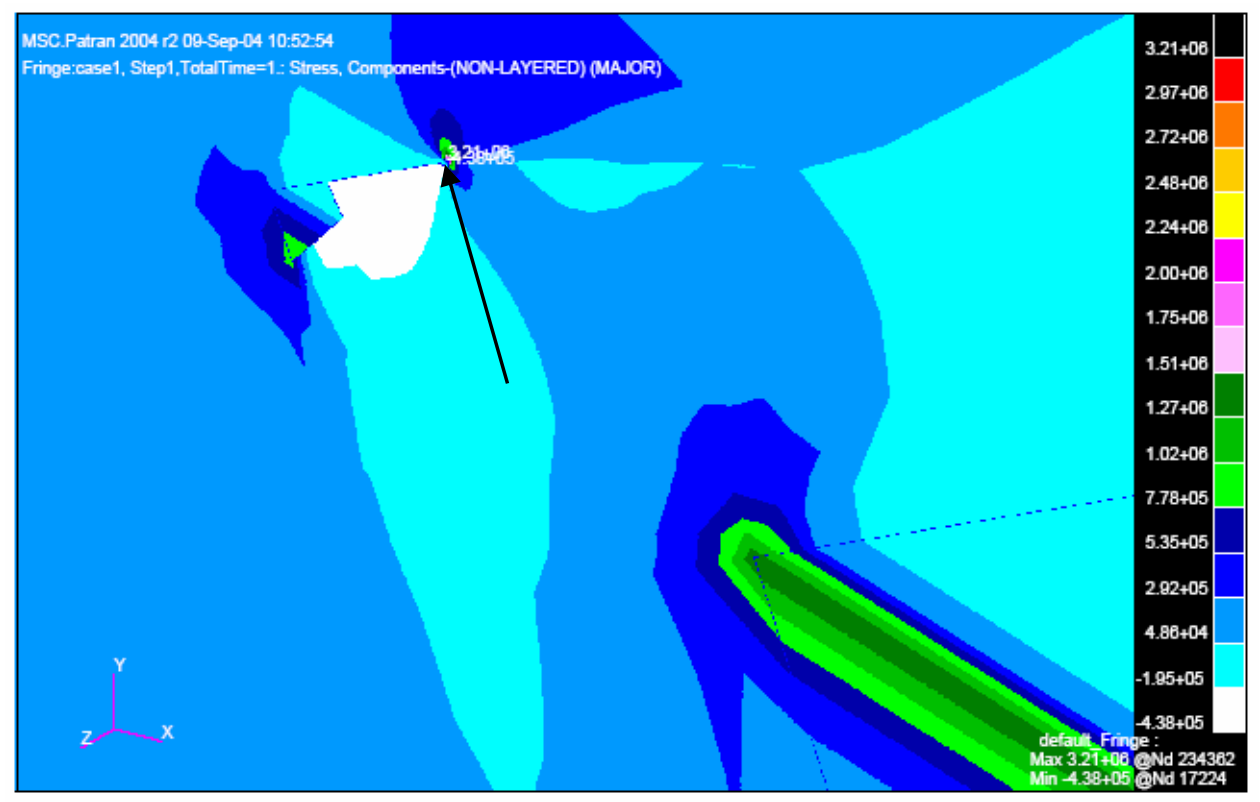

Fig. 55. Maximum principal stress contours at bottom corner of mid-layer of global model; the highest maximum principal stress is at crack tip identified with an arrow.

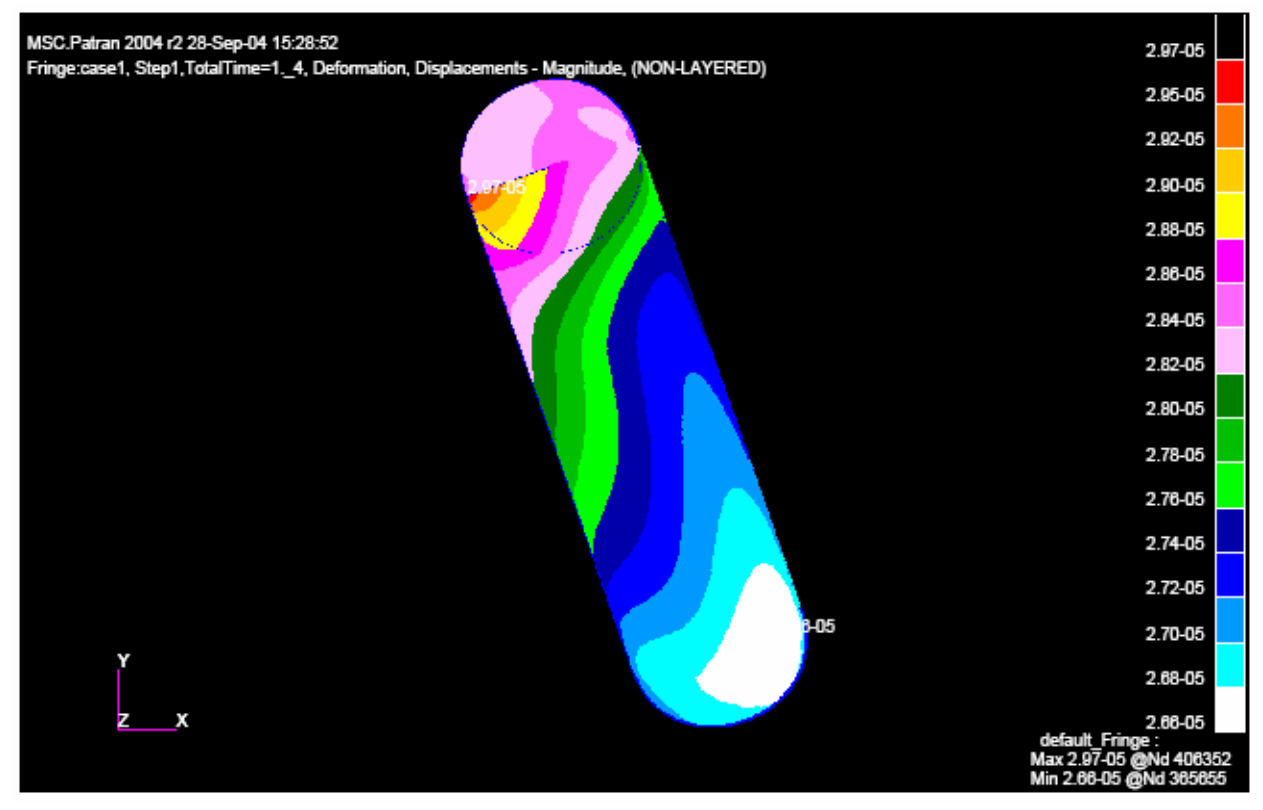

Fig. 56. Deformation displacement of sub-model configuration. 


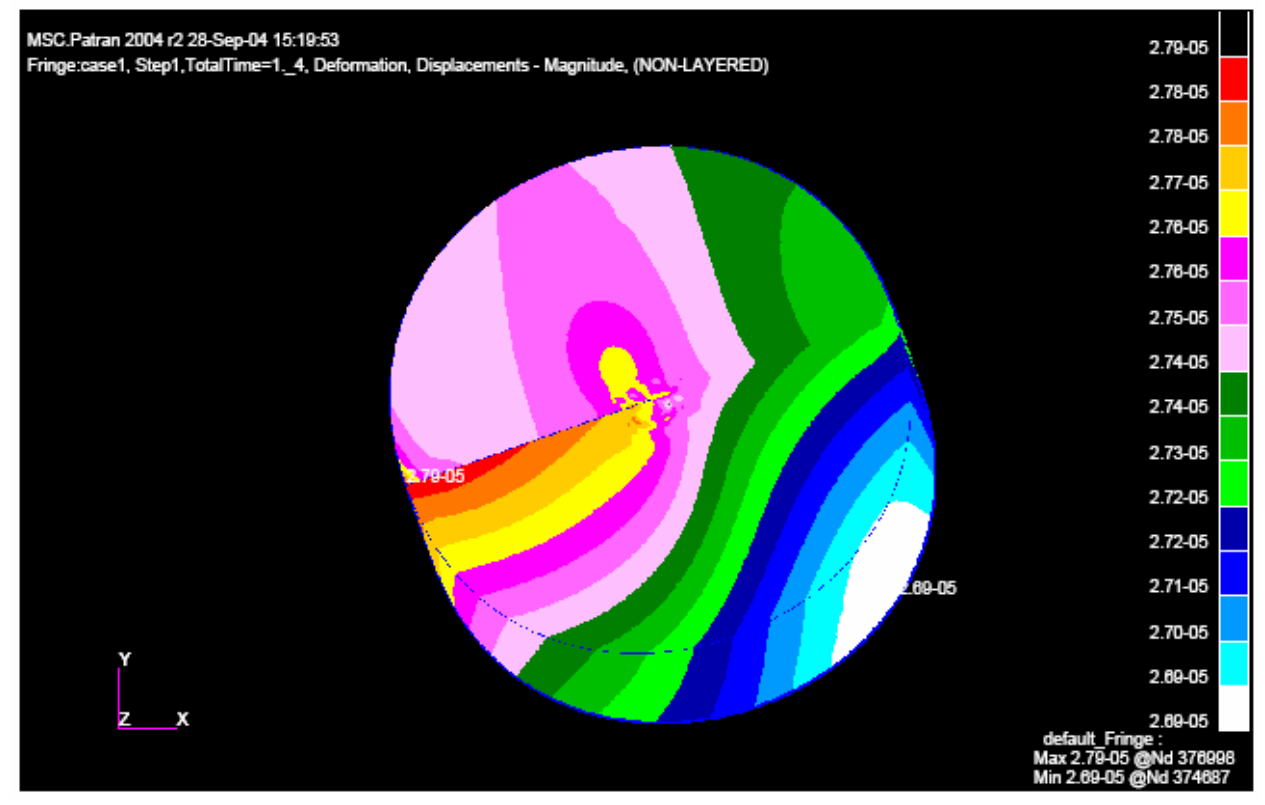

Fig. 57. Deformation displacement at the mid-layer of the sub-model.

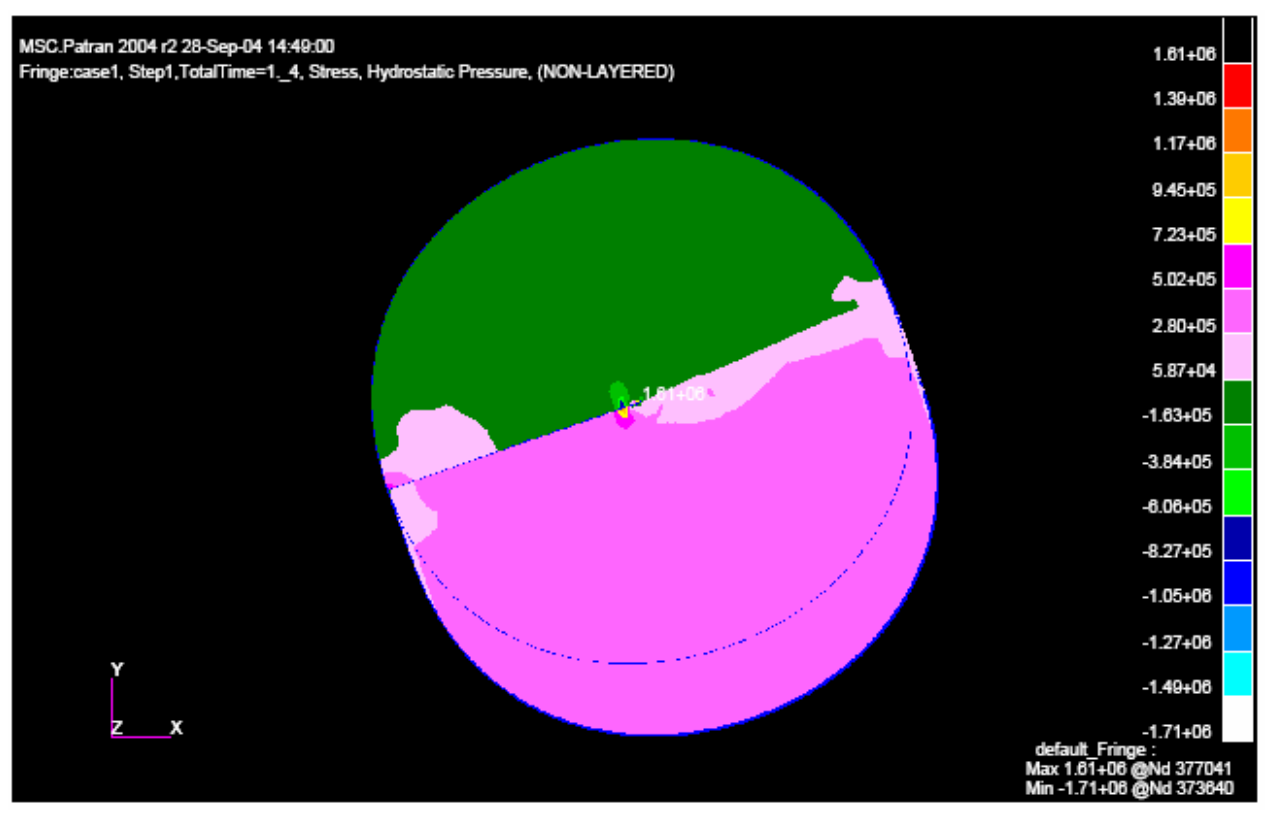

Fig. 58. Hydrostatic pressure stress contour at mid-layer of sub-model. 


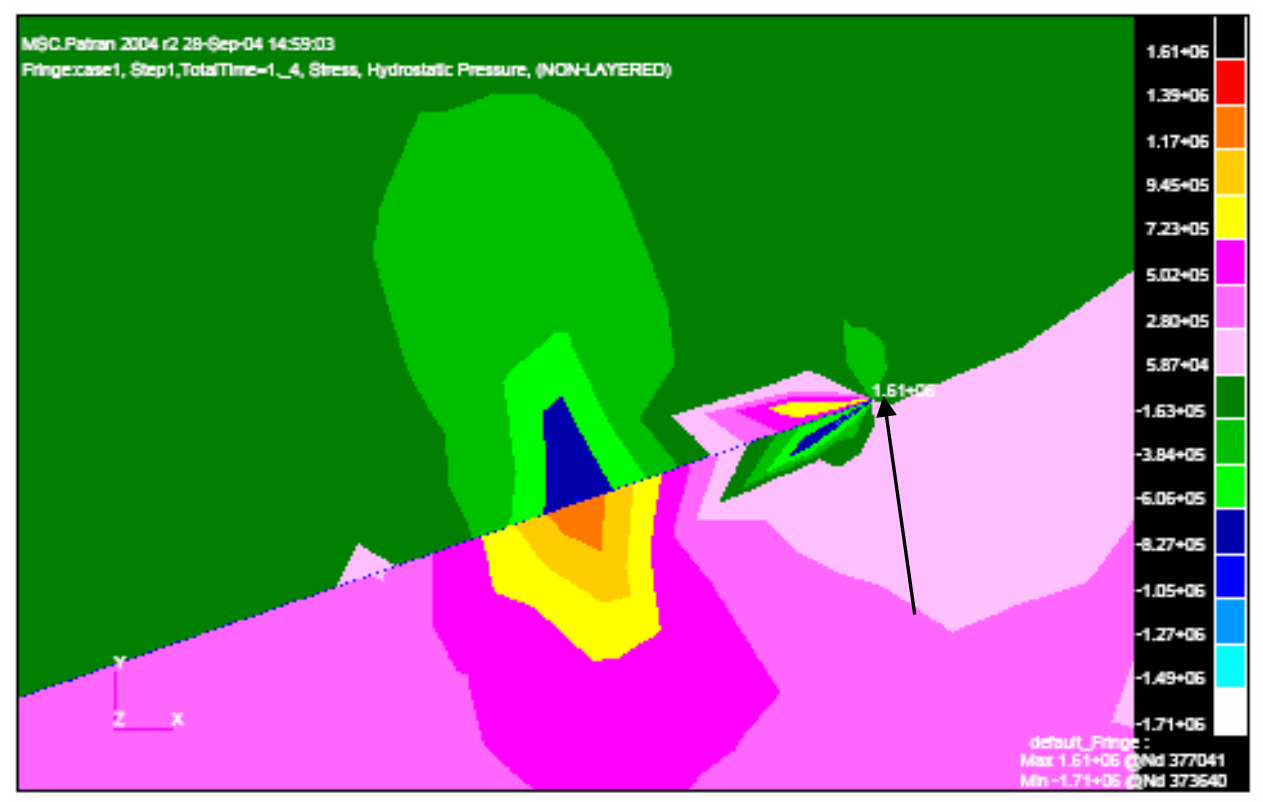

Fig. 59. Hydrostatic pressure near the crack tip at mid-layer of sub-model; the highest negative pressure is indicated with arrow at the crack tip.

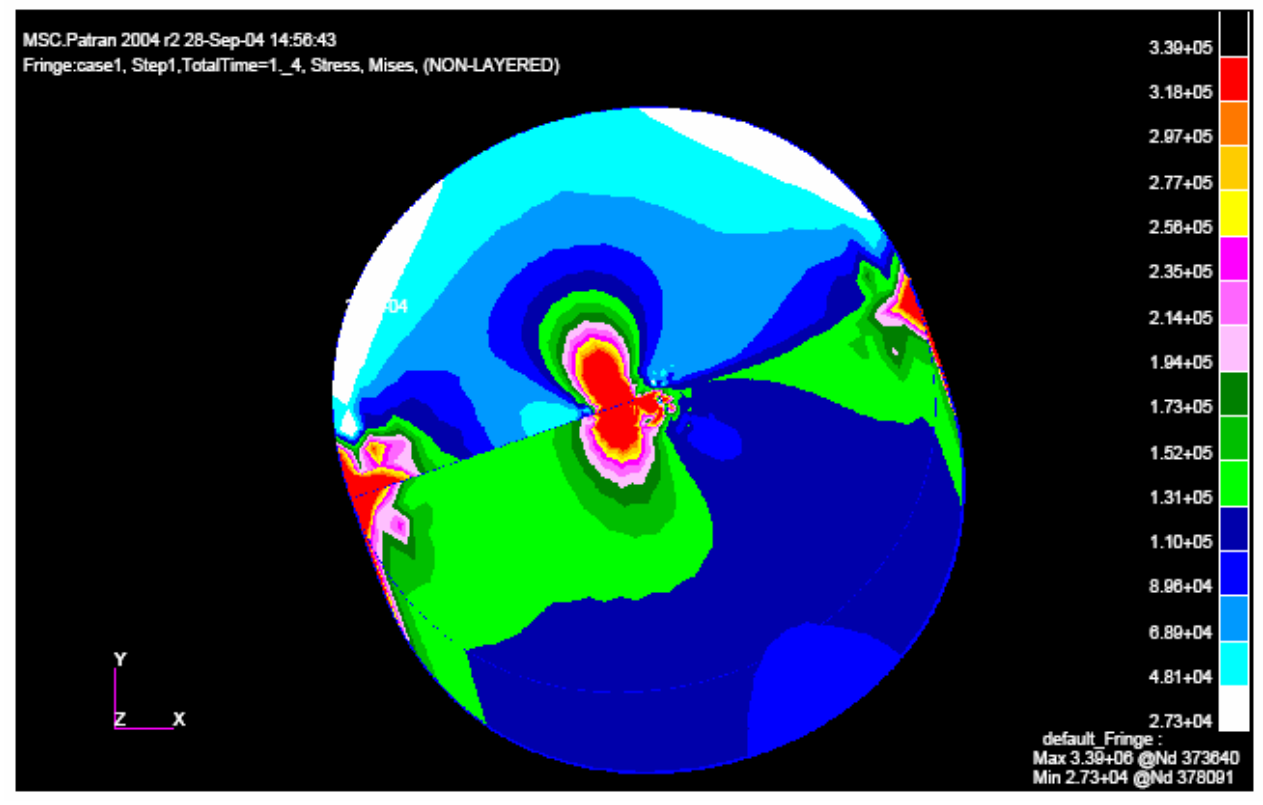

Fig. 60. Von Mises stress contours at the mid-layer of sub-model, which indicates the dissimilar stress contours around the crack tip, an important characteristic of a bi-material interface. 


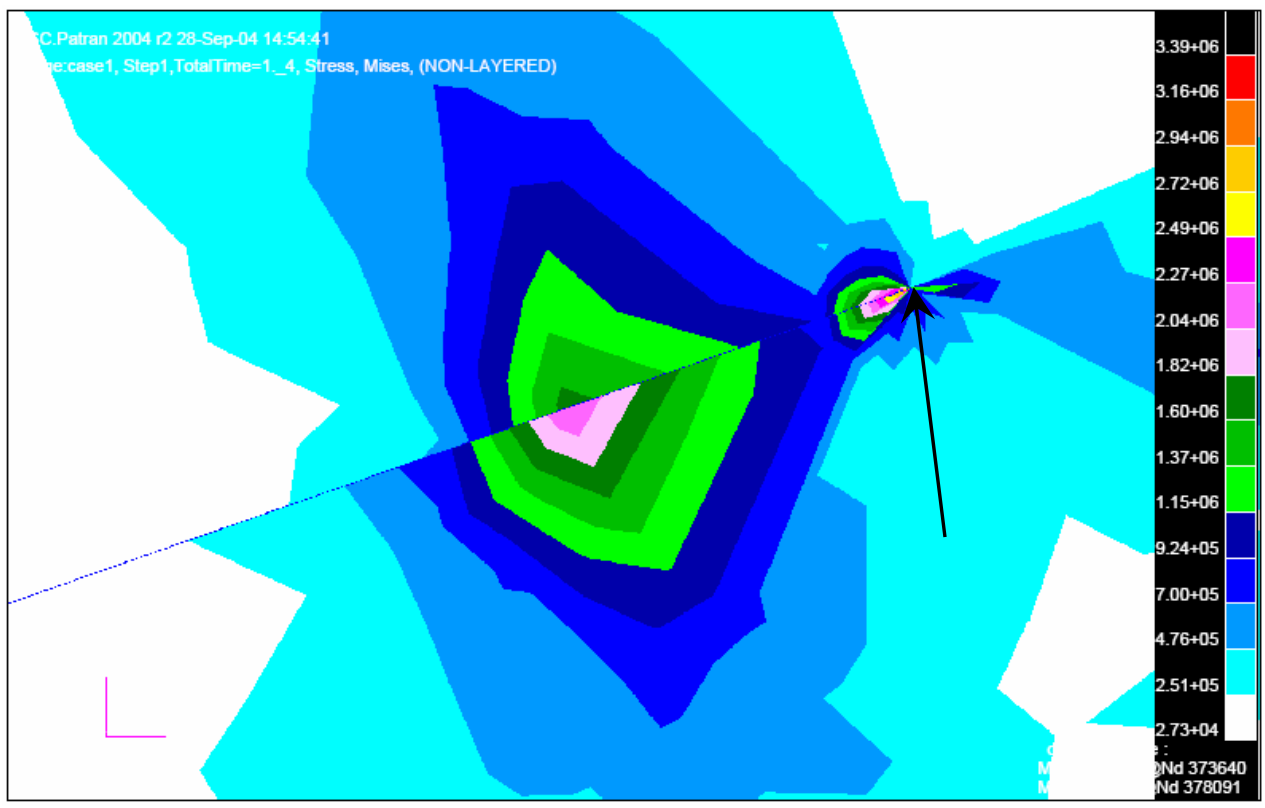

Fig. 61. Von Mises stress contours near the crack tip at mid-layer of sub-model; the arrow indicates the site of highest Von Mises stress, at the crack tip.

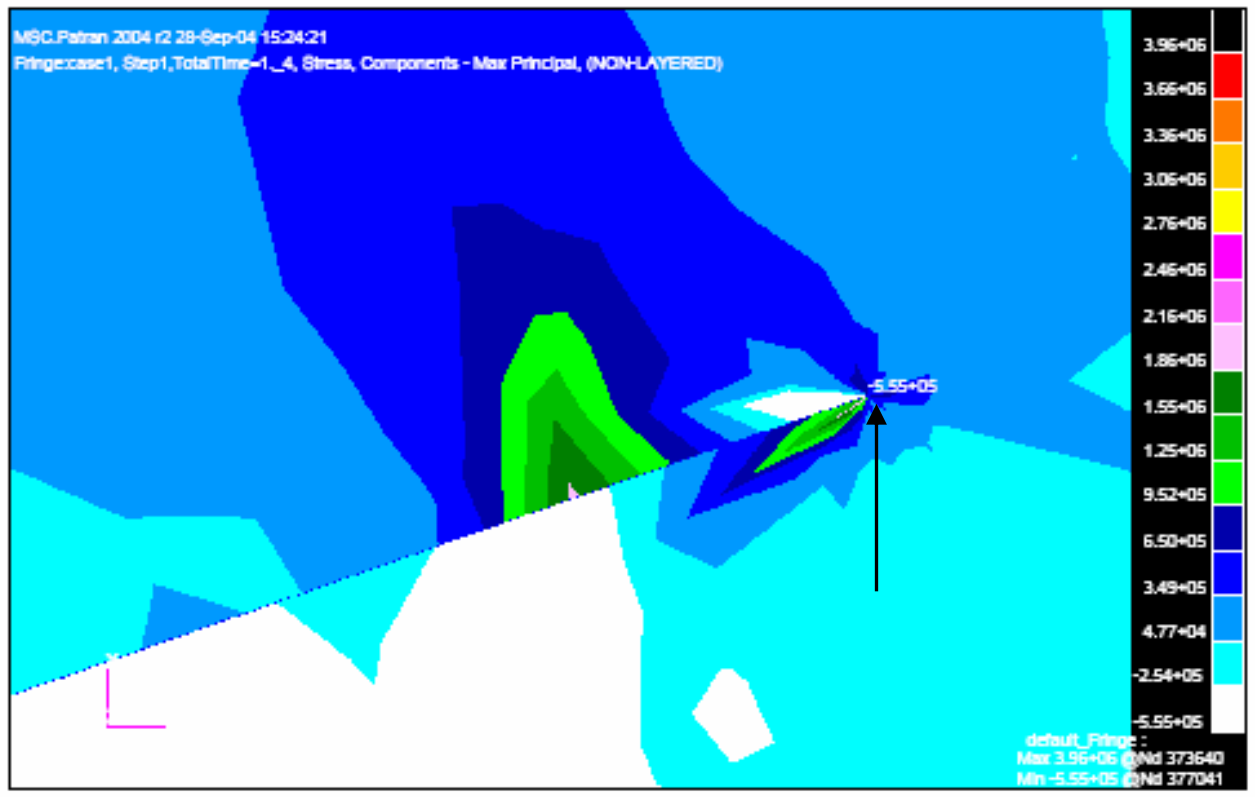

Fig. 62. Maximum principal stress near the crack tip at mid-layer of sub-model; the arrow indicates the site of the highest maximum principal stress, at the crack tip. 


\section{DISCUSSION}

A unique approach has been developed for utilizing the SNTT method to estimate interface fracture toughness. It gave the estimated interface fracture toughness as $3.7 \mathrm{~N}-\mathrm{m} / \mathrm{m}^{2}\left(0.021 \mathrm{lb}-\mathrm{in} . / \mathrm{in} .{ }^{2}\right)$ and the estimated equivalent Mode I interface fracture toughness as $1.1 \mathrm{MPa} \sqrt{m}(0.97 \mathrm{ksi} \sqrt{\text { in. }})$. An oxide SNTT specimen (without fatigue precrack) having a spiral U-groove line at $45^{\circ}$ pitch subjected to pure torsion is used in the current study. Further investigation using a non-precracked SNTT sample with a spiral Vgroove for thin film interface fracture toughness evaluation is needed. This new approach for interface toughness research was validated by using MA956 material, but the developed methodology can be extended to other coating materials or bi-materials in general. Regarding the analytical evaluation, a more detailed parameter study and further refinement of the FEMs are needed. This additional analytical investigation would provide more details regarding the sensitivity of the varied parameters - such as the void element, the location of the crack tip, and the choices of the sub-model configuration - to the accuracy of the evaluated interface fracture toughness.

The experimental evaluation, postmortem examination, and the analytical evaluation, seem to support that the interface is the weakest link for a non-precracked SNTT thin film sample. The extremely high compressive residual stress embedded within the thin film will retard the crack initiation but keeps the thin film intact. Therefore, for the SNTT thin film sample, the spallation failure of alumina scale involves a two-step process. First, the crack initiates at the interface and then propagates along the interface; this will release the associated tensile residual stress in the substrate locally just underneath the thin film. Second, torque-induced external tensile stress applied to the substrate and the alumina at the interface, shown in Fig. 4, has a tendency to cause the delaminated alumina scale to move away from the substrate. The section of delaminated alumina scale resembles a non-lateral-support column with a compression loading. It will eventually buckle at a threshold crack length along the interface and result in the spallation of alumina scale.

The residual stress of a thin film material is largely a direct result of the CTE mismatch between the scale and substrate during the cooling. Thus, from a material history view, the residual stress represents a pre-loading boundary condition but also a thin film material property. Therefore, the residual stress plays an important role in the interface fracture toughness evaluation. The alumina spallation at the top corner of the U-groove of SNTT samples may present a problem; but because of its physical location, far away from the bottom corner of the U-groove where the interface fracture toughness is evaluated, the associated impact of alumina spallation at the top corner on toughness evaluation can be considered as secondary. Furthermore, it is expected that slightly different compressive residual stresses of alumina scale will be experienced (or measured) at the side groove if different shapes of side grooves, such as Uor V-shapes are used. However, the associated stress-strain states of the substrate at the side groove, both before or during the torque loading, will also be different because of different geometry constraints if different side grooves are used. The combined effect of the compressive residual stress and the loading stress states of the substrate may offset each other for different groove geometries and result in less dependence on side groove geometry for a valid interface fracture toughness evaluation. However, this sensitivity issue regarding the side groove geometry impact on the interface fracture toughness evaluation will need to be validated from future study. 


\section{CONCLUSIONS}

Given the increasing reliance on the properties of thin films to provide critical functions in applications ranging from microelectronics to large propulsion and power generation equipment, and the need for procedures to ensure that such films are correctly applied, the ability to make accurate measurements of the interface strength would be a great benefit in quality control and fitness-for-service procedures. In addition, in applications that are critically dependent on the correct functioning of thin films and coatings, the ability to accurately measure the strength of the critical interfaces as a function of exposure to the service environment provides a basis for developing reliable lifetime models. The models can be used in conjunction with condition monitoring approaches to improve the security of operation of the component by scheduling appropriate maintenance and avoiding unexpected failure.

This project offers an innovative testing procedure for the determination of interface fracture toughness that is applicable to thin coating materials in general. The effort included development of instrumentation, testing procedures, and analytical and finite element procedures for calculating interface fracture toughness. This new torsion bar testing procedure has been successfully developed and extended to bi-material interface fracture research. The feasibility study indicated that this approach for studying thin film interface fracture is repeatable and reliable with much less uncertainty than other approaches. The demonstrated test method closely adheres to and is consistent with classical fracture mechanics theory. The interface fracture toughness from finite element analysis is estimated as $3.7 \mathrm{~N}-\mathrm{m} / \mathrm{m}^{2}(0.021$ lb-in./in. $\left.{ }^{2}\right)$ and the estimated equivalent Mode I interface fracture toughness as $1.1 \mathrm{MPa} \sqrt{\mathrm{m}}(0.97$ ksi $\sqrt{\text { in. }) . ~}$

The unique features of the testing method demonstrated are these:

- The stress and strain fields produced by pure torsion of a circular bar are a function of the bar radius only, and they are the same everywhere along the notch line. The length of the spiral crack is equivalent to the thickness of a compact tension specimen. The size effect that normally is a serious concern in compacttype specimens and others is virtually eliminated in an SNTT specimen. Therefore, miniature specimens can be used effectively in the SNTT method.

- Fracture failure in combined mixed-mode (modes I and III) pertinent to pressure vessel piping systems can be tailored for simulation studies by varying the pitch angle of the starting notch line or, alternatively, having the standard specimen subjected to various combinations of loads in tension and torsion.

- Because of the controllable crack growth behavior and miniaturization characteristics of the SNTT technique, there is potential for its use to determine the fracture toughness values for interfaces in inhomogeneous materials and the mechanical properties of heat-affected zones.

The SNTT technique offers new opportunities to promote the development of new thin film and coating materials, provides a reliable method for use in assessing material performance, and provides industry with a means to establish and standardize quality control. Therefore, this new approach, with a main focus on measurement, is expected to have wide-ranging impact on important industrial sectors and their supply chains, including power generation, construction, aerospace, automotive, and electronics. 


\section{REFERENCES}

1. S. E. Lyshevski, Nano- and Microelectromechanical Systems, CRC Press, Boca Raton, Florida, 2000.

2. M. Madou, Fundamentals of Microfabrication, CRC Press, Boca Raton, Florida, 1997.

3. A. Maricocchi, A. Bartz, and D. Wortman, "PVD TBC Experience on GE Aircraft Engines," pp. 79-90 in Proceedings of the Thermal Barrier Coating Workshop, NASA Lewis Research Center, NASA Conference Publication 3312, National Aeronautics and Space Administration, 1995.

4. N. E. Paton, "Materials for Advanced Space Propulsion Systems," J. Mater. Sci. Eng. A143, $21-$ 29 (1991).

5. M. J. Stiger et al., "Thermal Barrier Coatings for the 21st Century," Z. Metallkd. 90, 1069-1078 (1999).

6. R. A. Miller, "Current Status of Thermal Barrier Coatings-An Overview," Surf. Coat. Technol. 30, 1-11 (1987).

7. R. A. Miller, "Thermal Barrier Coatings for Aircraft Engines: History and Directions," J. Therm. Spray Technol. 6, 35-42 (1997).

8. W. J. Brindley and R. A. Miller, "TBCs for Better Engine Efficiency," Adv. Mater. Proc. 136, 29-33 (1989).

9. W. Beele, G . Marijnissen, and A. van Lieshout, "The Evolution of Thermal Barrier CoatingsStatus and Upcoming Solutions for Today's Key Issues," Surf. Coat. Technol. 121, 61-67 (1999).

10. A. M. Karlsson, T. Xu, and A. G. Evans, "The Effect of the Thermal Barrier Coating on the Displacement Instability in Thermal Barrier Systems," Acta Mater. 50, 1211-1218 (2002).

11. C. A. Johnson, J. A. Ruud, R. Bruce, and D. Wortman, "Relationships Between Residual Stress, Microstructure and Mechanical Properties of Electron Beam-Physical Vapor Deposition Thermal Barrier Coatings," Surf. Coat. Technol. 109, 80-85 (1998).

12. Z. A. Chaudhury et al., "Chronological Evaluation of Interfacial Damage in TBC due to Thermal Cycling,” J. Mater. Sci. 34, 2475-2481 (1999).

13. J. R. Brandon and R. Taylor, "Thermal Properties of Ceria and Yttria Partially Stabilized Zirconia Thermal Barrier Coatings,” Surf. Coat. Technol. 39/40, 143-151 (1989).

14. J. A. Nesbitt, "Thermal Response of Various Thermal Barrier Coatings in a High Heat Flux Rocket Engine," Surf. Coat. Technol. 43, 458-469 (1990).

15. D. M. Zhu and R. A. Miller, "Thermal Conductivity and Elastic Modulus Evolution of Thermal Barrier Coatings under High Heat Flux Conditions," J. Therm. Spray Technol. 9, 175-180 (2000).

16. A. K. Ray, "Failure Mode of Thermal Barrier Coatings for Gas Turbine Vanes under Bending," Int. J. Turbo Jet Eng. 17, 1-24 (2000).

17. B. A. Pint et al., "Substrate and Bond Coat Compositions: Factors Affecting Alumina Scale Adhesion,” Mater. Sci. Eng. A 245, 201-211 (1998). 
18. M. J. Pindera, J. Aboudi, and S. M. Arnold, "The Effect of Interface Roughness and Oxide Film Thickness on the Inelastic Response of Thermal Barrier Coatings to Thermal Cycling," Mater. Sci. Eng. A 284, 158-175 (2000).

19. A. G. Evans, J. W. Hutchinson, and M. Y. He, "Micromechanics Model for the Detachment of Residually Compressed Brittle Films and Coatings," Acta Mater. 47, 1513-1522 (1999).

20. M. R. Begley and J. M. Ambrico, "Delamination of Thin Films from Two-Dimensional Interface Flaws at Corners and Edges," Int. J. Fract. 112, 205-222 (2001).

21. H. H. Yu, M. Y. He, and J. W. Hutchinson, "Edge Effects in Thin Film Delamination," Acta Mater. 49, 93-107 (2001).

22. P. K. Wright and A. G. Evans, "Mechanisms Governing the Performance of Thermal Barrier Coatings," Curr. Opin. Solid State Mater. Sci. 4, 255-265 (1999).

23. M. Gell, K. Vaidyanathanm, B. Barber, J. Cheng, and E. Jordan, "Mechanism of Spallation in Platinum Aluminide/Electron Beam Physical Vapor-Deposited Thermal Barrier Coating," Metall. Mater. Trans. 30A, 427-435 (1999).

24. A. G. Evans et al., "Mechanisms Controlling the Durability of Thermal Barrier Coatings," Progr. Mater. Sci. 46, 505-553 (2001).

25. D. R. Mumm, A. G. Evans, and I. Spitsberg, "Characterization of a Cycle Displacement Instability for a Thermally Grown Oxide in a Thermal Barrier System," Acta Mater. 49, 23292340 (2001).

26. J. A. Ruud et al., "Strength Degradation and Failure Mechanism of Electron-Beam PhysicalVapor-Deposited Thermal Barrier Coatings," J. Am. Ceram. Soc. 84, 1545-1552 (2001).

27. A. M. Karlsson, J. W. Hutchinson, and A. G. Evans, "A Fundamental Model of Cyclic Instabilities in Thermal Barrier Systems," J. Mech. Phys. Solids 50, 1565-1589 (2002).

28. A. M. Karlsson and A. G. Evans, "A Numerical Model for the Cyclic Instability of Thermally Grown Oxides in Thermal Barrier Systems," Acta Mater. 49, 1793-1804 (2001).

29. V. Tolpygo and D. R. Clarke, "Surface Rumpling of a (Ni, Pt) Al Bond Coat Induced by Cyclic Oxidation," Acta Mater. 48, 3283-3293 (2000).

30. M. L. Williams, "The Stress Around a Fault or Crack in Dissimilar Media," Bull. Seismol. Soc. Am. 49, 199-204 (1959).

31. F. Erdogan, "Stress Distribution in Bounded Dissimilar Materials with Cracks," J. Appl. Mech. 32, 403-410 (1965).

32. D. B. Bogy, "Two Edge-Bonded Elastic Wedge of Different Materials and Wedge Angles under Surface Traction," J. Appl. Mech. 38, 377-386 (1970).

33. J. R. Rice, "Elastic Fracture Mechanics Concepts for Interfacial Cracks," J. Appl. Mech. 55, 98103 (1988).

34. F. Shih, "Cracks on Bimaterial Interfaces: Elasticity and Plasticity Aspects," J. Mater. Sci. Eng. A143, 77-90 (1991).

35. J. W. Hutchinson and A. Suo, "Mixed Mode Cracking in Layered Materials," Adv. Appl. Mech. 29, 63-191 (1992). 
36. J. R. Rice, Z. Suo, and J.-S. Wang, "Mechanics and Thermodynamics of Brittle Interfacial Failure in Bimaterial Systems," pp. 269-294 in Acta-Scripta Metallurgica Proceedings Series, ed. M. Ruhle, A. G. Evans, M. F. Ashby, and J. P. Hirth, Pergamon Press, Oxford, England, 1990.

37. M. R. Turner and A. G. Evans, "An Experimental Study of the Mechanisms of Crack Extension along an Oxide/Metal Interface," Acta Mater. 44(3), 863-871 (1996).

38. P. G. Charalambides, J. Lund, A. G. Evans, and R. M. McMeeking, "A Test Specimen for Determining the Fracture Resistance Bimaterial Interface," J. Appl. Mech. 55, 77-82 (1989).

39. Z. Suo and J. W. Hutchinson, "Sandwich Test Specimens for Measuring Interface Crack Toughness," Mater. Sci. Eng., A 107, 135-143 (1989).

40. J. L. Beuth et al., "Measurement of Interfacial Toughness Loss in Thermal Barrier Coating and Oxide Systems," in Proceedings of ASME International Mechanical Engineering Congress and Exposition, Nashville, November 14-19, 1999.

41. J. Wang, R. L. Weaver, and N. R. Sottos, "A Parametric Study of Laser Induced Thin Film Spallation,” J. Exp. Mech. 42(1), 74-83 (2002).

42. V. Gupta, A. S. Argon, J. A. Cornie, and D. M. Parks, "Measurement of Interface Strength by a Laser Spallation Technique," J. Mech. Phys. Solids 40, 141-180 (1992).

43. J. A. Wang, K. C. Liu, D. E. McCabe, and S. A. David, An Innovative Small Specimen Testing Technique for the Determination of Fracture Toughness, ORNL/M-6366, Oak Ridge National Laboratory, Oak Ridge, Tennessee, 1999.

44. J. A. Wang, K. C. Liu, D. E. McCabe, and S. A. David, "Using Torsion Bar Testing to Determine Fracture Toughness, $\mathrm{K}_{\mathrm{IC}}$," J. Fatigue Fract. Eng. Mater. Struct. 23, 45-56 (2000).

45. J. A. Wang, K. C. Liu, I. G. Wright, and R. L. Xu, “An Innovative Technique for Bi-Material Interface Toughness Research," accepted for presentation at the ASME International Mechanical Engineering Congress (IMEC2004), Anaheim, California, November 13-19, 2004.

46. J. A. Wang, K. C. Liu, and D. E. McCabe, “An Innovative Technique for Measuring Fracture Toughness of Metallic and Ceramic Materials," Fatigue and Fracture Mechanics, vol. 33, ASTM STP 1417, ed. W. G. Reuter and R. S. Piascik, American Society for Testing and Materials, West Conshohocken, Pennsylvania, 2002.

47. J. A. Wang, K. C. Liu, and G. A. Joshi, "Using Torsion Bar Testing to Determine Fracture Toughness of Ceramic Materials," in ASME Proceedings of ETCE 2002 Conference on Composite Materials Design \& Analysis, Houston, Texas, 2002.

48. J.-A. Wang, "Oak Ridge National Laboratory Spiral Notch Torsion Test System," J. Pract. Failure Anal. 3(4), 23-27 ( August 2003).

49. J. A. Wang and K. C. Liu, "A New Approach to Evaluate Fracture Toughness of Structural Materials," in Proceedings of ASME 2003 Pressure Vessel and Piping, Cleveland, Ohio, July 2024, 2003.

50. H-X. Li, R. H. Jones, J. P. Hirth, and D. S. Gelles, "Fracture Toughness of the F-82H SteelEffect of Loading Modes, Hydrogen, and Temperature," J. Nucl. Mater. 233, 258-263 (1998).

51. H. Li, R. H. Jones, J. P. Hirth, and D. S. Gelles, "Effect of Loading Mode on the Fracture Toughness of a Reduced-Activation Ferritic/Martensitic Stainless Steel," J. Nucl. Mater. 212215, 741-745 (1994). 
52. Yang et al., "Temperature Evolution and Fatigue Damage of Reactor Pressure Vessel (RPV) Steels," pp. 25-36 in Proceedings, TMS (The Minerals, Metals \& Materials Society), St. Louis, Missouri, October 8-12, 2000.

53. H. Wang et al., "Application of High-Speed IR Imaging During Mechanical Fatigue Tests," in SPIE Conference-Thermo Sense, Orlando, FL, USA, SPIE, April 24-28, 2000, SPIE-The International Society for Optical Engineering, Bellingham, Washington, 2000.

54. G. Wright, B. A. Pint, L. M. Hall, and P. F. Tortorelli, pp. 339-358 in Lifetime Modelling of High-Temperature Corrosion Processes, ed. M. Schütze, W. J. Quadakkers, and J. R. Nicholls, EFC Publication No. 34, Maney Publishing, London, 2001.

55. F. H. Stott and A. Atkinson, "The Modeling of Growth Stresses During High-Temperature Oxidation," Mater. High Temp. 12, 195-207 (1994).

56. Q. Ma and D. R. Clarke, "Stress Measurement in Single-Crystal and Polycrystalline Ceramics Using Their Optical Fluorescence," J. Am. Ceram. Soc. 76, 1433 (1993).

57. M. Lipkin and D. R. Clarke, "Measurement of the Stress in Oxide Scales Formed by Oxidation of Alumina-Forming Alloys," Oxid. Met. 45, 267 (1996).

58. V. K. Tolpygo and D. R. Clarke, "Spalling Failure of a-Alumina Films Grown by Oxidation: I. Dependence on Cooling Rate and Metal Thickness," Mater. Sci. Eng. A278, 142 (2000).

59. J. K. Wright et al., "Residual Stresses in Convoluted Oxide Scales," Mater. Sci. Eng. A262, 246255 (1999).

60. R. L. Williamsons et al., "Numerical Analysis of Surface Cracks at Regions of Curvature in Oxide Scales," Mater. Sci. Eng. A342, 109-119 (2002).

61. LOCAN 320 User Manual, Physical Acoustics Corporation, Princeton, New Jersey, 1988.

62. C. H. Hsueh and A. G. Evans, "Residual Stresses in Metal/Ceramic Bonded Strips," J. Am. Ceram. Soc. 68(5), 241-248 (1985).

63. C. H. Hsueh, "Modeling of Elastic Deformation of Multilayers due to Residual Stresses and External Bending," J. Appl. Phys. 91(12), 9652-9656 (2002).

64. N. P. O’Dowd, C. F. Shih, and M. G. Stout, "Test Geometries for Measuring Interface Fracture Toughness,” Int. J. Solids Struct. 29(5), 571-589 (1992).

65. R. O. Ritchie et al., "Mechanics and Mechanisms of Crack Growth at or Near Ceramic-Metal Interfaces: Interface Engineering Strategies for Promoting Toughness," Mater. Sci. Eng. A166, 221-235 (1993).

66. G. R. Irwin, "Analysis of Stresses and Strains Near the End of Crack Traversing a Plate,” J. Appl. Mech. 24, 361-364 (1957).

67. H. Ishikawa, H. Kitagawa, and H. Okamara, "J-Integral of a Mixed Mode Crack and Its Application," pp. 447-455 in Proceedings 3rd International Conference on Mechanical Behavior of Materials, Vol. 3, Pergamon, Oxford, England, 1980.

68. C. F. Shih and R. J. Asaro, "Elastic-Plastic Analysis of Cracks on Bimaterial Interfaces: Part ISmall Scale Yielding,” J. Appl. Mech. 55, 299-316 (1988).

69. C. F. Shih, B. Moran, and T. Nakamura, "Energy Release Rate along a Three-Dimensional Crack Front in a Thermally Stressed Body," Int. J. Fract. 30, 79-102 (1986). 
70. Z. Suo, "Singularities, Interfaces and Cracks in Dissimilar Anisotropic Media," Proc. R. Soc. London, Ser. A 427, 331-358 (1990).

71. ASM Engineered Materials Reference Book, 2nd ed., ed. M. Bauccio, ASM International, Materials Park, Ohio, 1994.

72. MatWeb Material Property Data: Alumina, Alpha $\mathrm{Al}_{2} \mathrm{O}_{3}$, http://www.matweb.com/SpecificMaterial.asp?bassnum=BA1A\&group=General, accessed Oct. 21, 2004.

73. M. Schutze, Fundamental Aspects of High Temperature Corrosion, ed. D. A. Shores, R. Rapp, and P. Y. Hou, Electro-Chemical Society, Pennington, New Jersey, 1997.

74. Y. Mitamura and Y. Wang, "Fracture Toughness of Single Crystal Alumina in Air and a Simulated Body Environment," Biomed. Mater. Res. 28(7), 813-817 (1994).

75. V. Guttmann, F. Hukel, and G. Borchardt, "The Role of Defects on the Mechanical Integrity of Alumina Scales on MA956," pp. 23-25 in High Temperature Surface Engineering, Proceedings of the Sixth International Conference, ed. J. Nicholls and D. Rickerby, September 1997.

76. W. D. Klopp, "Ferritic Stainless Steel, FeNM-1450 (MA956)," p. 14 in Aerospace Structural Metals Handbook, Purdue Research Foundation, West Lafayette, Indiana 74907, 1992.

\section{ACKNOWLEDGMENTS}

The authors gratefully acknowledge Dr. Edgar Lara-Curzio and Dr. Peter Tortorelli for their interest in and support of this research, Dr. Shengjun Yin and Dr. Gorti Sarma for their valuable comments on FEM development, and Mr. Fahmy Haggag for providing ABI test results. The authors also wish to thank Alice Rice for preparing the manuscript. The research was sponsored by the ORNL Laboratory-Directed Research and Development Seed Money Program, the Mechanical Characterization and Analysis User Center, and the Radiation Safety Information Computational Center, under DOE contract DE-AC0500OR22725 with UT-Battelle, LLC. 

ORNL/TM-2004/221/R1

\section{INTERNAL DISTRIBUTION}

1. Laboratory Records (OSTI)

2-3. Laboratory Records

4. Central Research Library

5. B. R. Bass

6. Paul F. Becher

7. Peter J. Blau

8. Timothy D. Burchell

9. Ashok Choudhury

10. William R. Corwin

11. Stan A. David

12. Mattison K. Ferber

13. S. R. Greene

14. D. J. Hill

15. Linda L. Horton

16. Joe A. Horton, Jr.

17. Chun-Hway Hsueh

18. B. L. Kirk

19. Michael J. Lance

20. E. Lara-Curzio

21. C. T. Liu

22. K. C. Liu

23. L. K. Mansur
24. Donald E. McCabe

25. John G. Merkle

26. R. K. Nanstad

27. Dan J. Naus

28. C. V. Parks

29. B. Radhakrishnan

30. Weiju Ren

31. James B. Roberto

32. T. M. Rosseel

33. J. E. Rushton

34. Gorti B. Sarma

35. Terrence P. Sjoreen

36. M. A. Sokolov

37. J. Michael Starbuck

38. R. E. Stoller

39. R. W. Swindeman

40. Peter F. Tortorelli

41. John Jy-An Wang

42. Ian Gordon Wright

43. Shengjun Yin

44. Thomas Zacharia

45. S. J. Zinkle

\section{EXTERNAL DISTRIBUTION}

46. Robert Bayles, Naval Research Lab., (bayles@ccs.nrl.navy.mil)

47. Bill Chao, University of South Carolina, ()

48. Sid Diamond, U.S. DOE, EE-2G, FORS, Washington, DC 20585 (sid.diamond@ee.doe.gov)

49. Matt Forsbacka, NASA, (mforsback@hq.nasa.gov)

50. John Lambros, University of Illinois, Aerospace Engineering, 310 Talbot Lab 104 S Wright, MC 236Urbana, IL 61801 (lambros@uiuc.edu)

51. John Landes, University of Tennessee, Mechanical Aerospace \& Biomedical Engr, 314 Perkins Hall, Knoxville, TN 37996-2210 (landes@utk.edu)

52. Peter K. Liaw, University of Tennessee, Mtrls Science \& Engr, 427b Dougherty Engineering Bldg., Knoxville, TN 37996-2200 (pliaw@utk.edu)

53. Theodore Nicholas, University of Dayton, RI-Structural Integ, 300 College Park, Dayton, OH 45469 (Theodore.Nicholas@udri.udayton.edu)

54. Yue Qi, GM R\&D Center, (yue.qi@gm.com)

55. R. O. Ritchie, Lawrence Berkeley National Laboratory, Materials Sciences, 1 Cyclotron Road, 62R0203Berkeley, CA 94720-8253 (RORitchie@lbl.gov)

56. Sreeparna Sengupta, Vanderbilt University, (sreeparna.sengupta@vanderbilt.edu)

57. Jiandong Shi, Dupont Photonics Technologies, (jd.shi@usa.dupont.com)

58. Don Shockey, Stanford Research Institute, (donald.shockey@sri.com)

59. Jogender Singh, Penn State, 0165 Arl Building, University Park, PA 16802 (jxs46@psu.edu)

60. Asuri Vasudevan, Office of Naval Research, (vasudea@onr.navy.mil) 
61. Y. Jack Weitsman, University of Tennessee, Mechanical Aerospace \& Biomedical Engr, 307 Perkins Hall, Knoxville, TN 37996-2210 (weitsman@utk.edu)

62. Scott West, Savannah River Natl. Lab., (scott.west@srs.gov)

63. Spencer T. Wu, Civ AFRL/AFOSR, (spencer.wu@afosr.af.mil)

64. Roy L. Xu, Vanderbilt University, (1.roy.xu@vanderbilt.edu) 